\title{
Simulation and Assessment of Long-Term Stormwater Basin Performance under Real-Time Control Retrofits
}

\author{
Zoë K. Schmitt
}

Thesis submitted to the faculty of the Virginia Polytechnic Institute and State University in partial fulfillment of the requirements for the degree of

Master of Science

In

Civil Engineering

\author{
Randel L. Dymond, Chair \\ Clayton C. Hodges \\ Kevin D. Young
}

May 8, 2019

Blacksburg, VA

Keywords: stormwater management, smart watersheds, real-time control (RTC), continuous monitoring and adaptive control (CMAC), retrofit 


\section{Simulation and Assessment of Long-Term Stormwater Basin Performance under Real-Time Control Retrofits}

Zoë K. Schmitt

ACADEMIC ABSTRACT

The use of real-time control (RTC) as an adaptation technique for improving existing stormwater systems has been gaining attention in recent years for its ability to enhance water quality and quantity treatment. A case study RTC retrofit of seven existing detention basins was simulated for a small (162 ha), urbanized watershed in Blacksburg, VA. Two heuristic, reactive control algorithms were tested and compared for their ability to improve hydraulic conditions at each detention basin and the watershed outlet through manipulation of an actuated valve, under various permutations of RTC retrofitting (single facility, multiple facilities, etc.). Change in peak flow during 24-hour design storms was assessed. RTC only reduced peak flows at some of the facilities for storms with a return period of 2 years or less. For larger storms, RTC maintained or increased peak flow rates. During a 15year simulation with historic precipitation data, total duration of erosive flows was reduced for most facility retrofit simulations; however, the duration of high intensity flows increased, or remained unchanged. This result was also reflected at the watershed outlet. 


\title{
Simulation and Assessment of Long-Term Stormwater Basin Performance under Real-Time Control Retrofits
}

\author{
Zoë K. Schmitt
}

\section{GENERAL AUDIENCE ABSTRACT}

Stormwater management helps protect natural waterways from the harmful impacts of human development. A growing field of research is investigating the potential for "smart" technologies to improve the efficiency of existing stormwater facilities. This study investigates the application of a "smart" stormwater retrofit, known as real-time control (RTC), to existing stormwater management facilities located in a small case study watershed. The RTC system is composed of hypothetical internet-connected sensors and control valves which control flows at several points within the test watershed. Two control algorithms were tested, and compared to the current conditions (scenario with no RTC), for a large range of storm events. Results of this study found that RTC would lead to improved stream health for most rainfall events, but could potentially worsen conditions for the largest, most rare storm events. In addition, RTC was found to be much more effective at some points in the watershed than other points. Prediction of where RTC will be most effective should be the focus of future research. 


\section{Acknowledgements}

The completion of this thesis would not have been possible without the help of many great people who have been in my life. Here, I would like to provide a small acknowledgement of the large debt of gratitude I owe them.

Thank you to my advisor, Randel Dymond, for bringing me into the urban hydrology research group, and for providing guidance and support throughout this research process. I also want to thank Clay Hodges for patiently answering my endless questions. He has provided me with research guidance, career advice, tips on where to go hiking, and a wealth of nerdy, random information, and for this I am so grateful. I would also like to thank Kevin Young for the valuable insight and feedback he provided during the proposal and research process.

To all the great people I have met in Blacksburg, thank you for making life here meaningful and fun. I can't imagine my VT experience without my wonderful neighbors. Chase, thank you for helping me out of countless research ruts and providing encouragement and ideas. Brendan and Hannah, thank you for inspiring me to pursue what I am passionate about. And to my parents, who have read my papers and provided feedback whenever I needed it for the past 12 years or so - thank you for your constant support and for instilling in me a curiosity about the world. 


\section{Table of Contents}

Acknowledgements ............................................................................................. iv

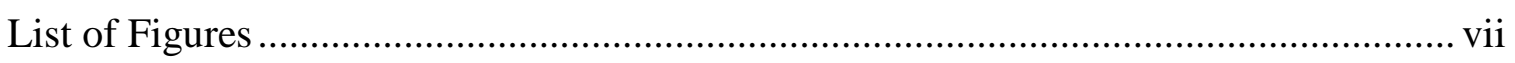

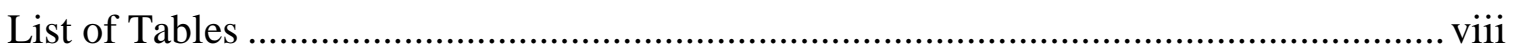

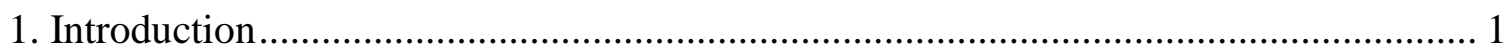

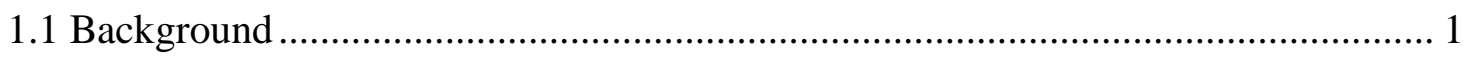

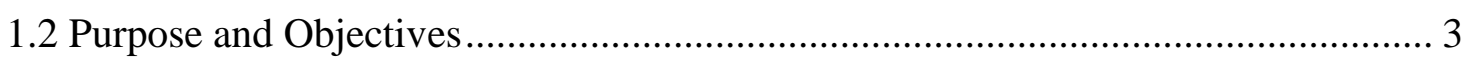

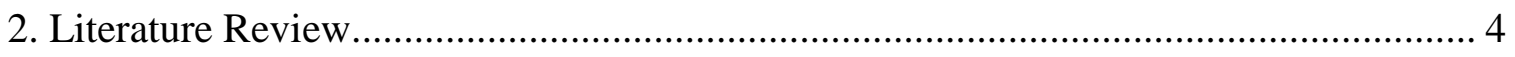

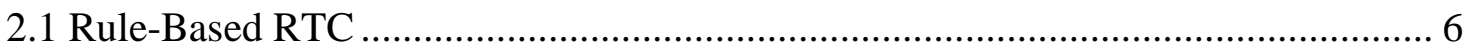

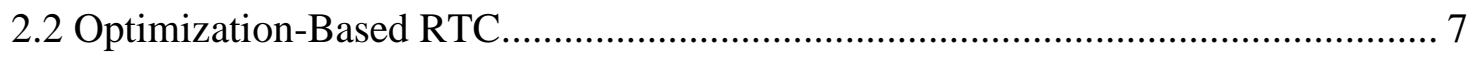

2.3 Existing Research Gaps ................................................................................... 9

3. Simulation and Assessment of Long-Term Stormwater Basin Performance under Real-

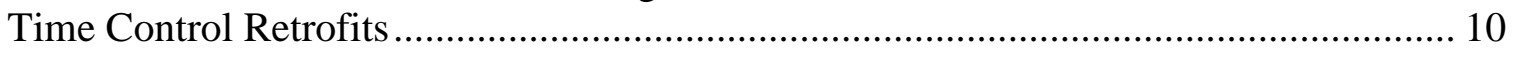

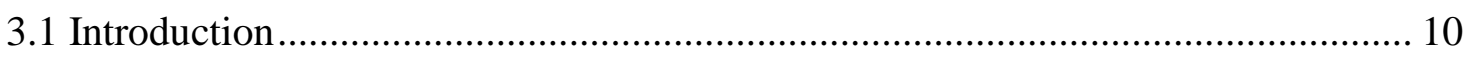

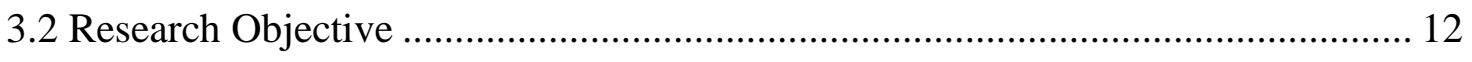

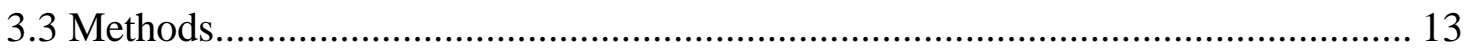

3.3.1 Study Watershed and Model Development ..................................................... 13

3.3.2 Simulation of a Real-Time Control Retrofit ..................................................... 15

3.3.3 Control Algorithms Tested ....................................................................... 16

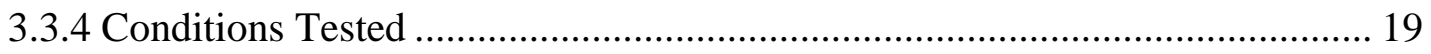

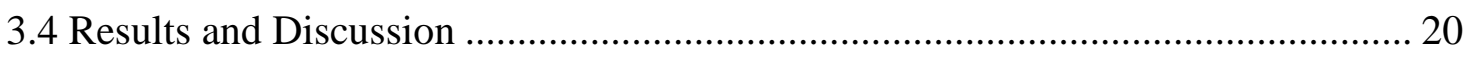

3.4.1 Impact of RTC on Local Conditions (at Facility Outlet) ................................. 20

3.4.2 Impact of RTC on Downstream Conditions (at Watershed Outlet)................. 28

3.4.3 Comparison of Algorithm Stability …………………………………...... 32 


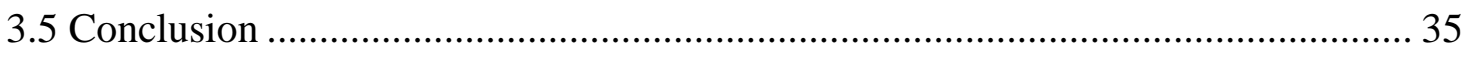

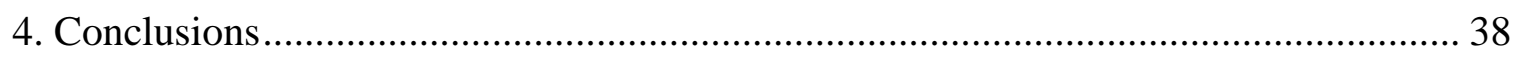

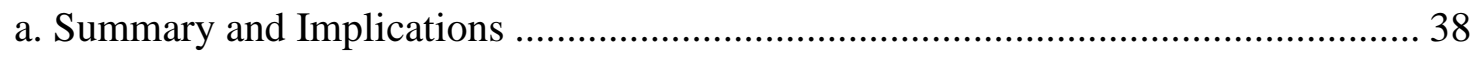

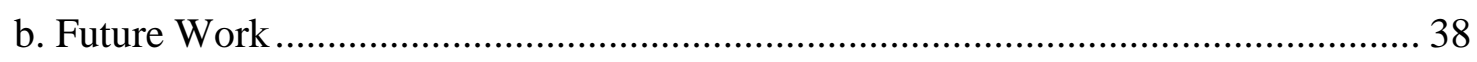

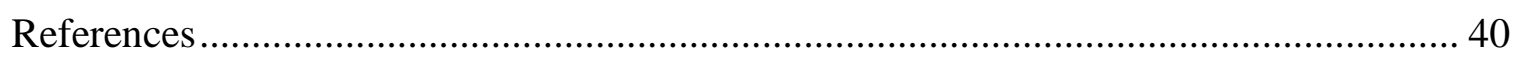

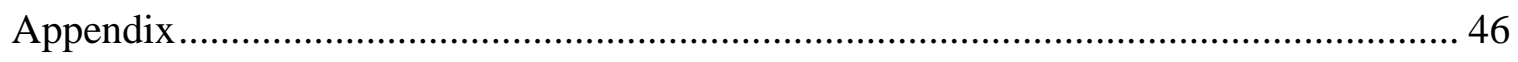

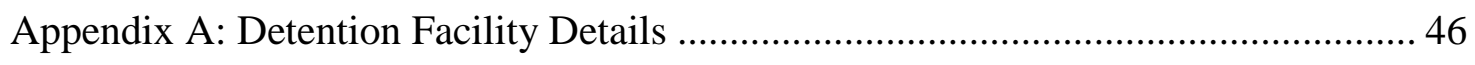

Appendix B: SWMM Model Details ........................................................... 50

Appendix C: PySWMM Sample Code .......................................................... 57

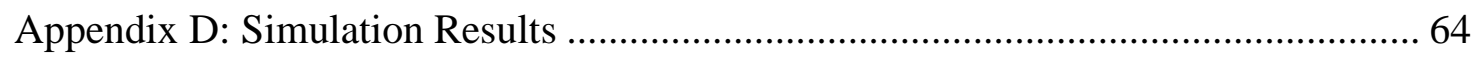

Appendix E: Temporal Aliasing Investigation ............................................... 90 


\section{List of Figures}

Figure 1. Study watershed in Blacksburg, VA ………………….............................. 14

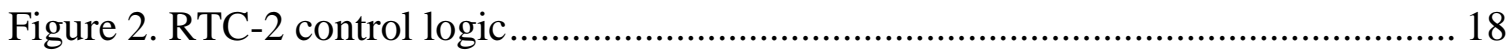

Figure 3. Change in peak flow with RTC for NRCS 24-hour Synthetic Design Storms of

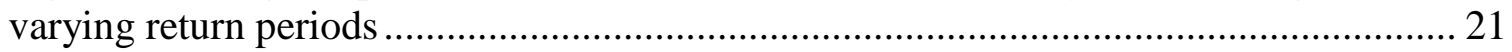

Figure 4. Performance of facility 2044 with no control, RTC-1, and RTC-2.................. 23

Figure 5. Flow Duration Curves at outlets of four facilities........................................... 25

Figure 6. Change in time exceeding selected flow rates at outlet of each detention basin, as compared to static

Figure 7. Change in time exceeding selected flow rates at watershed outlet, as compared to static. 31

Figure 8. Count of valve movements over 15-year simulation........................................... 33

Figure 9. Outflow hydrograph of facility 4860 during a storm event .............................. 34 


\section{List of Tables}

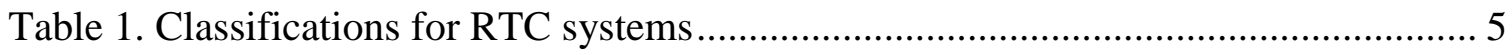

Table 2. Detention Basin and Drainage Area Characteristics..................................... 16

Table 3. Percent change in peak flow at watershed outlet with RTC ............................ 29

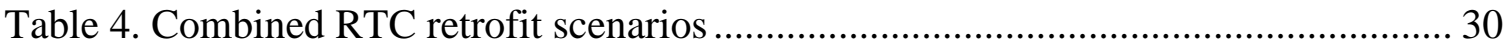




\section{Introduction}

\subsection{Background}

The purpose of stormwater management is to protect people and property from flood hazards and mitigate the harmful impact of urbanization on natural waters - both problems of growing importance in today's world. The increased impervious cover resulting from development restricts infiltration and increases runoff volumes, leading to higher and longer peak discharges and increased sediment loading on waterways (Dietz and Clausen 2008; McGrane 2016). This leads to "urban stream syndrome", which is characterized by streambed erosion, decreased water quality, and loss of aquatic habitat and biodiversity, extending far downstream of the urban area (Jackson and Booth 1997; Vietz et al. 2015).

Low Impact Development (LID) is a common methodology for reducing the hydrologic impacts of urbanization. LID aims to mimic the pre-development hydrology of a site through retention, infiltration, and evaporation of stormwater close to its source (Prince George's County 1999). Specific structures used in LID, called stormwater control measures (SCMs), include detention basins, green roofs, and bioretention filters. These measures are capable of mitigating peak flows; however, due to the static nature of this infrastructure, SCMs may only improve conditions for rainfall events similar to those for which they were designed (Hixon and Dymond 2014; Nehrke and Roesner 2004). Most SCMs are designed and implemented on a local (parcel-level) scale. However, past research shows that local stormwater controls, while successful in reducing the peak flow leaving a site, may not produce desirable downstream outcomes (Emerson et al. 2005; Goff and Gentry 2006; McCuen 1979).

The introduction of "smart" technologies into stormwater management is a concept that has been gaining traction around the world in recent years (García et al. 2015; Mullapudi et al. 2017; Schütze et al. 2004; Shishegar et al. 2018). Smart stormwater systems join the science of urban hydrology with the technology of the Internet of Things (IoT) to adapt to changing watershed conditions and optimize stormwater management. A promising form 
of smart stormwater management is real-time control (RTC). Through internet connected sensors and actuators (such as motorized valves and pumps), RTC allows for runoff to be stored in parts of the urban drainage system that have excess capacity, relieving pressure from other, more overburdened areas in the system. To date, this technology has most commonly been used in combined sewer systems (CSSs) to mitigate combined sewer overflow (CSO) events. Compared to traditional infrastructure updates, installing RTC is equally (if not more) effective, less intrusive, and lower cost. For example, RTC implemented in South Bend, IN reduced CSO volumes by as much as 50\%. Achieving the same CSO reduction through traditional infrastructure updates would have cost an additional \$150 million (Montestruque and Lemmon 2015). This form of RTC retrofitting has been implemented since the 1980s in cities around the world, including Paris, France; Philadelphia, PA; Quebec City, Canada; and Barcelona, Spain (Cheung et al. 2005; Ocampo-Martinez et al. 2013; Stinson et al. 2000).

In contrast to combined sewers, the application of RTC to separate sewers with the purpose of improving stormwater outcomes remains a relatively new area of research. Past examples display how RTC can be used to retrofit existing SCMs and create local hydrologic benefits. For example, by installing actuated valves in retention ponds previously used only for flood-mitigation, the outlet orifice can be closed to detain runoff from smaller storms, creating water quality improvements through increased detention time and sedimentation (Middleton and Barrett 2008; Muschalla et al. 2014; Opti RTC and Geosyntec Consultants Inc. 2017). However, the use of RTC at multiple points within a watershed has only been investigated by a limited number of studies (Wong and Kerkez 2018). Furthermore, a large focus in many studies has been on the potential for water quality improvements with RTC during small storm events, rather than the impact of RTC on hydraulic conditions over a large range of precipitation conditions. Therefore, the need remains to demonstrate how the installation of multiple RTC-retrofits within a catchment may impact local and system-wide long-term stormwater quantity outcomes. 


\subsection{Purpose and Objectives}

The research presented here aims to advance the understanding of how a RTC retrofit of multiple existing stormwater detention basins may impact hydraulic conditions in a watershed. A calibrated hydrologic model of the Central Stroubles watershed in Blacksburg, VA was subjected to a simulation of real-time control on the outlets of seven existing detention basins. A large variety of rainfall conditions were applied to the test watershed in order to observe the robustness of the RTC strategy under a large variety of conditions.

This study has the following objectives:

1. Review relevant literature, focusing on RTC in separate stormwater systems.

2. Simulate RTC retrofits of detention basins using a calibrated hydrologic model.

3. Compare performance between two RTC algorithms; one novel approach and one from a previous study.

4. Assess the effect of RTC on peak flow rate for various synthetic design storms.

5. Assess the effect of RTC on the flow duration curve and critical flow rate exceedance time for a long-term simulation with real rainfall data.

6. Analyze the results for the outlet of each facility (local) and at the watershed outlet (regional/downstream). 


\section{Literature Review}

Real-time control systems take form in varying degrees of complexity. The original "realtime control" consists of an operator manually adjusting valves, gates, or weirs on site, known as manual local control (Vitasovic 2006). This level of RTC, while simplistic in nature, is a practical, low cost option for sites requiring only intermittent adjustments, such as for the maintenance of extended detention ponds (Nashville and Davidson County 2009; Oregon Department of Transportation 2014; USEPA 2009). Remote supervisory control is made possible by installing a motorized actuators and a means of data transmission. In this slightly more complex form of RTC, the human operator is still central to decision making, but the control actions (physical changing of a valve position) are executed remotely, via a digital signal (Vitasovic 2006).

RTC may be automated by replacing the operator with a computer control algorithm which uses live sensor data to make decisions on how actuators will be manipulated. Automation is becoming increasingly feasible thanks to the dropping cost of IoT technology (Sundmaeker et al. 2010), and this form of RTC is the focus of this study. When implementing automatic control logic, there are many considerations that will impact the system operation and decision making process. A summary of the different types of automatic RTC systems is given in Table 1, which has been adapted from work by Vitasovic (2006) and García et al. (2015). 
Table 1. Classifications for RTC systems

\begin{tabular}{cl}
\hline Aspect of RTC & \multicolumn{1}{c}{ Classification Definitions } \\
\hline Type of Urban & $\begin{array}{l}\text { Combined - wastewater and stormwater enter into one drainage } \\
\text { network, eventually leading to a wastewater treatment plant. }\end{array}$ \\
Separate - stormwater is conveyed by a drainage system that does \\
not lead to a wastewater treatment plant, but drains directly to a \\
receiving water body.
\end{tabular}

In addition to the classifications shown in Table 1, there are several categories to consider when physically implementing RTC, such as the level of system supervision, or the method of data transmission between system elements (Vitasovic 2006). These considerations were not included as they do not affect computer simulation of RTC. The categories listed are only concerned with aspects of control systems that are significant for theoretical modelling (i.e. the control algorithm), as this is the main focus of this study. The following sections will present a review of relevant literature for both types of control logic and a discussion of existing research gaps. 


\subsection{Rule-Based RTC}

The simplest form of automated RTC is local, rule-based control (RBC), also known as heuristic control logic. In RBC, the control actions are set manually before the RTC system is online, typically in the style of an "if-then-else" logic structure. Because of this, RBC systems typically require expert knowledge of the UDS for their design and implementation (Vitasovic 2006). The control algorithm must be pre-programmed to handle all possible circumstances, which is why these systems are often developed in an iterative way (Gaborit et al. 2013; Goodman and Quigley 2015).

Jacopin et al. (2001), in an early study of rule-based control, tested two "extreme" control schemes. The first maintains maximum capacity of detention basins at all times to prevent flooding during large storms. The second detains water to promote sedimentation during smaller events. Jacopin's work established that both hydraulic control and water quality objectives can be met with RTC, but the decision making process to switch between the two strategies was left to future research.

In work by Gaborit et al. (2013), simple control rules based on pond depth, current precipitation measurements, and water accumulation time are used to maximize the hydraulic retention time of stormwater runoff in a detention basin and reduce large discharge rates. Further modeling of this system with a calibrated water quality model showed improvement in the detention basin's nutrient treatment capabilities from the RTC installation (Muschalla et al. 2014), which was also verified by field experimentation of the system (Carpenter et al. 2014). The use of RTC has been shown to improve water quality treatment through prolonged retention time in a variety BMPs, such as green roofs, constructed wetlands, and wet ponds (Bartos et al. 2018; Lefkowitz et al. 2016; Middleton and Barrett 2008; Opti RTC and Geosyntec Consultants Inc. 2017).

Another heuristic control innovation uses a flow-duration curve to match post-development BMP outflows to an approximation of pre-development runoff rates (Goodman and Quigley 2015). Rather than only reduce the peak flow from a few low-frequency events, 
such as using multi-stage outflow risers to address 2- and 10-year peak flows, this technique would allow for full flow-regime management, which is shown to more effectively reduce unnatural erosion of waterways (Palhegyi 2010; Tillinghast et al. 2011; Vietz et al. 2015). However, the curve-matching approach presented by Goodman and Quigley (2015) requires extensive modeling and many iterations - a potentially expensive endeavor. Additionally, the concept of pre-development flow has no universally accepted definition, made clear by the myriad definitions for "pre-development flow" given in US stormwater regulations (USEPA 2016).

While the majority of RBC is implemented locally, some attempts have been made to apply regional coordination. A simple technique is described by McCarthy (1994) to coordinate two detention pond flows so that they do not exceed capacity of a downstream channel. Another study by Mullapudi et al. (2017) balanced the discharges from two detention basins into a wetland to maximize its treatment and to prevent overflow. In an experimental RTC set up, the releases from two detention ponds were alternated to create on-phase and off-phase interaction of flows at a downstream point (Mullapudi et al. 2018). This method uses experimentally-gathered travel time and shape of downstream hydrographs from each detention basin. This work provides important advances for coordination of several RTC elements, however the interactions of more than two RTC elements in the same watershed is an area that remains poorly understood. Thus far, urban drainage system operators and academics have turned toward global optimization-based control approaches to address this problem.

\subsection{Optimization-Based RTC}

Optimization methods help to predict the interactions of complex, nonlinear systems, such as in an urban drainage system, which is why many academics have embraced optimization-based RTC algorithms (García et al. 2015; Lund et al. 2018). An optimization-based control algorithm employs mathematical techniques to maximize benefits or minimize costs for a system of inputs and outputs. When applied for systemwide control, this is referred to as global optimal real-time control (GO RTC). The 
algorithmic families most commonly applied for GO RTC of urban drainage systems, loosely ordered from most to least prevalent, include Model Predictive Control (MPC), Linear Quadratic Regulators (LQR), Evolutionary Algorithms (EA), and Population Dynamics (García et al. 2015).

MPC and LQR both incorporate an online system model for their execution, which allows for the control logic to have a system-wide perspective. Many advancements in LQR control have been developed for reservoir routing (Wasimi and Kitanidis 1983) and operation of irrigation canals (Balogun et al. 1988; Lemos and Pinto 2012), but LQR has also been applied for the control of urban drainage system in both combined (Marinaki and Papageorgiou 2003) and separate sewers (Wong and Kerkez 2018). MPC incorporates future disturbances, such as forecasted rainfall and runoff, allowing for feedforward, as well as feedback, control. This use of predictive information is particularly relevant to urban drainage systems as it allows for anticipatory actions based on weather forecasts, such as the drawdown of storage facilities before a large storm. Many scholars agree that Model Predictive Control has the greatest potential for optimal management of urban drainage systems (García et al. 2015; Lund et al. 2018), but its complexity may be hindering this potential. A 2018 review of applications of MPC in urban drainage systems found few examples of real operations actively employing MPC (Lund et al. 2018). This directly contrasts with the conclusion from García et al. (2015) that MPC is one of the most used forms of GO RTC. This contradiction may indicate that work in MPC to this point has been largely theoretical and simulation based, rather than applied, possibly due to hesitation by local governments to implement such a complex and opaque control strategy.

Evolutionary Algorithms are well suited for multi-objective optimization problems with nonlinear inputs (Muschalla 2008). In most of the existing literature, EA is used for offline analysis of urban drainage systems (Barreto et al. 2010; Cho et al. 2004; Muleta and Boulos 2007; Muschalla 2008), with limited examples of EA used for online real-time control (Vezzaro and Grum 2014). Similarly, application of Population Dynamics to RTC remains relatively unexplored (García et al. 2015). Work by Barreiro-Gomez et al. (2015) 
appears to be the only example in which Population Dynamics is applied for the control of an urban drainage system.

\subsection{Existing Research Gaps}

The existing body of research on RTC shows its great potential to improve urban drainage systems. However, past studies have common drawbacks that should be addressed by future work. One such drawback is the lack of comparison between control approaches in the existing literature. The majority of papers apply their novel control approach to a test watershed or drainage network, but only compare the RTC scenario to a static control scenario (or to an uncontrolled scenario, as in Bilodeau et al. 2019). No two sewersheds are alike, making it unfeasible to assess how alternate strategies would function in a different urban drainage system without a direct comparison. This problem is exacerbated by the fact that many studies do not include enough specific detail on the control algorithm (including both heuristic and optimization-based) to allow follow-up investigations by other research. This must be resolved by future RTC studies so that the efficacy of RTC strategies may be verified.

Another common drawback of RTC studies is that they only evaluate control scenarios over a short period of real precipitation data or a limited number of synthetic design storms (Degrave et al. 2013; Dong et al. 2017; Jacopin et al. 2001; Joksimovic and Sander 2016; De Korte et al. 2009; Middleton and Barrett 2008). In order to verify the robustness of a control approach for a range of scenarios, it is necessary to subject it to both an extended period of real precipitation data, as well as a wide range of synthetic design storms (Pitt and Clarke 2008; Rohrer and Armitage 2017; Wong and Kerkez 2018). 


\section{Simulation and Assessment of Long-Term Stormwater Basin Performance under Real-Time Control Retrofits}

\subsection{Introduction}

As urban development continues to increase, the role of stormwater management becomes crucial to the sustainability of expansion. Urbanization is known to alter flow regimes of surface and ground waters by restricting infiltration, resulting in larger runoff volumes and "flashier" flows characterized by higher peak discharges and velocities (Dietz and Clausen 2008; McGrane 2016). Hydrologic changes result in degradation of surface waters downstream of developed areas due to erosion, increased sediment loading, and loss of aquatic habitat and biodiversity (Jackson and Booth 1997; Vietz et al. 2015).

Integration of Real-Time Control (RTC) with existing stormwater infrastructure is a promising, low cost adaptation for improving functionality, or adjusting to a changing hydrologic environment (Kerkez et al. 2016). RTC combines the science of urban hydrology with the technology of the Internet of Things (IoT) to allow for adaptive stormwater management. A RTC system employs internet-connected sensors (depth sensors, precipitation gauges, flow meters, etc.) to observe conditions and actuators (motorized valves, pumps, etc.) that respond to stimuli by manipulating outlet discharge almost instantaneously, or in "real time". For the purpose of this study, the term RTC may be considered equivalent to the term Continuous Monitoring and Adaptive Control (CMAC) found in previous literature (Lefkowitz et al. 2016; Roman et al. 2017; Wright and Marchese 2018).

RTC has been used in combined sewer systems to mitigate harmful combined sewer overflow (CSO) events. By taking advantage of existing capacity, RTC implemented in South Bend, IN reduced CSO volumes by as much as 50\%, and cost approximately $\$ 150$ million less than a traditional infrastructure upgrade (Montestruque and Lemmon 2015). Similar results have been achieved for other case studies in the United States, Canada, Germany, Denmark, and Spain (Nielsen et al. 2010; Ocampo-Martinez et al. 2013; 
Seggelke et al. 2013; Stinson et al. 2000). The application of RTC to separate storm sewers is a relatively new area of research, with objectives that differ from those of combined sewer systems.

While stormwater infrastructure is largely static, dynamic valves, gates, and weirs have long been recognized for their ability to more closely achieve desired hydraulic conditions. The use of manually adjustable valves is common practice in the design and maintenance of extended detention ponds, and can be applied for emergency facility drawdown, dredging purposes, or other maintenance activities. (Nashville and Davidson County 2009; Oregon Department of Transportation 2014; USEPA 2009). With recent advancements and reduced cost of internet connected sensors and actuators, it is feasible to add automatic controls to previously passive (or manually controlled) stormwater facilities (Bartos et al. 2018; Kerkez et al. 2016). Automation of RTC commonly applies a rule-based - or heuristic - control algorithm (Gaborit et al. 2013; Goodman and Quigley 2015; Jacopin et al. 2001; Middleton and Barrett 2008). Here, control rules are manually programmed before the RTC system is online, typically in the style of an "if-then-else" logic structure. Rule-based control (RBC) systems typically require expert knowledge of the urban drainage system for their design and implementation (Vitasovic 2006).

Jacopin et al. (2001), in an early study of RBC, successfully demonstrated the ability of RTC to meet two objectives: maintaining maximum capacity of detention basins for flood prevention during large events, and increasing detention time to promote sedimentation during smaller events. The decision-making process to switch between the two objectives, however, was left to future research. Gaborit et al. (2013) applied simple control rules based on pond depth and precipitation to maximize the hydraulic retention time and reduce discharge rates for a detention basin. Further modeling of this system with a calibrated water quality model demonstrated improvement in the detention basin's nutrient treatment capabilities due to the RTC installation (Muschalla et al. 2014). The use of RTC has been shown to improve water quality treatment through prolonged retention time in a variety of best management practices (BMPs), such as green roofs, constructed wetlands, and wet 
ponds (Bartos et al. 2018; Lefkowitz et al. 2016; Middleton and Barrett 2008; Opti RTC and Geosyntec Consultants Inc. 2017).

The water quality benefits due to gravitational settling in dry detention facilities, however, are short term in nature; sediments will likely be re-suspended during the next large event without regular dredging. The RTC of detention basins can best improve water quality by limiting the duration and intensity of erosive flows which cause streambank instability, typically from high frequency storm events (smaller than the 2-year storm; Jackson and Booth 1997; Palhegyi 2010; Tillinghast et al. 2011; Vietz et al. 2015). Goodman and Quigley (2015) addressed this idea with an innovative control method which uses a flowduration curve to match post-development BMP outflows to an approximation of predevelopment runoff rates, allowing for comprehensive flow-regime management.

While the majority of RBC is implemented locally, some attempts have been made to apply regional coordination. Works by McCarthy (1994) and Mullapudi et al. (2017) both present simple techniques to balance discharges from two detention ponds to prevent downstream capacity exceedance. Despite these advances, the interactions of more than two RTC stormwater elements in the same watershed remain poorly understood. Thus far, RTC researchers and practitioners have turned toward global optimization-based control approaches, such as linear-quadratic regulators and model predictive control, to address this problem (García et al. 2015; Marinaki and Papageorgiou 2003; Wong and Kerkez 2018). However, these systems are computationally intensive and decisions are made in a "black box", where they cannot be easily understood and adjusted by operations personnel (Vitasovic 2006). The novelty of RTC technology for stormwater applications may be a hindrance to its adoption, but the implementation of translucent, rule-based control strategies could mitigate this issue.

\subsection{Research Objective}

This research aims to advance the understanding of how a rule-based RTC retrofit of several dry detention basins will affect ecologically significant hydraulic factors, both 
locally and downstream, with emphasis placed on cumulative impacts over a long simulation period with varying degrees of precipitation intensity and inter-event time. This is done through the simulation of RTC on existing detention facilities in a case study watershed using two RBC algorithms. The algorithms tested here are reactive (based on existing, not future, conditions) and locally implemented.

\subsection{Methods}

\subsubsection{Study Watershed and Model Development}

The RTC test watershed, located in Blacksburg, VA, was chosen to represent a typical urbanized headwater catchment; it has an area of 162 ha, of which $26 \%$ is impervious, with a mixed land use, composed of residential, commercial, and public areas. About $65 \%$ of the watershed area drains to one (or two in series) of seven stormwater detention facilities within the study watershed (Figure 1). The detention basin ID corresponds to the facility's storage volume in $\mathrm{m}^{3}$. 


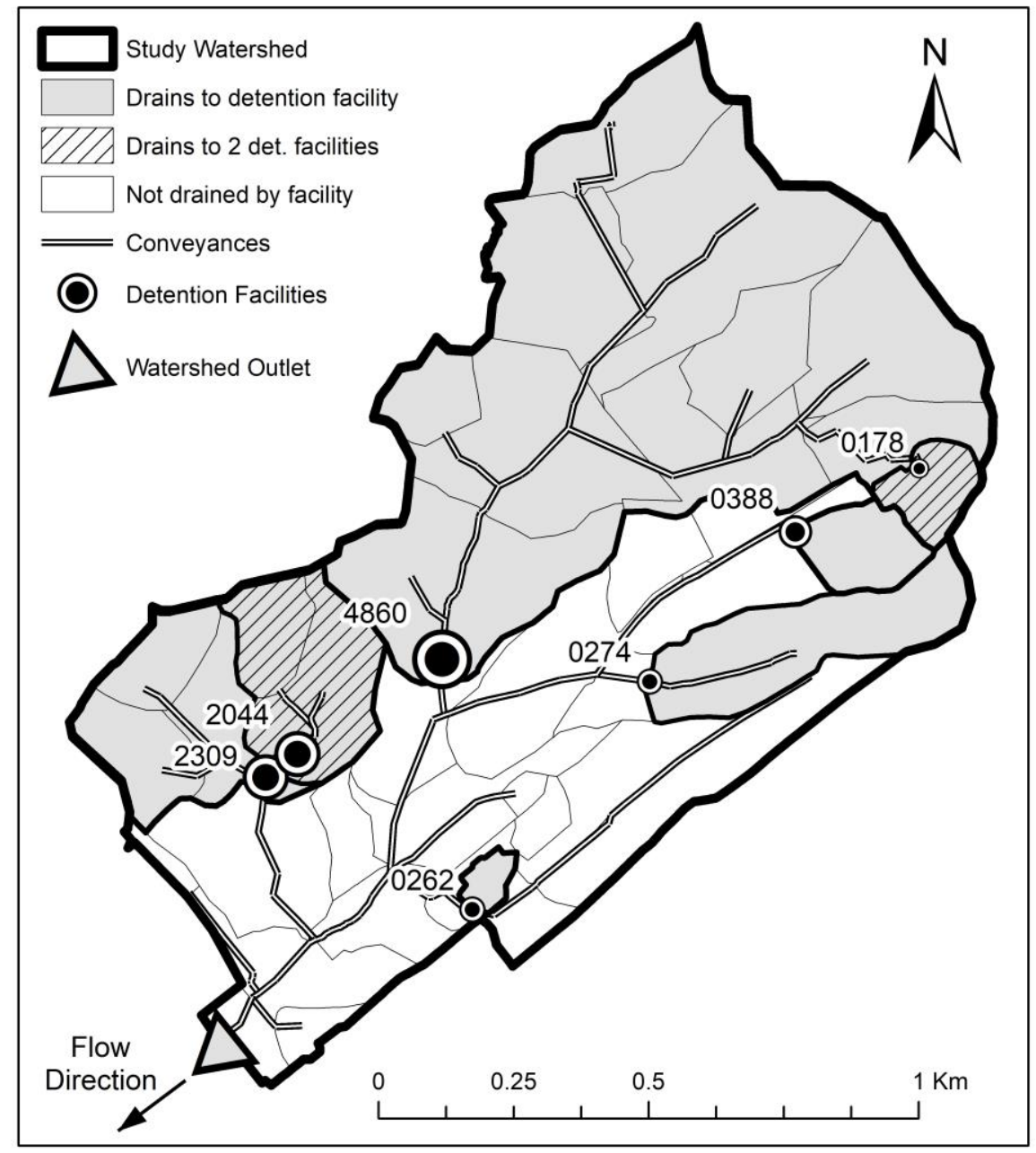

Figure 1. Study watershed in Blacksburg, VA

The test watershed was modeled in EPA SWMM 5.1, an open source program for hydrologic and hydraulic simulation from the U.S. EPA (Rossman 2015). SWMM is commonly used for RTC simulations as control algorithms may be programmed directly into the model or applied externally via a programming wrapper (Degrave et al. 2013; Gaborit et al. 2013, 2016; Goodman and Quigley 2015; Heusch and Ostrowski 2011; Joksimovic and Sander 2016; Muschalla et al. 2014; Wong and Kerkez 2018). SWMM model inputs included high resolution land cover, topographic, and infrastructure datasets from the Town of Blacksburg's GIS database and soil characteristics from the NRCS SSURGO Database ("Web Soil Survey" 2018). The model was calibrated and validated using data from an in-channel stream sensor at the watershed outlet according to guidelines 
from Titterington et al. (2017). Runoff was modeled with the default SWMM Runoff method and the Green-Ampt infiltration model (Rossman 2015). System hydraulics were represented with dynamic wave routing using a routing time step and conduit lengthening step of 15 seconds, each.

\subsubsection{Simulation of a Real-Time Control Retrofit}

Real-time control of the test watershed model was simulated using PySWMM, a Python programming language package that allows for the step-wise observation and modulation of SWMM models as they execute (McDonnell et al. 2016). PySWMM tools may observe and manipulate nearly any parameter in the SWMM model; however, to create a realistic scenario, RTC was applied using only data that could be feasibly monitored in a real-world application. RTC scenarios were simulated with the following assumed real-time components:

- Depth sensors in each detention basin

- Actuated valves in each detention basin outlet (diameters vary based on the original orifice diameter - see Table 2)

- Rain gauge (one for entire test watershed).

The control algorithm is executed at a 5 minute time step, which allows for adequate temporal resolution, while still maintaining a realistic interval to receive and transmit data and control commands (Bartos et al. 2018). At this interval, PySWMM interrupts the SWMM simulation and retrieves the relevant measurements (current depth, precipitation, etc.). This information is fed into the control algorithm, which decides the percentage open for the detention basin outlet valves. PySWMM sets the actuator to the required position, and the SWMM simulation continues until the following time step.

A RTC retrofit must work within the confines of local stormwater regulations, which has implications for the design of control logic. In Virginia, where the test watershed is located, detention basins must maintain $30.48 \mathrm{~cm}$ (1 foot) of freeboard from the top of berm during a 100-year storm, if an emergency spillway is present (VADCR 1999). Therefore, the 
maximum control depth of each detention basin is $30.48 \mathrm{~cm}$ below its maximum depth. Many detention basins also have a primary spillway designed to pass a moderate storm event (the 10-year storm in Virginia). For detention basins with a primary spillway (facilities 4860, 2309, and 0274 in Figure 1), the maximum control depth was chosen to be $10 \mathrm{~cm}$ below the primary (10-year) spillway elevation. Physical characteristics of the detention basins and their contributing drainage areas (CDAs) are provided in Table 2.

Table 2. Detention Basin and Drainage Area Characteristics: (a) Basin ID equals total facility volume in $\mathrm{m}^{3}$, (b) Height from outlet invert to top of berm, (c) Depth above which control rules are suspended, (d) Volume below the maximum control depth (CV), (e) Outlet control valve diameter, (f) Contributing drainage area, (g) CDA as proportion of watershed area, (h) CDA \% impervious, (i) Ratio of control volume to CDA, (j) Ratio of CV to CDA impervious area, (k) Ratio of length of sewer to CDA, and (1) Ratio of CV to maximum control depth.

\begin{tabular}{|c|c|c|c|c|c|c|c|c|c|c|c|}
\hline \multirow[b]{2}{*}{$\begin{array}{c}\text { (a) } \\
\text { Basin } \\
\text { ID }\end{array}$} & \multicolumn{7}{|c|}{ Physical Parameters } & \multicolumn{4}{|c|}{ Indicator Variables } \\
\hline & $\begin{array}{l}\text { (b) } \\
\text { Max. } \\
\text { Depth } \\
\text { (m) }\end{array}$ & $\begin{array}{c}\text { (c) } \\
\text { Max. Ctrl } \\
\text { Depth } \\
\text { (m) }\end{array}$ & $\begin{array}{c}(\mathrm{d}) \\
\text { Control } \\
\text { Vol. } \\
\left(\mathrm{m}^{3}\right) \\
\end{array}$ & $\begin{array}{c}(\mathrm{e}) \\
\text { D }_{\text {Valve }} \\
(\mathrm{cm})\end{array}$ & $\begin{array}{c}\text { CDA } \\
\text { (ha) }\end{array}$ & $\begin{array}{l}(\mathrm{g}) \\
\text { CDA / } \\
\text { WSA } \\
(\%) \\
\end{array}$ & $\begin{array}{c}(\mathrm{h}) \\
\mathrm{CDA}_{\text {imp }} \\
(\%) \\
\end{array}$ & $\begin{array}{c}\text { (i) } \\
\text { CV / } \\
\text { CDA } \\
\text { (mm) }\end{array}$ & $\begin{array}{c}(\mathrm{j}) \\
\mathrm{CV} / \\
\mathrm{CDA}_{\text {imp }} \\
(\mathrm{mm}) \\
\end{array}$ & $\begin{array}{c}(\mathrm{k}) \\
\text { Drainage } \\
\text { Density } \\
\left(\mathrm{m} / \mathrm{m}^{2}\right) \\
\end{array}$ & $\begin{array}{c}\text { (l) } \\
\text { CV / Ctrl } \\
\text { Depth } \\
\left(\mathrm{m}^{3} / \mathrm{m}\right) \\
\end{array}$ \\
\hline 4860 & 1.98 & 1.57 & 2,547 & 38.10 & 73.6 & 45.5 & 21.1 & 3.5 & 16.4 & 6.0 & 1,624 \\
\hline 2309 & 1.70 & 1.19 & 1,272 & 30.48 & 18.2 & 11.3 & 24.8 & 7.0 & 28.1 & 4.3 & 1,065 \\
\hline 2044 & 1.72 & 1.43 & 1,444 & 38.10 & 8.5 & 5.3 & 22.6 & 16.9 & 75.0 & 3.3 & 1,017 \\
\hline 0388 & 1.51 & 1.20 & 237 & 30.48 & 3.1 & 1.9 & 39.2 & 7.7 & 19.8 & 14.3 & 197 \\
\hline 0262 & 1.83 & 1.52 & 198 & 30.48 & .84 & 0.5 & 62.5 & 23.6 & 37.8 & 9.5 & 130 \\
\hline 0274 & 1.83 & 1.65 & 199 & 50.80 & 8.7 & 5.4 & 15.4 & 2.3 & 14.9 & 3.4 & 121 \\
\hline 0178 & 1.13 & 0.83 & 87 & 38.10 & 2.4 & 1.5 & 33.9 & 3.6 & 10.6 & 8.0 & 106 \\
\hline
\end{tabular}

\subsubsection{Control Algorithms Tested}

Two algorithms (RTC-1 and RTC-2) were applied to simulate real-time control of the detention basin outlet valves. The first algorithm was adapted from a control methodology originally presented by Gaborit et al. (2013), and further examined by Gaborit et al. (2016). The second algorithm is a new approach developed during this study. Both control strategies are local, heuristic, and reactive. 


\section{$\underline{\text { RTC-1: Approach from Existing Literature }}$}

This strategy was developed with the following objectives: maximize detention time, avoid overflow, capture the first-flush, drawdown pond volume smoothly, and minimize valve operations (Gaborit et al. 2013). Of the several RTC methods tested in the original paper, "Evolved C" was found to be the most effective, and therefore was chosen for use in this study. The algorithm uses real-time measurements of pond depth, current and accumulated rainfall depth, and detention time. The depth-based control rules were converted from the original facility to the seven test facilities studied herein using the depths relative to each facility's maximum control depth. The control algorithm was developed specifically for the detention basin to which it was originally applied; therefore, performance differences between this study and the original results were expected.

\section{$\underline{\text { RTC-2: Development of New Rule-Based Control Approach }}$}

Since the facilities in this case study are dry detention basins, the biggest improvements to water quality will come from hydraulic modifications that reduce the quantity and duration of erosive flows to promote downstream channel stability. The primary objective of this RTC strategy, therefore, was water quantity improvement and improved valve stability when compared to RTC-1.

The RTC-2 control rules are based on measurable hydrologic parameters; therefore, they are non-site specific. Data inputs for this strategy include real-time water depth, current and accumulated rainfall depth, and detention time. RTC-2 also uses the stage-storage curve, CDA, curve number $(\mathrm{CN})$, and time of concentration $\left(\mathrm{t}_{\mathrm{c}}\right)$ as control calibration inputs. Runoff volume from the rainfall over the last respective " $\mathrm{t}_{\mathrm{c}}$ " minutes to each facility is calculated using the NRCS runoff curve number method (NRCS 1986), and compared to the excess volume (max. control volume - current pond volume) to assess how rapidly to drawdown the facility (Figure 2). The control logic's "percent open" equates to the fraction of the orifice's effective flow area compared to fully open conditions. However, 
in real-life implementation with a butterfly valve, this effective area must be translated to a rotation angle.

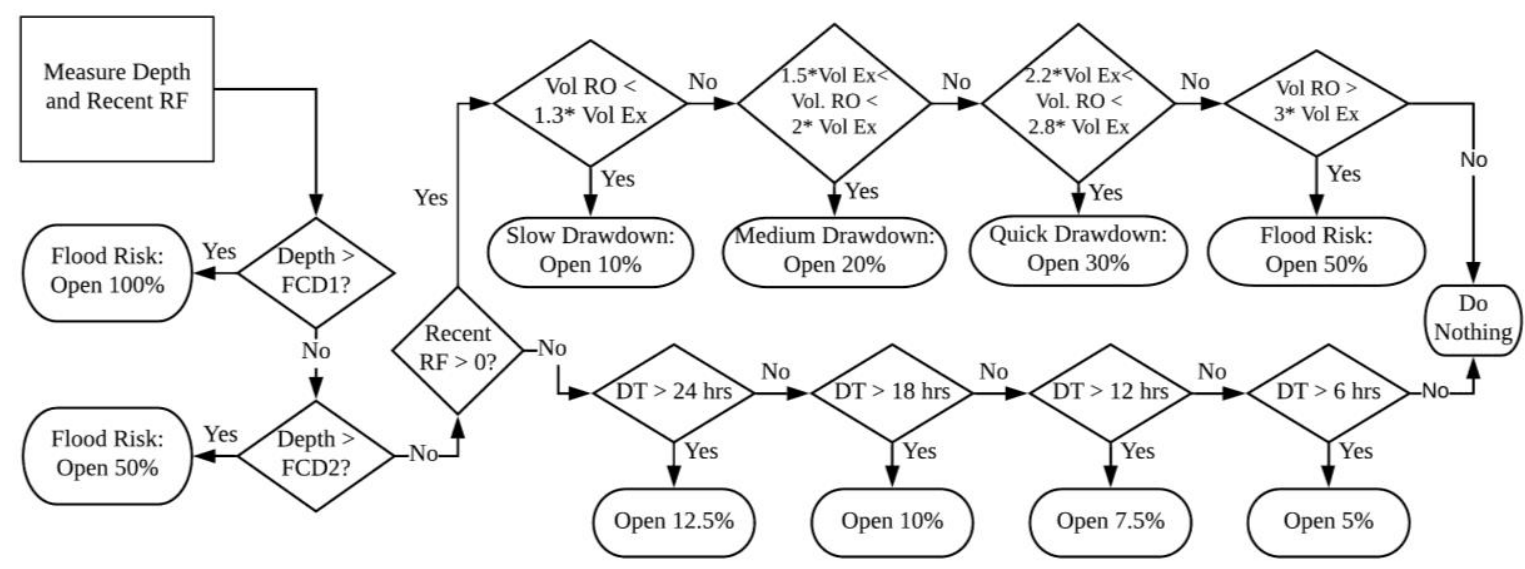

Figure 2. RTC-2 control logic, executed every five minutes. RF = rainfall. $\mathrm{FCD} 1=$ flood control depth \#1, equal to elevation of maximum control depth. FCD2 = flood control depth $\# 2$, elevation $5 \%$ of volume below FCD1. Vol RO = volume of runoff estimated from recent RF using NRCS curve number method. Vol Ex = control volume - current volume of water in facility. DT = detention time.

Both strategies incorporate deadband in the control rules to improve stability (i.e. reduce large fluctuations of motorized valve). RTC-2 has additional rules aimed to improve stability over that of RTC-1. Upon reaching one of two critical depth thresholds (FCD1 and FCD2 in Figure 2), rules are suspended for 30 minutes. In addition, a "slowing mechanism" prevents the valve from closing by more than 5\% in a time step (5 minutes). Both of these factors prevent the rapid opening and closing of the actuated valve, which would lead to hydraulic shocks and overuse of the actuated valve. Stepped drawdown in both methods aims to prevent hydraulic shock to downstream channels. In RTC-1, the valve remains closed after an event until 48 hours have passed. RTC-2 gradually increases the valve $\%$ open starting at 6 hours after the storm event; the facilities drain in $<48$ hours, as required per local regulations (VADCR 1999). 


\subsubsection{Conditions Tested}

\section{$\underline{\text { Retrofit Permutations }}$}

Fourteen permutations of RTC retrofitting within the test watershed were tested for each of the two RTC strategies. This included seven permutations where RTC was applied to each facility individually (with all other facilities static), and seven permutations of combined RTC retrofit scenarios (two or more facilities have RTC). Results of the seven individual RTC scenarios were analyzed at the outlet of each facility and at the watershed outlet. Results of the seven combined scenarios were assessed at the watershed outlet.

\section{$\underline{\text { Baseline Watershed Conditions }}$}

In addition to the RTC scenarios, static and predevelopment scenarios were modeled. The static condition, with all basin outlets fully open and unmoving, was evaluated to establish a baseline of current stormwater management in the watershed. A predevelopment condition was simulated, with assumed land cover values of $70 \%$ forest, $27 \%$ open space, and 3\% impervious surface. Channel roughness (Manning's $n$ coefficient) of 0.030 was used. These parameters represent a reasonable estimate for the watershed's pre-urbanized state and allow for comparison of RTC performance to hydraulic conditions that promote local stream health.

\section{Precipitation Scenarios}

All watershed test conditions (static, predevelopment, RTC-1, and RTC-2) were subjected to both synthetic design storms and real precipitation data. The design storms consisted of NRCS Type II storms, with a duration of 24 hours and return periods ( $T_{R}$ 's) ranging from 0.25 years ( 3 months) to 100 years. In addition, 15 years of regional NOAA precipitation data was used to evaluate the net performance of RTC under realistic, irregular rainfall conditions over a long duration (5,479 days of simulated weather). The 15-year rainfall record had an average annual precipitation of $1,170 \mathrm{~mm}$, which is higher than the local long-term average of $1,038 \mathrm{~mm}$. 


\subsection{Results and Discussion}

The simulated RTC retrofits were analyzed using the following criteria:

1. Impact on peak outflow and duration of erosive flows at the facility outlet.

2. Impact on peak outflow and duration of erosive flows at the watershed outlet.

3. Level of algorithm instability (as characterized by a high rate of valve fluctuations).

In addition, the relationship between facility RTC performance and facility physical characteristics is discussed.

\subsubsection{Impact of RTC on Local Conditions (at Facility Outlet)}

\section{$\underline{\text { RTC Performance during Discrete Storm Events }}$}

The peak flow of each design storm was found at the outlet of each facility under static conditions, RTC-1, and RTC-2. The RTC scenarios were each compared to the static scenario to find the percent change in peak flow. Results plotted in Figure 3 show that performance varied significantly across the facilities. The only consistent result appears to be that peak flow rates for the largest magnitude precipitation events were typically made worse, or remained unchanged, in the presence of real-time control. For events with a return period of 2 years and less, some detention ponds experience significant reductions in peak flow rate; e.g. $\mathrm{Q}_{\mathrm{p}-0.25 \mathrm{yr}}$ of facility 0262 decreased by 82 and $85 \%$ using RTC-1 and RTC-2, respectively. However, for the same storm events, other ponds experience increased peak flows, up to $150 \%$ greater than static condition ( $\mathrm{Q}_{\mathrm{p}-\mathrm{yr}}$ for facility 0274$)$. For storms with $T_{R} \geq 5$ years, there is no observed benefit to peak flow with RTC at any of the detention basins. The negative impact of RTC seems to lessen as storm magnitudes increase from the 5-year to the 100-year, as expected. For the largest storms, the relative impact of RTC lessens (as the outflow valve is likely completely open for most of the event), and therefore the change in peak flow with respect to the static condition approaches zero percent. Because the peak flows and volumes of smaller storm events are relatively small, the 
change due to RTC has the potential to be very high, in both positive and negative directions.

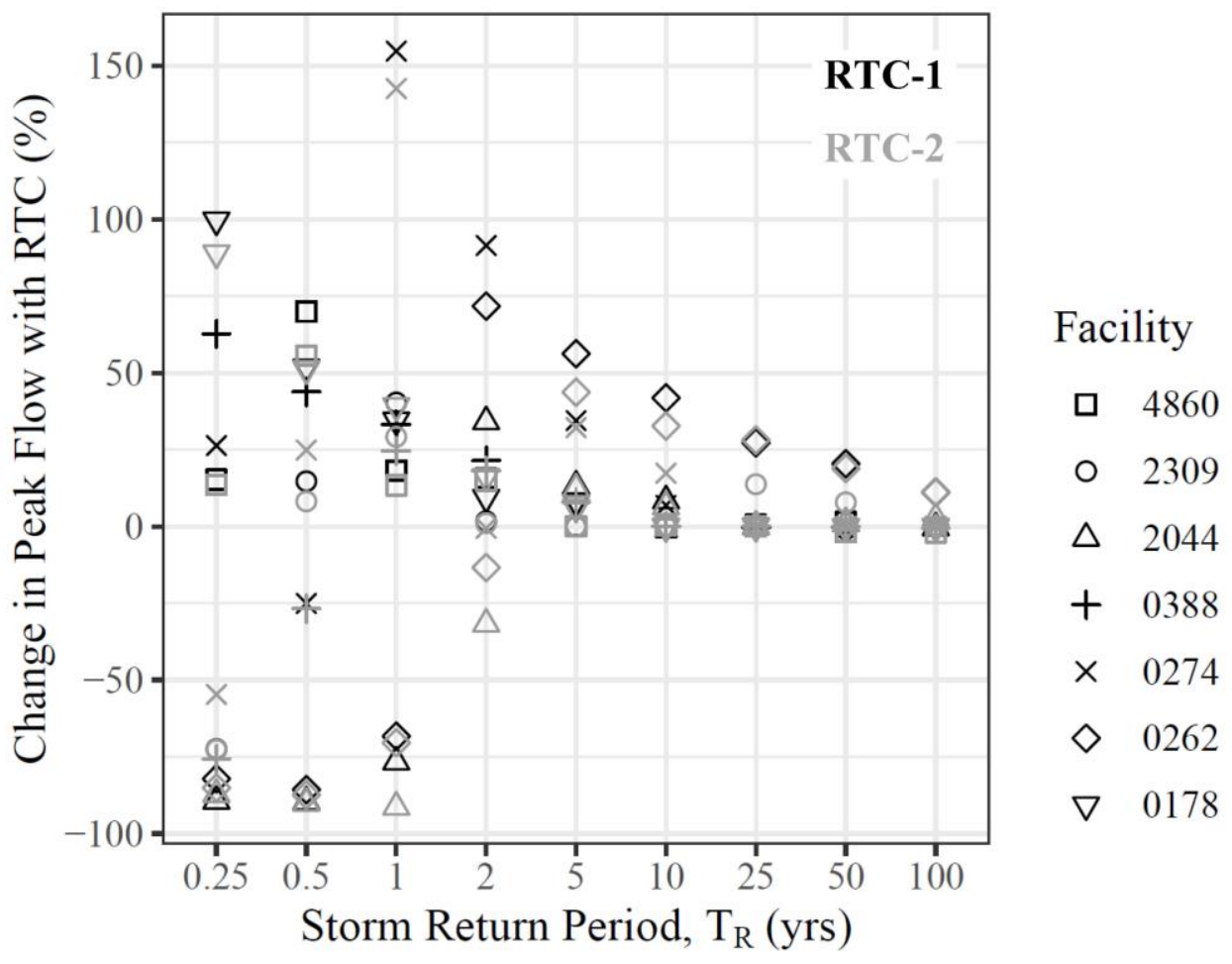

Figure 3. Change in peak flow with RTC for NRCS 24-hour Synthetic Design Storms of varying return periods. Positive \% change indicates increased peak flow with RTC compared to static, and vice versa.

Figure 4 details more of the processes influencing these changes in peak flow. The left hand plots in the figure ( $a l$ to $d 1$ ) show the behavior of facility 2044 during the 1-year storm, demonstrating an example where improvements were made with RTC. The right hand plots ( $a 2$ to $d 2$ ) show the same facility's behavior during the 5-year storm, when RTC causes increased peak flow.

As seen in Figure 4(b1), the 1-year peak flow is reduced from $0.24 \mathrm{~m}^{3} / \mathrm{s}$ to $0.05 \mathrm{~m}^{3} / \mathrm{s}$ with RTC-1 and $0.02 \mathrm{~m}^{3} / \mathrm{s}$ with RTC-2. In the hydrograph for the larger storm (Figure 4[b2]), both RTC methods cause peak flow to increase by about $13 \%$. This is likely caused by the reactive nature of the RTC strategies tested. Both strategies restrict outflow and retain volume more than the static condition at the beginning of the event. At a certain point, the 
volume of water in the detention basin approaches critical flood risk levels, causing the valve to quickly open to $50 \%$ or $100 \%$ of its total area. Although the orifice size in the RTC scenario is no larger than that of the static, the RTC orifice head is higher than the static water level at the moment of valve opening (Figure 4[d2] and [c2]), causing a higher peak discharge. This behavior causes the increased peak flows seen in Figure 3. It is likely that the incorporation of quantitative precipitation forecasts to estimate future runoff would mitigate the negative effects of RTC during large storm events, as the technique has demonstrated positive outcomes in field experimentation (Marchese et al. 2018; Opti RTC and Geosyntec Consultants Inc. 2017). In addition, computer simulations of predictive RTC have found it to improve conditions for large storm events (Bilodeau et al. 2019; Gaborit et al. 2016; Wong 2017).

Depth oscillations occur with RTC-1 but not with RTC-2 (Figure 4[d2]). This is due to the rule-suspension programmed into RTC-2 which prevents the valve from closing for 30 minutes after water depth exceeds a flood risk level (Figure $4[d 2]$, light gray dotted lines). Without this measure, RTC-1 causes the valve to close and open two additional times before the runoff finally diminishes. 

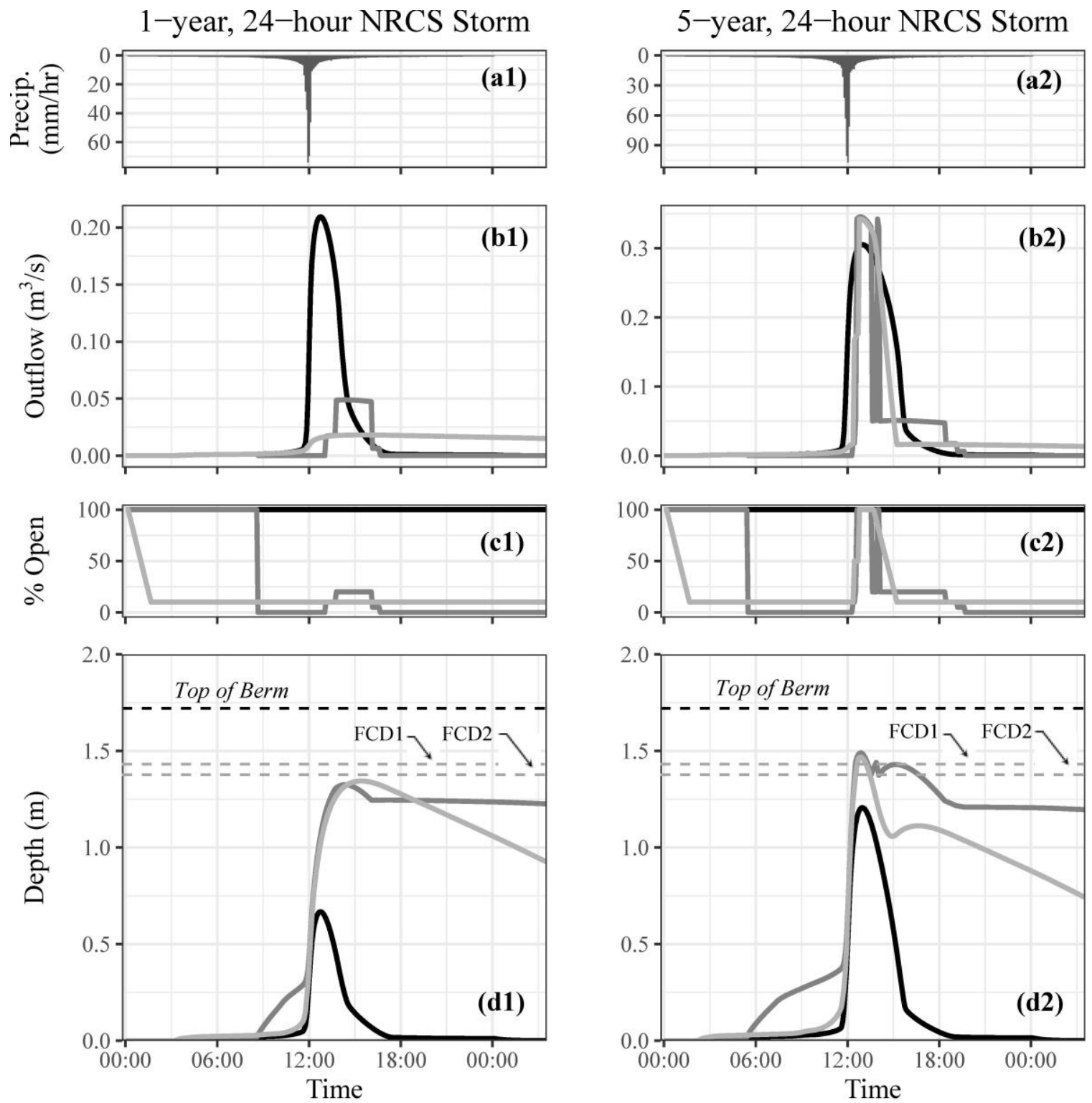

$\mathrm{RTC}-0-1=2$

Figure 4. Performance of facility 2044 with no control (static: shown in black), RTC-1 (middle gray), and RTC-2 (light gray) for the 1-year and 5-year design storms. Precipitation, basin discharge, valve position (\% open), and depth of water in the basin are depicted. Basin top of berm (black dashed) and flood control depths (gray dashed) depicted $(\mathrm{d} 1, \mathrm{~d} 2)$. 


\section{$\underline{\text { RTC Performance during 15-Year Simulation }}$}

While the peak flow rate is an important consideration of any stormwater management strategy, current literature has found the flow duration curve (FDC) to be a more scientifically sound tool for assessing the efficacy of a management technique (Goodman and Quigley 2015; Jackson and Booth 1997; Marchese et al. 2018; Nehrke and Roesner 2004; Palhegyi 2010). The FDC shows the frequency with which flows of varying magnitudes are exceeded and is useful to understand the impact a control measure has on the entire flow regime.

While many stormwater regulations focus on mitigating the 2- and 10-year peak flows, it is likely that smaller, more frequent events cause the majority of geomorphological impacts on the stability of a stream channel (Tillinghast et al. 2011). The critical flow rate is the minimum discharge associated with streambank erosion (Jackson and Booth 1997), and this parameter can be used to quantify the net effect of RTC on total erosive flows. To accurately quantify the critical flow rate, analysis of local hydraulics and stream bed characteristics is needed; however, this type of analysis is outside of the scope of this study. From Jackson and Booth (1997), one half of the 2-year predevelopment peak flow rate is considered an appropriate estimate of critical flow rate. This metric was used for establishing the critical flow rate throughout this analysis.

Flow duration curves of the 15-year simulation were computed for the outlet of each facility, allowing for comparison between RTC and static scenarios across the full flow regime (Figure 5). Where the RTC curve is below the static curve, RTC has reduced the duration of the corresponding flows (ordinates of Figure 5). Where the RTC curve is above the static curve, the duration of those flows has increased. For ordinate values above $\mathrm{Q}_{\text {crit, }}$ reduced duration of flows has a positive impact on improving stream stability, and vice versa. Differences between RTC and static scenarios below $\mathrm{Q}_{\text {crit }}$ are likely insignificant to geomorphological change. 

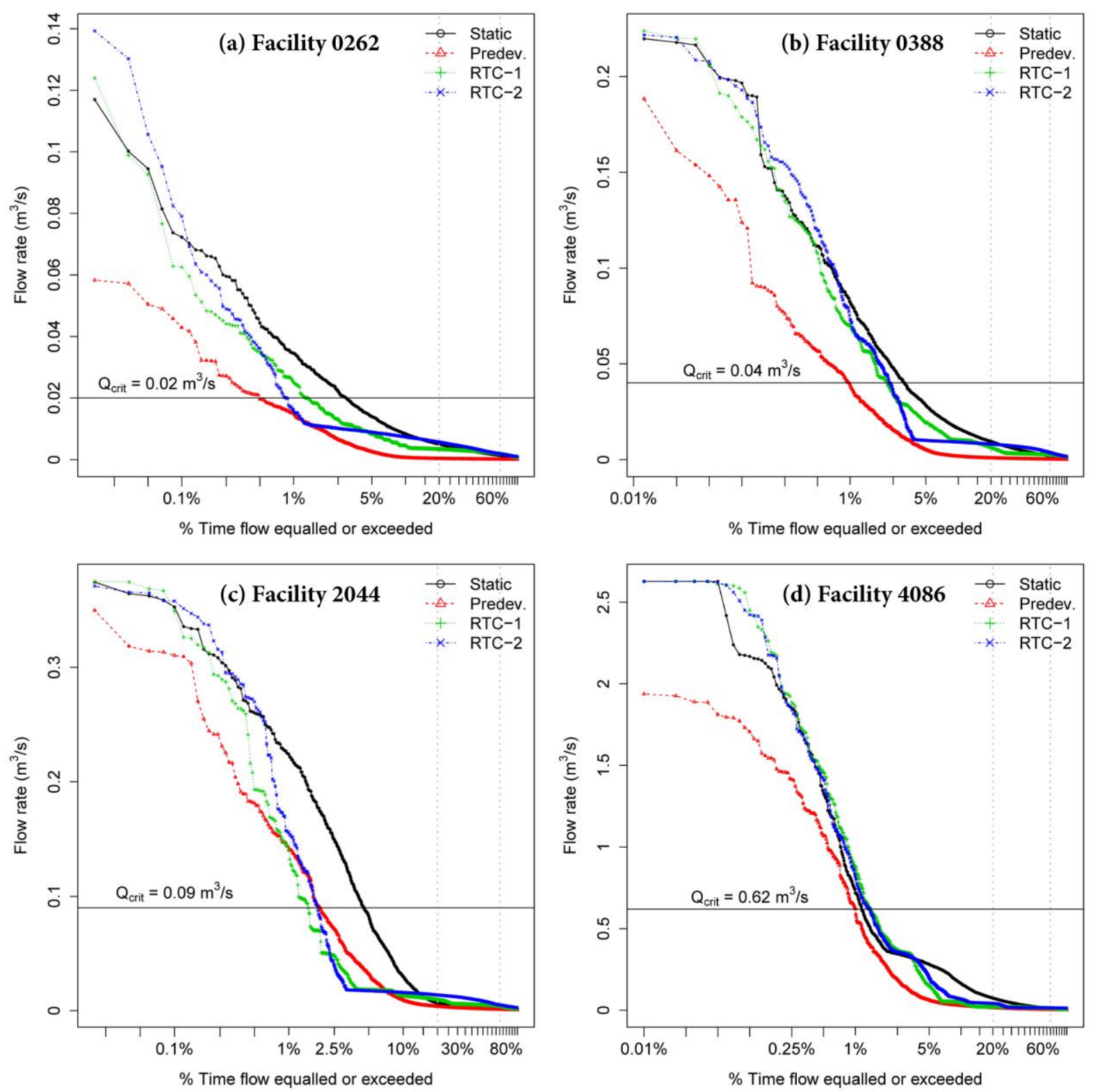

Figure 5. Flow Duration Curves at outlets of four facilities.

The majority of FDCs show mixed results, where RTC reduced the duration of a certain range of flows while increasing the duration of another. Four FDCs are shown in Figure 5 to demonstrate the range of impacts the RTC strategies have on flow regimes at the facility outlets. Both RTC-1 and RTC-2 cause reduced duration of flows just above $\mathrm{Q}_{\text {crit }}$ in facilities 0262 and 2044 (Figure 5Figure 5[a] and $[c]$ ). However, the RTC improvements diminish 
for the lower frequency, high magnitude flow rates. RTC-1 approaches the static condition and RTC-2 exceeds the static condition for greater discharges in facilities 0262 and 2044. The FDC for facility 0388 shows a similar pattern, but the improvements from RTC are less, since these flow duration curves do not stray far from the static condition. Conditions at facility 4860 are only made worse, or remain unchanged, by RTC for all discharges exceeding the critical flow rate. FDCs from the facilities 0274 and 0178 (not shown) closely resemble that of facility 0388, and the FDC of facility 2309 (not shown) has a similar pattern to that of facility 4860 .

To summarize the quantity of erosive flows, the total time that flows exceeded the critical flow rate, or $\mathrm{Q}_{\text {crit }}$ exceedance time (ET), was calculated for each facility outlet, for the four watershed conditions (static, predevelopment, RTC-1, and RTC-2). Changes in Qcrit ET for RTC-1, RTC-2, and predevelopment scenarios were normalized as a percent deviation from the static condition of each facility (Figure 6Figure 6[a]). This process was repeated with two additional flow rate thresholds: the two-year predevelopment peak, $\mathrm{Q}_{\mathrm{p} 2 \mathrm{yr}}$, and the

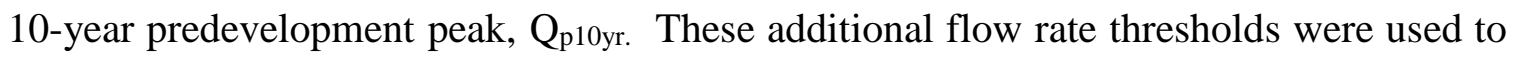
differentiate the behavior during more extreme flows (Figure 6Figure 6[b] and $[c]$ ). 


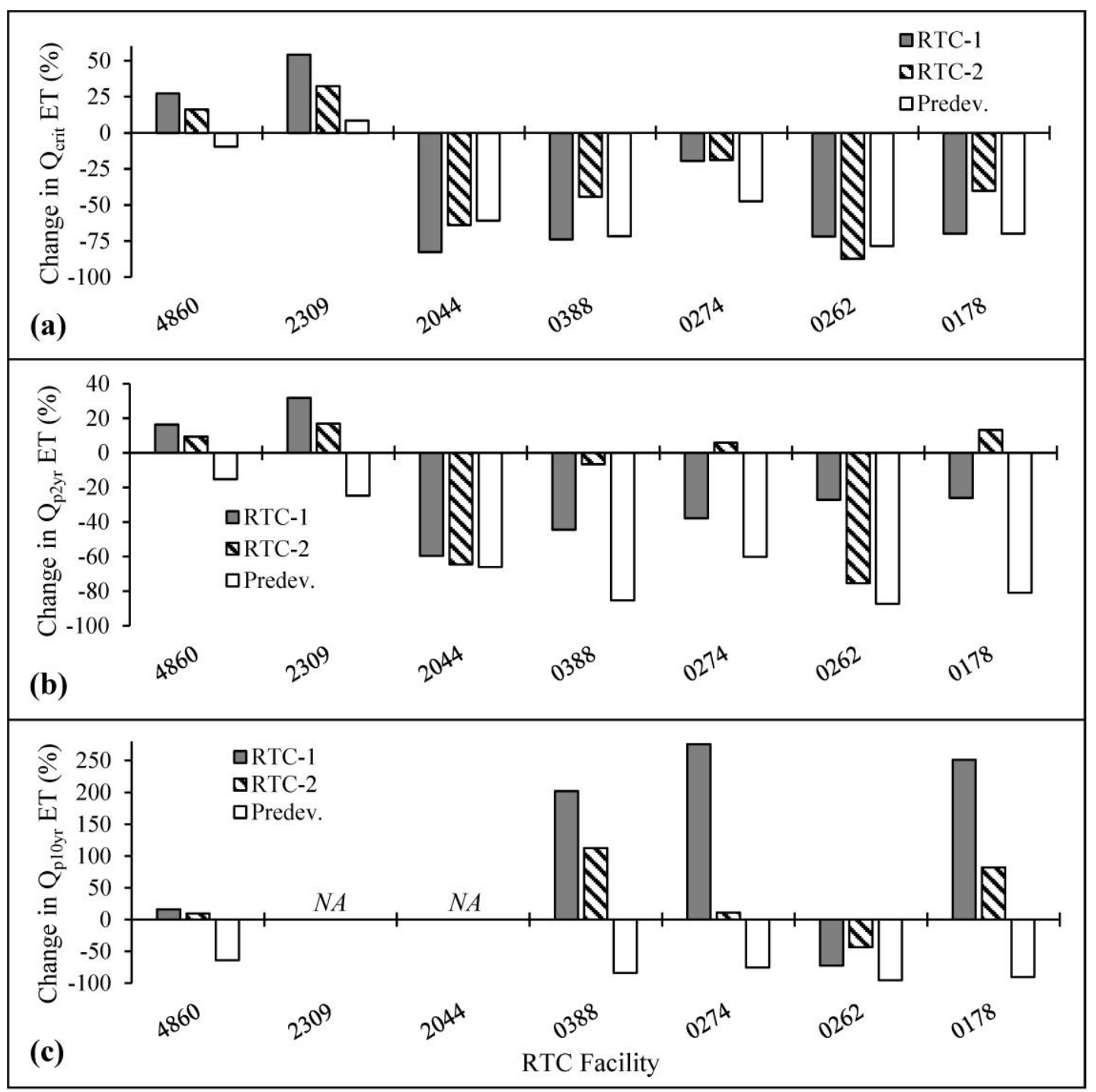

Figure 6. Change in time exceeding selected flow rates at outlet of each detention basin, as compared to static: (a) critical flow rate (equal to $1 / 2$ of the predevelopment 2 -year peak flow), (b) predevelopment 2-year peak flow, (c) predevelopment 10-year peak flow.

$\mathrm{Q}_{\text {crit }}$ ET was reduced by both RTC strategies for the five smallest facilities, often coming close to the predevelopment value (Figure $6[a]$ ). RTC of the two largest detention basins (4860, 2309) caused increased Q $Q_{\text {crit }}$ ET compared to the static scenario. Interestingly, for both of these detention basins, the static and the predevelopment conditions had similar values for $\mathrm{Q}_{\text {crit }} \mathrm{ET}(<10 \%$ difference), meaning that there was little room for improvement by RTC over static control. 
$\mathrm{Q}_{\mathrm{p} 2 \mathrm{yr}} \mathrm{ET}$ increased for the two largest basins and decreased for three of the basins in both RTC strategies (Figure 6Figure 6[b]). Facilities 0274 and 0178 experienced reduced $\mathrm{Q}_{\mathrm{p} 2 \mathrm{yr}}$ ET with RTC-1 and increased $\mathrm{Q}_{\mathrm{p} 2 \mathrm{yr}}$ ET with RTC-2. Figure 6(c) shows that four of five facilities experienced worsened conditions (increased $\mathrm{Q}_{\mathrm{p} 10 \mathrm{yr}} \mathrm{ET}$ ) due to RTC. Conditions for facility 0262 were improved with RTC (decreased $\mathrm{Q}_{\mathrm{p} 10 \mathrm{yr}} \mathrm{ET}$ ). Facilities 2309 and 2044 had no flows above $\mathrm{Q}_{\mathrm{p} 10 \mathrm{yr}}$ during the 15-year simulation, and could not be compared.

In general, the net effect of RTC was positive for most detention basins; however, conditions were often worsened for more extreme (rarer) events, consistent with previous research examining the effect of RTC on FDC (Parolari et al. 2018). This impact caused the duration of flooding to increase in the presence of RTC for all seven facilities by as much as 7 hours during the 15-year simulation.

\subsubsection{Impact of RTC on Downstream Conditions (at Watershed Outlet)}

Results of RTC retrofitting were evaluated at the watershed outlet in order to assess the extended impact that local RTC may have on downstream conditions.

\section{$\underline{\text { RTC Performance during Discrete Storm Events }}$}

The impact of RTC on peak discharge at the outlet of the watershed was inconsistent across detention basins and over storms of varying magnitudes (Table 3 ). The only consistently positive result was for the smallest storm ( $\mathrm{T}_{\mathrm{R}}=0.25$ years), where $\mathrm{RTC}$ on any detention basin reduced peak flow at the watershed outlet by $0.1 \%$ to $20.5 \%$. This finding is curious since four facilities with RTC-1 and two facilities with RTC-2 experienced increases in local peak flow during the same 0.25 -year storm (Figure 3). This result may be due to shifts in runoff peak arrival at the downstream location. Additional downstream peak flow reductions were observed, despite local peak flow increases. For example, during the 5year storm, Figure 3 shows that RTC did not reduce peak flows at any basin outlet, but Table 3 shows that RTC caused slight reductions in peak flow at the watershed outlet in most cases. RTC may positively influence downstream peak flows, but the potential for worsened conditions must also be considered. 
Table 3. Percent change in peak flow at watershed outlet with RTC relative to the static condition. Increased peak flow is shown in bold, and decreased peak flow is shown in italics.

\begin{tabular}{|c|c|c|c|c|c|c|c|c|c|c|c|c|c|c|c|}
\hline \multirow{3}{*}{\multicolumn{2}{|c|}{$\begin{array}{r}\text { Facility: } \\
\text { RTC } \\
\text { Method: }\end{array}$}} & \multicolumn{14}{|c|}{ Change in Peak Flow (\%) } \\
\hline & & \multicolumn{2}{|c|}{4860} & \multicolumn{2}{|c|}{2309} & \multicolumn{2}{|c|}{2044} & \multicolumn{2}{|c|}{0388} & \multicolumn{2}{|c|}{0262} & \multicolumn{2}{|c|}{0274} & \multicolumn{2}{|c|}{0178} \\
\hline & & 1 & 2 & 1 & 2 & 1 & 2 & 1 & 2 & 1 & 2 & 1 & 2 & 1 & 2 \\
\hline \multirow{9}{*}{ 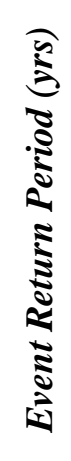 } & 0.25 & -20.5 & -19.6 & -7.2 & -6.3 & -0.5 & -1.5 & -4.8 & -3.1 & -5.4 & -5.1 & -1.1 & -0.2 & -1.3 & -0.1 \\
\hline & 0.5 & 1.0 & 3.3 & 1.4 & 2.2 & 2.7 & -2.0 & -5.3 & -4.7 & -1.4 & -1.1 & -2.7 & -1.0 & -0.6 & -0.3 \\
\hline & 1 & 58.1 & 0.4 & -2.0 & -1.7 & -0.2 & -0.8 & -3.5 & -2.9 & -3.0 & -3.3 & -1.1 & -0.2 & -1.7 & -0.9 \\
\hline & 2 & -20.9 & -18.5 & -0.7 & -4.5 & 3.6 & 6.3 & -0.7 & -1.8 & 0.6 & -1.5 & 6.9 & 7.0 & 4.3 & 6.9 \\
\hline & 5 & 4.5 & 7.0 & 0.1 & -0.5 & -1.0 & -5.6 & -0.2 & -0.6 & -1.3 & -1.7 & -0.3 & -0.5 & -0.2 & -0.1 \\
\hline & 10 & -2.9 & -0.7 & 0.0 & 0.6 & 0.3 & -0.1 & -1.0 & -1.6 & -0.4 & -2.2 & -1.3 & -0.4 & -0.5 & -0.5 \\
\hline & 25 & 9.5 & 1.3 & 3.2 & 3.2 & -0.9 & -1.8 & -1.8 & -3.4 & -2.1 & -3.7 & -3.1 & -2.4 & 0.2 & -1.1 \\
\hline & 50 & 17.3 & 7.5 & 1.2 & 1.9 & 2.5 & 0.5 & 0.1 & 0.8 & -0.9 & 0.5 & 0.1 & 0.8 & 0.3 & 2.1 \\
\hline & 100 & -0.8 & -0.8 & -3.7 & -3.9 & -1.0 & -0.9 & 0.3 & -0.1 & 0.2 & -0.2 & 0.3 & -0.3 & 0.1 & 0.2 \\
\hline
\end{tabular}

\section{$\underline{\text { RTC Performance during 15-Year Simulation }}$}

Critical flow rate was calculated for the watershed outlet point using the same method discussed previously. RTC scenarios included seven permutations of single basin retrofits and seven combination retrofits (Table 4). The $\mathrm{Q}_{\text {crit }} \mathrm{ET}$ at the watershed outlet was reduced in almost every RTC retrofit permutation (Figure $7[a]$ ). The performance at the watershed outlet differs from the performance at the basin outlet in this regard, as RTC increased the duration of erosive flows of facility 4860 and facility 2309 at the detention basin outlet. This indicates that worsened local conditions may have some net positive effect on conditions downstream (as with peak flows, discussed before). 
Table 4. Combined RTC retrofit scenarios

\begin{tabular}{|c|c|c|c|c|c|c|c|c|}
\hline & \multicolumn{7}{|c|}{ Facilities Controlled } & \multirow{2}{*}{$\begin{array}{l}\text { \% of Watershed } \\
\text { with RTC }\end{array}$} \\
\hline & 4860 & 2309 & 2044 & 0388 & 0274 & 0262 & 0178 & \\
\hline Combo \#1 & $\mathrm{X}$ & $\mathrm{X}$ & $\mathrm{X}$ & $\mathrm{X}$ & $\mathrm{X}$ & $\mathrm{X}$ & $\mathrm{X}$ & $64.5 \%$ \\
\hline Combo \#2 & $\mathrm{X}$ & $X$ & $\mathrm{X}$ & $X$ & & $\mathrm{X}$ & & $59.1 \%$ \\
\hline Combo \#3 & $\mathrm{X}$ & $\mathrm{X}$ & $\mathrm{X}$ & & & $\mathrm{X}$ & & $57.3 \%$ \\
\hline Combo \#4 & $\mathrm{X}$ & $X$ & X & & & & & $56.7 \%$ \\
\hline Combo \#5 & & & & $\mathrm{X}$ & & $\mathrm{X}$ & & $2.4 \%$ \\
\hline Combo \#6 & & $\mathrm{X}$ & $\mathrm{X}$ & $\mathrm{X}$ & & $\mathrm{X}$ & & $13.7 \%$ \\
\hline Combo \#7 & & & $\mathrm{X}$ & & & $\mathrm{X}$ & & $5.8 \%$ \\
\hline
\end{tabular}

The impact of a single facility retrofit on downstream duration of erosive flows was found to be relatively small (less than $4 \%$ change). This impact does not scale linearly with the percent of watershed area draining to a given detention basin; for example, a retrofit of facility 4860 lead to similar downstream performance as that of facility 2044, despite the fact that the facilities drain vastly different proportions of the watershed area: $45.5 \%$ and $5.3 \%$, respectively.

Compared to single facility retrofits, the combined RTC scenarios had a greater magnitude of impact at the watershed outlet. The largest reductions in $\mathrm{Q}_{\text {crit }}$ ET were from Combo \# 1 and \# 2 using RTC-2. In both of these combinations, a majority of the watershed area drains to a RTC stormwater facility (65 and 59\%, respectively), but similar results were found for Combo \#6, where RTC affect only $14 \%$ of the watershed area (Table 4).

RTC's impact on watershed $\mathrm{Q}_{\mathrm{p} 2 \mathrm{yr}}$ and $\mathrm{Q}_{\mathrm{p} 10 \mathrm{yr}}$ ET showed mixed trends (Figure 7[b] and $[c]$ ). RTC on facility 4860 and facility 2309 increased Qp2yr ET (Figure 7[b]); a retrofit of these locations would likely exacerbate conditions for larger, less frequent discharge events. The remaining detention basins succeeded in reducing ET for the 2- and 10-year predevelopment peak flows, with facility 2044 having the greatest benefit. 


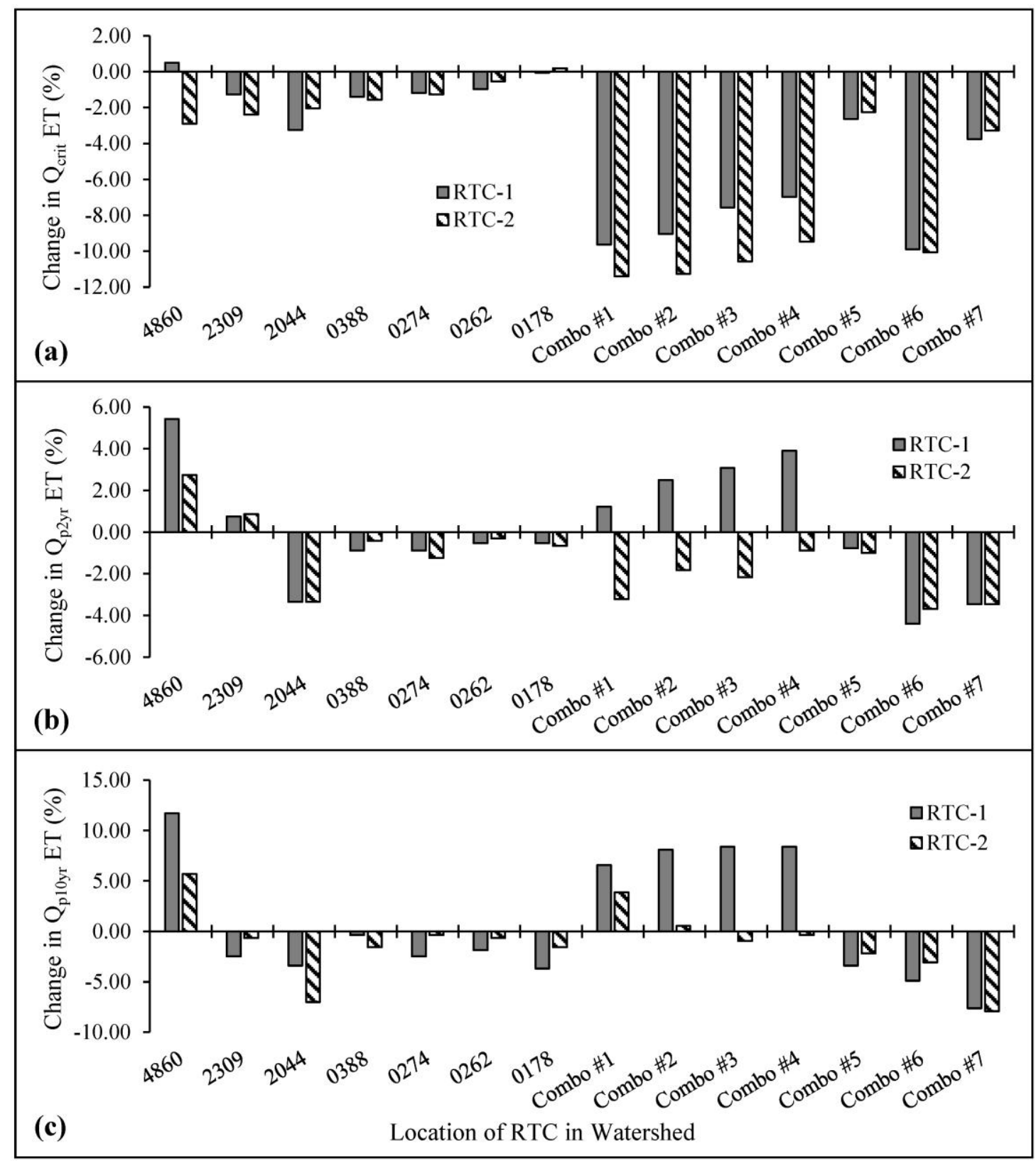

Figure 7. Change in time exceeding selected flow rates at watershed outlet, as compared to static: (a) critical flow rate (equal to $1 / 2$ of the predevelopment 2 -year peak flow), (b) predevelopment 2-year peak flow, and (c) predevelopment 10-year peak flow. RTC was simulated at the location indicated, either on a single detention basin, or a combination of detention basins.

For RTC strategy 1, combined control scenarios tended to worsen ET of $\mathrm{Q}_{\mathrm{p} 2 \mathrm{yr}}$ and $\mathrm{Q}_{\mathrm{p} 10 \mathrm{yr}}$ if facility 4860 was included in the combined control (Combo \#1 -4). Combination scenarios of RTC-2 also had a more positive impact if they did not include RTC at facility 4860 
(Figure 7[b] and $[c]$ ). Neither RTC algorithm was superior in all instances, although RTC2 reduced $\mathrm{Q}_{\text {crit }} \mathrm{ET}$ the most in the combined scenarios. Additionally, many conditions where RTC-1 had a negative impact (increased ET), RTC-2 was found to have a positive impact, or a lesser negative impact (Figure 7).

The differences between predevelopment and static exceedance times (ETs) were calculated to be $-46 \%\left(\mathrm{Q}_{\mathrm{crit}} \mathrm{ET}\right),-51 \%\left(\mathrm{Q}_{\mathrm{p} 2 \mathrm{yr}}\right)$, and $-81 \%\left(\mathrm{Q}_{\mathrm{p} 10 \mathrm{yr}}\right)$. When these numbers are compared with the ordinate scale values in Figure 7 , it is clear that the downstream impacts of RTC were far from achieving predevelopment ET values.

\subsubsection{Comparison of Algorithm Stability}

The stability of the control algorithm (i.e. its resistance to rapid fluctuations/oscillations in valve position) is an important aspect of RTC performance. If the algorithm is unstable, the valve will be subjected to more rapid wear and tear. Additionally, spikes in discharge due to sudden changes in valve position are more likely to induce hydraulic shocks in downstream channels, potentially leading to streambank erosion.

The total movements in valve position during the 15 -year simulation were summed across the seven detention basins (Figure 8). RTC-1 caused more changes in valve position compared to RTC-2 for all facilities except 4860. In addition, RTC-1 caused more medium and large fluctuations in valve position (> 5\% change in effective area) across all detention basins. Certain stabilizing characteristics of the RTC-2 algorithm are believed to have caused this improved stability, such as the time-based rule suspension employed if pond depths exceed flood risk levels. Additionally, because the valve is never fully closed in RTC-2, a change in valve position is not needed for many small storm events. 


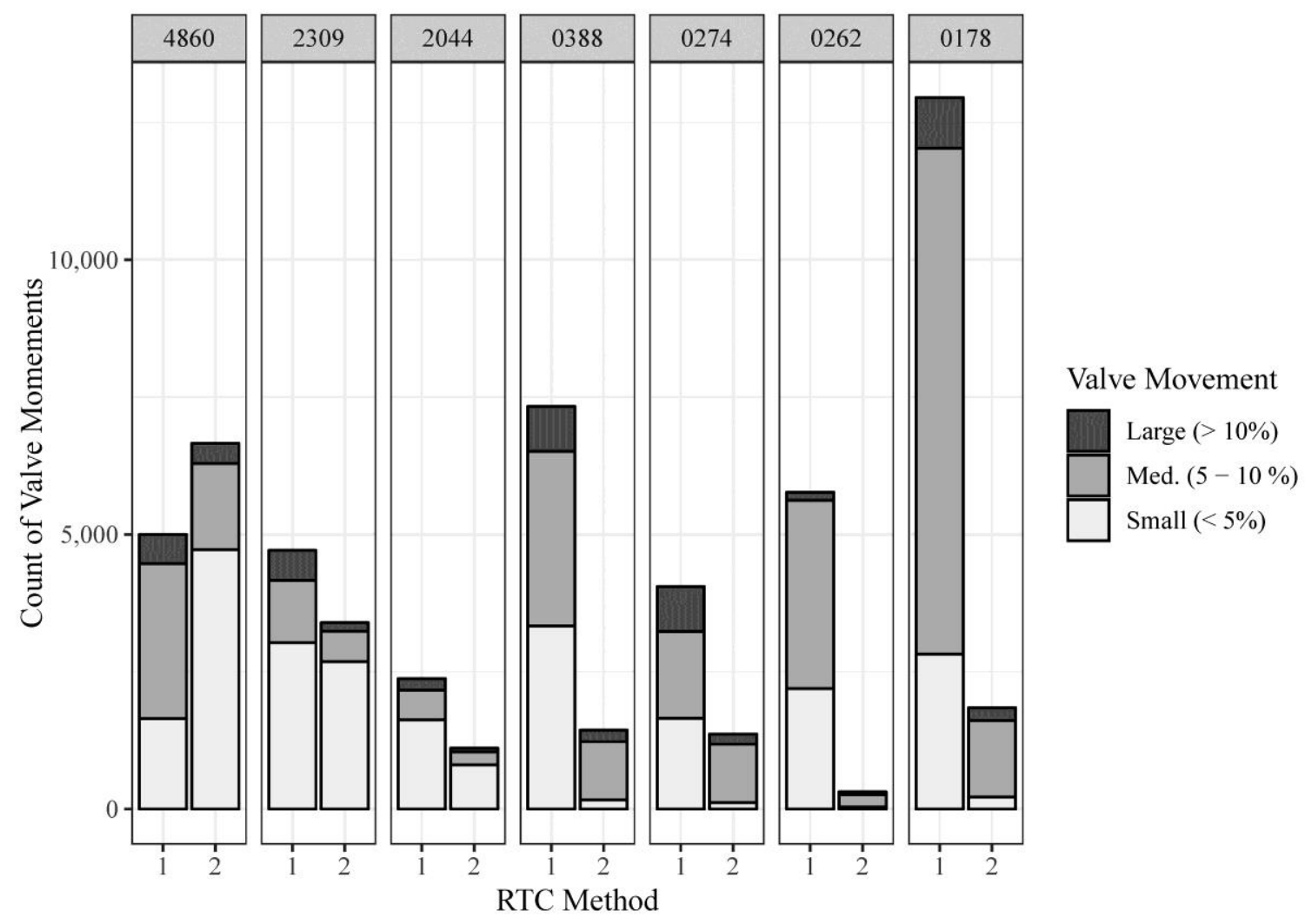

Figure 8. Count of valve movements over 15 -year simulation.

Additional problems with algorithm instability of RTC-1 are illustrated in Figure 9. The real precipitation event shown, which is equivalent to a 10-year, 24-hour storm, was extracted from the 15-year simulation. During the event, RTC-1 causes 23 total valve movements, and RTC-2 causes 65 total valve movements. Large fluctuations in discharge occur with RTC-1 because the movements have larger oscillatory amplitude (> 10\%). Most of the 65 valve moves with RTC-2 were small adjustments, allowing for much smoother discharge despite a larger total quantity of movements. 


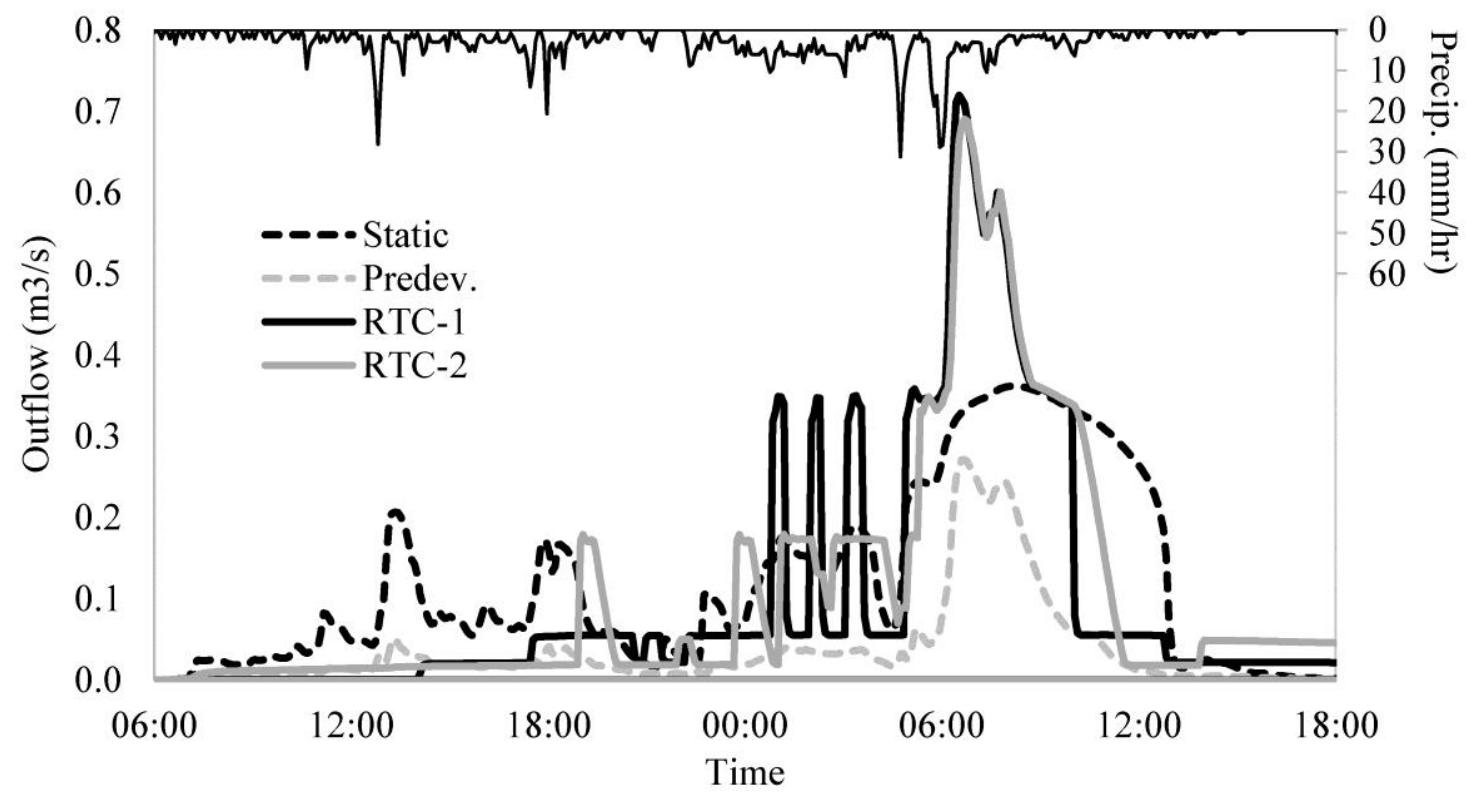

Figure 9. Outflow hydrograph of facility 4860 during a storm event for four conditions: static, predevelopment, RTC-1, and RTC-2.

\subsubsection{Comparison of RTC Performance to Facility Indicator Variables}

Due to large variability of results, a concise statement about which facilities were best suited for a RTC retrofit is impractical. It is easy to conclude that facility 4860 performed the worst in nearly every metric. Locally, peak flows and $Q_{\text {crit }}$ ET were both made worse, and at the watershed outlet, the RTC of this basin increased duration of the highest flow rates. Facility 2309 would likely be ranked as the second worst-suited for retrofit since real-time control of this basin also caused increased ET of $\mathrm{Q}_{\text {crit }}, \mathrm{Q}_{\mathrm{p} 2 \mathrm{yr}}$, and $\mathrm{Q}_{\mathrm{p} 10 \mathrm{yr}}$ locally. An argument could be made for the superior performance of RTC on facilities 2044 and 0262. The RTC of both basins significantly reduced peak flows for all design storms up to TR = 1-year with RTC-1, TR = 2-year with RTC-2, and contributed to reduced ET of all threshold flow rates at the watershed outlet.

Correlation of a facility's RTC retrofit potential with one or more physical attributes of the detention basin or its drainage area would be beneficial, as this type of relationship would allow engineers and city officials to make informed RTC retrofit decisions without extensive modeling. The following simple indicator variables were considered (Table 2): 
1. CV/CDA: the ratio of control volume to contributing drainage area

2. $\mathrm{CV} / \mathrm{CDA}_{\text {imp }}$ : the ratio of control volume to impervious contributing drainage area

3. Drainage density: the ratio of the CDA to the length of storm sewer within CDA

4. CV/Control Depth: the ratio of basin control volume to the maximum control depth

Of these four parameters, the first two were found to loosely correspond to a basin's RTC performance. The worst-performing detention basin (4860) has the second lowest value of CV/CDA $(3.5 \mathrm{~mm})$, and third lowest value of CV/CDA $\mathrm{Cmp}(16.4 \mathrm{~mm})$. The two bestperforming basins (2044 and 0262) had the two highest values of CV/CDA (16.9 mm and $23.6 \mathrm{~mm}$ ) and of $\mathrm{CV} / \mathrm{CDA}_{\mathrm{imp}}(75.0 \mathrm{~mm}$ and $37.8 \mathrm{~mm}$, respectively). For context, the facility original tested by Gaborit et al. (2013), which had largely positive results from

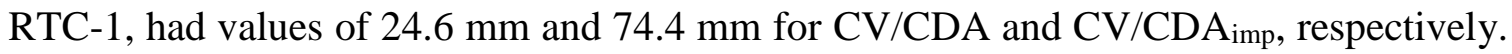
Neither of the other two parameters appeared to correspond with facility RTC performance.

This finding is statistically inconclusive due to the large variation in RTC results and the relatively small sample size ( $\mathrm{n}=7$ facilities). Nonetheless, it is logical that the ratio of $\mathrm{CV} / \mathrm{CDA}$ would be positively correlated to RTC potential, as this ratio represents the depth of runoff that the facility can store. If a facility's capacity is limited in the static condition, then it would not be able to retain the additional water needed for RTC benefits. However, with excess capacity, RTC may make a positive impact.

\subsection{Conclusion}

A small headwater catchment was modeled for RTC retrofit of its existing stormwater detention basins in order to assess the potential hydraulic benefits that may be gained from this type of modification. Two RTC algorithms, both heuristic, reactive, and local, were tested for synthetic design storms of varying magnitudes, and for 15 years of real precipitation data from the region. The resulting hydraulic conditions with and without RTC were assessed locally (at the outlet of each detention basin) and downstream, at the watershed outlet. From the results, the following conclusions can be made: 
1. For smaller, high frequency events ( $T_{R} \leq 2$-years), RTC reduced peak discharges at the outlets of some detention basins, while increasing the peak flow for others. Across all detention facilities, no reduction in peak flow from RTC was observed for events larger than the 2-year storm. The increase in peak flow rates occurred when the pond depth exceeded a critical flood risk depth, and the outlet valve was forced to open suddenly.

2. The impact of RTC on peak flow rates at the watershed outlet was positive for the 0.25 -year storm ( 0.1 to $20 \%$ reduction in peak flow), but had mixed results for all larger storm events (some positive and some negative).

3. The total duration of erosive flows at the facility outlet was reduced by RTC in most cases (five of seven detention facilities). However, even if the net impact on $\mathrm{Q}_{\text {crit }}$ ET was positive, RTC often exacerbated ET of the highest flows, and caused increased duration of facility flooding in all cases.

4. At the watershed outlet, all single-facility RTC scenarios lead to slightly reduced durations of $\mathrm{Q}_{\text {crit }} \mathrm{ET}$ (reduced by < 4\%) compared to the static condition, even those which caused increased $Q_{c r i t}$ ET locally. Combined RTC scenarios also lessened Qcrit ET, with a maximum reduction of $11.4 \%$ by applying RTC-2 to all seven detention basins. Worsened ET of $\mathrm{Q}_{\mathrm{p} 2 \mathrm{yr}}$ and $\mathrm{Q}_{\mathrm{p} 10 \mathrm{yr}}$ occurred with RTC of the largest facility (4860).

5. In general, algorithm RTC-2 lead to greater stability due to stabilizing aspects of the control logic. RTC-1 tended to lead to a greater number of valve movements (especially oscillations greater than $10 \%$ ).

6. There is evidence that facility performance under RTC could be linked to certain facility characteristics, such as $\mathrm{CV} / \mathrm{CDA}$ and $\mathrm{CD} / \mathrm{CDA}_{\mathrm{imp}}$, but variation is too high and sample size too low to make a confident assertion.

The results presented herein demonstrate that RTC retrofitting of existing structures has the potential to improve hydraulic conditions, both locally and downstream. However, without proper algorithm design and facility selection, results indicate that RTC retrofitting may lead to increased peak flows, duration of erosive discharges, duration of local 
flooding, and high instability. These findings underscore the importance of considering a wide range of precipitation conditions when testing new stormwater control measures.

Many negative outcomes observed in this research occurred when RTC did not maintain adequate capacity for the imminent storm. In actual implementation, a human operator would be present, and capable of suspending the RTC preceding a large forecasted rainfall event. Additionally, if rainfall forecasts had been incorporated into the control logic, then these problems can potentially be avoided. The findings presented here demonstrate the importance of the ongoing research regarding predictive RTC methods. Additionally, further research is needed to test the relationship between the physical characteristics of a detention basin and its potential for creating watershed-level benefits with a RTC retrofit, using a large sample size of candidate facilities. 


\section{Conclusions}

\section{a. Summary and Implications}

In this study, two reactive, rule-based RTC algorithms were tested at multiple stormwater facilities to assess the long-term hydraulic benefits of a RTC retrofit. Results showed that some hydrologic benefit is to be had from applying RTC to most of the facilities studied; however, there was also the potential for worsened conditions with this technological upgrade in the form of increased peak flow rates and increased duration of the largest flows and facility flooding. These findings show that not all facilities are appropriate for RTC retrofitting. In addition, some control strategies may be effective for small storm events, but ineffective, or even dangerous, when applied during large events. This work emphasizes the importance of testing new technologies, such as stormwater RTC, under adverse conditions which may cause failure. It is by pushing our innovations to their limits that improvements can be made to methods of stormwater management.

\section{b. Future Work}

The SWMM model and PySWMM scripts developed for this study were used to test a specific scenario of RTC for existing detention facilities. However, this research by no means exhausted the possibilities for RTC retrofitting within the test watershed. Future simulations of this test watershed may include different control algorithms (e.g. predictive control, optimization-based control) or future climate scenarios with variations in rainfall intensity. To facilitate any future research using the subject watershed in this study, the following items were included in Appendix A through C: detention facility storage and outlet geometries, model calibration and validation results, relevant SWMM input details, and sample PySWMM scripts used to create static, RTC-1, and RTC-2 scenarios. Complete datasets of this study's results are presented in Appendix D. Additionally, to assess how the 5-minute RTC sampling interval affected watershed modelling, the impact of temporal aliasing on different RTC time steps was investigated and the findings are presented in Appendix F. The impact of temporal aliasing on the measurement of peak flow rate - and 
therefore assessment of the effect of RTC - was found to vary significantly depending on the interval size (tested from 1-minute to 10-minute intervals). Future research in RTC applications should consider the significance of the sampling interval when designing control algorithms for the efficacy of the RTC strategy and the potential error in results.

Finally, this research represents only a part of a greater effort to integrate smart technology into urban stormwater management, specifically in the Town of Blacksburg (TOB). Current work is underway to create interactive hydrologic analysis tools for use by TOB stormwater managers, similar to those developed by Brendel et al. (2019). These real-time tools go hand in hand with RTC retrofitting to pave the way for the future of smart stormwater management. 


\section{References}

Balogun, O. S., Hubbard, M., and Devries, J. J. (1988). "Automatic control of canal flow using linear quadratic regulator theory." Journal of Hydraulic Engineering, 114(1), $75-102$.

Barreiro-Gomez, J., Obando, G., Riano-Briceno, G., Quijano, N., and Ocampo-Martinez, C. (2015). "Decentralized control for urban drainage systems via population dynamics: Bogotá case study." 2015 European Control Conference, ECC 2015, 2426-2431.

Barreto, W., Vojinovic, Z., Price, R., and Solomatine, D. (2010). "Multiobjective evolutionary approach to rehabilitation of urban drainage systems." Journal of Water Resources Planning and Management, 136(5), 547-554.

Bartos, M., Wong, B., and Kerkez, B. (2018). "Open storm: A complete framework for sensing and control of urban watersheds." Environmental Science: Water Research and Technology, Royal Society of Chemistry, 4(3), 346-358.

Bilodeau, K., Pelletier, G., and Duchesne, S. (2019). "Real-time control of stormwater detention basins as an adaptation measure in mid-size cities." Urban Water Journal, Taylor \& Francis, 15(9), 858-867.

Brendel, C. E., Dymond, R. L., and Aguilar, M. F. (2019). “An interactive web app for retrieval, visualization, and analysis of hydrologic and meteorological time series data." Environmental Modelling \& Software, Elsevier, 117(February), 14-28.

Carpenter, J. F., Vallet, B., Pelletier, G., Lessard, P., and Vanrolleghem, P. A. (2014). "Pollutant removal efficiency of a retrofitted stormwater detention pond." Water Quality Research Journal of Canada, 49(2), 124-134.

Cheung, P., Schultz, N., and Prince, B. (2005). "Case studies using RTC as a NMC and as a stormwater BMP." ASCE/EWRI Impacts of Global Climate Change.

Cho, J. H., Seok Sung, K., and Ryong Ha, S. (2004). "A river water quality management model for optimising regional wastewater treatment using a genetic algorithm." Journal of Environmental Management, 73(3), 229-242.

Degrave, R., Schoorens, J., and Litrico, X. (2013). "Real-time control of a small urban stormwater network." 2013 10th IEEE International Conference on Networking, Sensing and Control (ICNSC), 526-531.

Dietz, M. E., and Clausen, J. C. (2008). "Stormwater runoff and export changes with development in a traditional and low impact subdivision." Journal of Environmental Management, 87(4), 560-566. 
Dong, X., Huang, S., and Zeng, S. (2017). "Design and evaluation of control strategies in urban drainage systems in Kunming city." Frontiers of Environmental Science and Engineering, 11(4), 13.

Emerson, C. H., Welty, C., and Traver, R. G. (2005). "Watershed-scale evaluation of a system of storm water detention basins." Journal of Hydrologic Engineering, 10(3), 237-242.

Gaborit, E., Anctil, F., Pelletier, G., and Vanrolleghem, P. A. (2016). "Exploring forecastbased management strategies for stormwater detention ponds." Urban Water Journal, 13(8), 841-851.

Gaborit, E., Muschalla, D., Vallet, B., Vanrolleghem, P. A., and Anctil, F. (2013). "Improving the performance of stormwater detention basins by real-time control using rainfall forecasts." Urban Water Journal, 10(4), 230-246.

García, L., Barreiro-Gomez, J., Escobar, E., Téllez, D., Quijano, N., and OcampoMartinez, C. (2015). "Modeling and real-time control of urban drainage systems: A review." Advances in Water Resources, 85, 120-132.

Goff, K. M., and Gentry, R. W. (2006). "The influence of watershed and development characteristics on the cumulative impacts of stormwater detention ponds." Water Resources Management, 20(6), 829-860.

Goodman, J. A., and Quigley, M. (2015). "Active hydromodification control." ASCE International Low Impact Development Conference 2015, 1-10.

Heusch, S., and Ostrowski, M. (2011). "Model predictive control with SWMM." Journal of Water Management Modeling, 19, 237-247.

Hixon, L. F., and Dymond, R. L. (2014). "Comparison of stormwater management strategies with an urban watershed model." Journal of Hydrologic Engineering, 20(9), 04014091 1-11.

Jackson, C. R., and Booth, D. B. (1997). "Urbanization of aquatic systems: degradation thresholds, stormwater detection, and the limits of mitigation." Journal of the American Water Resources Association, 33(5), 1077-1090.

Jacopin, C., Lucas, E., Desbordes, M., and Bourgogne, P. (2001). "Optimisation of operational management practices for the detention basins." Water Science and Technology, 44(2-3), 277-285.

Joksimovic, D., and Sander, M. (2016). "Performance modelling of actively controlled green infrastructure options in a mixed use neighborhood retrofit." World Environmental and Water Resources Congress, 96-105. 
Kerkez, B., Gruden, C., Lewis, M., Montestruque, L., Quigley, M., Wong, B., Bedig, A., Kertesz, R., Braun, T., Cadwalader, O., Poresky, A., and Pak, C. (2016). "Smarter stormwater systems." Environmental Science and Technology, 50(14), 7267-7273.

De Korte, K., Van Beest, D., Van Der Plaat, M., De Graaf, E., and Schaart, N. (2009). "RTC simulations on large branched sewer systems with SmaRTControl." Water Science and Technology, 60(2), 475-482.

Lefkowitz, J. R., Sarmanian, A. K., and Quigley, M. (2016). "Continuous monitoring and adaptive control - the internet of things transforms stormwater management." Journal of the New England Water Environment Association, 50(1), 44-51.

Lemos, J. M., and Pinto, L. F. (2012). "Distributed linear-quadratic control of serially chained systems: Application to a water delivery canal." IEEE Control Systems, 32(6), 26-38.

Lund, N. S. V., Falk, A. K. V., Borup, M., Madsen, H., and Steen Mikkelsen, P. (2018). "Model predictive control of urban drainage systems: A review and perspective towards smart real-time water management." Critical Reviews in Environmental Science and Technology, Taylor \& Francis, 48(3), 279-339.

Marchese, D., Johnson, J., Akers, N., Huffman, M., and Hlas, V. (2018). "Quantitative comparison of active and passive stormwater infrastructure: Case study in Beckley, West Virginia." Proceedings of the Water Environment Federation, 4298-4311.

Marinaki, M., and Papageorgiou, M. (2003). "Linear-quadratic regulators applied to sewer network flow Control.” European Control Conference (ECC), 2407-2412.

McCarthy. (1994). “Stormwater control system.” US Patent 5342144.

McCuen, R. H. (1979). "Downstream effects of stormwater management basins.” Journal of Hydraulics Division, 105(11), 1343-1356.

McDonnell, B. E., Westover, J., Peña-Castellanos, G., Roberts, S., Mullapudi, A., Ratliff, K., and Kertesz, R. (2016). "PySWMM: Python wrapper for Stormwater Management Model (SWMM5)."

McGrane, S. J. (2016). "Impacts of urbanisation on hydrological and water quality dynamics, and urban water management: a review." Hydrological Sciences Journal, Taylor \& Francis, 61(13), 2295-2311.

Middleton, J. R., and Barrett, M. E. (2008). "Water quality performance of a batch-type stormwater detention basin." Water Environment Research, 80(2), 172-178.

Montestruque, L., and Lemmon, M. D. (2015). "Globally coordinated distributed storm water management system." Proceedings of the 1st ACM International Workshop on 


\section{Cyber-Physical Systems for Smart Water Networks.}

Muleta, M. K., and Boulos, P. F. (2007). "Multiobjective optimization for optimal design of urban drainage systems." World Environmental and Water Resources Congress, 110.

Mullapudi, A., Bartos, M., Wong, B., and Kerkez, B. (2018). "Shaping streamflow using a real-time stormwater control network." Sensors, 18(7), 2259.

Mullapudi, A., Wong, B. P., and Kerkez, B. (2017). "Emerging investigators series: building a theory for smart stormwater systems." Environmental Science: Water Research \& Technology, Royal Society of Chemistry, 3(1), 66-77.

Muschalla, D. (2008). “Optimization of integrated urban wastewater systems using multiobjective evolution strategies.” Urban Water Journal, 5(1), 59-67.

Muschalla, D., Vallet, B., Anctil, F., Lessard, P., Pelletier, G., and Vanrolleghem, P. A. (2014). "Ecohydraulic-driven real-time control of stormwater basins." Journal of Hydrology, Elsevier B.V., 511, 82-91.

Nashville and Davidson County. (2009). "Stormwater wet ponds." Nashville Stormwater Management Manual, PTP-01 1-25.

Nehrke, S. M., and Roesner, L. A. (2004). "Effects of design practice for flood control and best management practices on the flow-frequency curve." Journal of Water Resources Planning and Management, 130(2), 131-139.

Nielsen, N. H., Ravn, C., and Mølbye, N. (2010). "Implementation and design of a RTC strategy in the sewage system in Kolding, Denmark." NOVATECH, 1-10.

NRCS. (1986). "Urban hydrology for small watersheds: TR-55." US Department of Agriculture.

Ocampo-Martinez, C., Puig, V., Cembrano, G., and Quevedo, J. (2013). “Application of predictive control strategies to the management of complex networks in the urban water cycle.” IEEE Control Systems, 33(1), 15-41.

Opti RTC, and Geosyntec Consultants Inc. (2017). Water Quality Summary Report.

Oregon Department of Transportation. (2014). "Chapter 14 Appendix E: Stormwater Treatment Facility Components.” Hydraulics Design Manual, 4-8.

Palhegyi, G. E. (2010). "Designing storm-water controls to promote sustainable ecosystems: Science and application.” Journal of Hydrologic Engineering, 15(6), 504-511. 
Parolari, A. J., Pelrine, S., and Bartlett, M. S. (2018). "Stochastic water balance dynamics of passive and controlled stormwater basins." Advances in Water Resources, Elsevier Ltd, 122(October), 328-339.

Pitt, R., and Clarke, S. E. (2008). "Integrated storm-water management for watershed sustainability." Journal of Irrigation and Drainage Engineering, 134(5), 548-555.

Prince George's County. (1999). Low-Impact Development Design Strategies - An Integrated Design Approach. Prince George's County, MD Department of Environmental Resources.

Rohrer, A. R., and Armitage, N. P. (2017). "Improving the viability of stormwater harvesting through rudimentary real time control." Water, 9(6).

Roman, D., Braga, A., Shetty, N., and Culligan, P. (2017). "Design and modeling of an adaptively controlled rainwater harvesting system." Water, 9(12), 974.

Rossman, L. A. (2015). "Storm Water Management Model user's manual version 5.1." US EPA Office of Research and Development, 353.

Schütze, M., Campisano, A., Colas, H., Schilling, W., and Vanrolleghem, P. A. (2004). "Real time control of urban wastewater systems - Where do we stand today?" Journal of Hydrology, 299(3-4), 335-348.

Seggelke, K., Löwe, R., Beeneken, T., and Fuchs, L. (2013). "Implementation of an integrated real-time control system of sewer system and waste water treatment plant in the city of Wilhelmshaven." Urban Water Journal, 10(5), 330-341.

Shishegar, S., Duchesne, S., and Pelletier, G. (2018). "Optimization methods applied to stormwater management problems: a review." Urban Water Journal, 15(3), 276-286.

Soil Survey Staff, Natural Resources Conservation Service, and United States Department of Agriculture. (2018). "Web Soil Survey." < https://websoilsurvey.nrcs.usda.gov/> (Jan. 8, 2019).

Stinson, M. K., Field, R., Jacquet, G., and Villeneuve, E. (2000). "Optimized real-time control of combined sewerage systems: Two case studies." Joint Conference on Water Resource Engineering and Water Resources Planning and Management, 1-10.

Sundmaeker, H., Guillemin, P., Friess, P., and Woelfflé, S. (2010). Vision and Challenges for Realising the Internet of Things. Cluster of European Research Projects on Internet of Things, European Union.

Tillinghast, E. D., Hunt, W. F., and Jennings, G. D. (2011). "Stormwater control measure (SCM) design standards to limit stream erosion for Piedmont North Carolina." Journal of Hydrology, Elsevier B.V., 411(3-4), 185-196. 
USEPA. (2009). "Stormwater wet pond and wetland management guidebook." Center For Watershed Protection.

USEPA. (2016). "Summary of state stormwater standards." US Environmental Protection Agency Office of Water, 148.

VADCR. (1999). Virginia Stormwater Management Handbook, First Edition. Richmond, VA.

Vezzaro, L., and Grum, M. (2014). "A generalised Dynamic Overflow Risk Assessment (DORA) for Real Time Control of urban drainage systems." Journal of Hydrology, $515,292-303$.

Vietz, G. J., Walsh, C. J., and Fletcher, T. D. (2015). "Urban hydrogeomorphology and the urban stream syndrome: Treating the symptoms and causes of geomorphic change." Progress in Physical Geography, 40(3), 480-492.

Vitasovic, Z. C. (2006). "Real time control of urban drainage networks." US Environmental Protection Agency Office of Research and Development, 96.

Wasimi, S. A., and Kitanidis, P. K. (1983). "Real- time forecasting and daily operation of a multireservoir system during floods by linear quadratic Gaussian control." Water Resources Research, 19(6), 1511-1522.

Wong, B. P. (2017). "Real-time measurement and control of urban stormwater systems." $\mathrm{PhD}$ diss., University of Michigan.

Wong, B. P., and Kerkez, B. (2018). "Real-time control of urban headwater catchments through linear feedback: Performance, analysis, and site selection." Water Resources Research, 54(10), 7309-7330.

Wright, J., and Marchese, D. (2018). "Briefing: Continuous monitoring and adaptive control: the "smart' storm water management solution." Proceedings of the Institution of Civil Engineers - Smart Infrastructure and Construction, 170(4), 8689. 


\section{Appendix}

\section{Appendix A: Detention Facility Details}

- Detention Basin Stage-Area Curves

- Detention Basin Outlet Structures 
Table A1. Detention Basin Stage-Area Curves

\begin{tabular}{|c|c|c|c|c|c|c|c|}
\hline \multicolumn{2}{|c|}{ Facility 4860} & \multicolumn{2}{|c|}{ Facility 2309} & \multicolumn{2}{|c|}{ Facility 2044} & \multicolumn{2}{|c|}{ Facility 0274} \\
\hline Stage (ft) & Area $\left(\mathrm{ft}^{2}\right)$ & Stage (ft) & Area $\left(\mathbf{f t}^{2}\right)$ & Stage (ft) & Area $\left(\mathbf{f t}^{2}\right)$ & Stage (ft) & $\operatorname{Area}\left(\mathrm{ft}^{2}\right)$ \\
\hline 0.454 & 23 & 0.578 & 664 & 0.658 & 79 & 0.887 & 6 \\
\hline 1.454 & 863 & 1.578 & 11,308 & 1.658 & 7,976 & 1.887 & 683 \\
\hline 2.454 & 12,659 & 2.578 & 17,350 & 2.658 & 14,342 & 2.887 & 1,484 \\
\hline 3.454 & 31,686 & 3.578 & 18,620 & 3.658 & 17,692 & 3.887 & 2,139 \\
\hline 4.454 & 43,872 & 4.578 & 21,056 & 4.658 & 20,510 & 4.887 & 2,879 \\
\hline 5.454 & 51,466 & 5.578 & 25,386 & 5.658 & 23,265 & 5.887 & 3,995 \\
\hline 6.454 & 56,770 & & & & & & \\
\hline
\end{tabular}

\begin{tabular}{|c|c|c|c|c|c|}
\hline \multicolumn{2}{|c|}{ Facility 0388} & \multicolumn{2}{|c|}{ Facility 0262} & \multicolumn{2}{|c|}{ Facility 0178} \\
\hline Stage (ft) & Area $\left(\mathrm{ft}^{2}\right)$ & Stage (ft) & Area $\left(\mathbf{f t}^{2}\right)$ & Stage (ft) & Area $\left(\mathrm{ft}^{2}\right)$ \\
\hline 0.945 & 482 & 0.000 & 108 & 0.710 & 431 \\
\hline 1.945 & 2,190 & 1.000 & 790 & 1.710 & 1,478 \\
\hline 2.945 & 3,354 & 2.000 & 1,246 & 2.710 & 2,522 \\
\hline 3.945 & 4,635 & 3.000 & 1,751 & 3.710 & 3,879 \\
\hline 4.945 & 6,165 & 4.000 & 1,977 & & \\
\hline & & 5.000 & 2,222 & & \\
\hline & & 6.000 & 2,450 & & \\
\hline
\end{tabular}

\begin{tabular}{|c|c|c|c|c|c|}
\hline Property & Value & Property & Value & Property & Value \\
\hline Name & Or12 & Name & Or08 & Name & Or07 \\
\hline Inlet Node & Owens_Street & Inlet Node & Owens_Street & Inlet Node & Owens_Street \\
\hline Outlet Node & 1363_ControlJunction & Outlet Node & 1363_ControlJunction & Outlet Node & 1130_ControlJunction \\
\hline Description & & Description & & Description & \\
\hline Tag & & Tag & & $\mid$ Tag & \\
\hline Type & SIDE & Type & ВотTOM & ||Type & BOTTOM \\
\hline Shape & CIRCULAR & Shape & CIRCULAR & Shape & CIRCULAR \\
\hline Height & 1.25 & Height & 4 & Height & 4 \\
\hline Width & 0 & Width & 0 & Width & 0 \\
\hline Inlet Offset & 0 & Inlet Offset & 5.583 & Inlet Offset & 5.479 \\
\hline Discharge Coeff. & 0.6 & Discharge Coeff. & 0.6 & || Discharge Coeff. & 0.6 \\
\hline Flap Gate & NO & Flap Gate & NO & Flap Gate & NO \\
\hline Time to Open/Close & 0 & Time to Open/Close & 0 & Time to Open/Close & 0 \\
\hline
\end{tabular}

Figure A1. Detention Basin 4860 Outlet Structures (unit = feet) 


\begin{tabular}{|c|c|c|c|}
\hline Property & Value & Property & Value \\
\hline Name & Or09 & Name & Or10 \\
\hline Inlet Node & Wong_Park_1 & Inlet Node & Wong_Park_1 \\
\hline Outlet Node & 1063_ControlJunction & Outlet Node & 1064_ControlJunction \\
\hline Description & & Description & \\
\hline Tag & & $\mid \operatorname{Tag}$ & \\
\hline Type & SIDE & Type & BOTTOM \\
\hline Shape & CIRCULAR & Shape & CIRCULAR \\
\hline Height & 1 & Height & 2.25 \\
\hline Width & 0 & Width & 0 \\
\hline Inlet Offset & 0 & Inlet Offset & 4.25 \\
\hline Discharge Coeff. & 0.6 & Discharge Coeff. & 0.6 \\
\hline Flap Gate & NO & Flap Gate & NO \\
\hline Time to Open/Close & 0 & Time to Open/Close & 0 \\
\hline
\end{tabular}

Figure A2. Detention Basin 2309 Outlet Structures (unit = feet)

\begin{tabular}{|l|l|}
\hline Property & Value \\
\hline Name & Or11 \\
\hline Inlet Node & Wong_Park_2 \\
\hline Outlet Node & 1076 ControlJunction \\
\hline Description & \\
\hline Tag & \\
\hline Type & SIDE \\
\hline Shape & CIRCULAR \\
\hline Height & 1.25 \\
\hline Width & 0 \\
\hline Inlet Offset & 0 \\
\hline Discharge Coeff. & 0.6 \\
\hline Flap Gate & NO \\
\hline Time to Open/Close & 0 \\
\hline
\end{tabular}

Figure A3. Detention Basin 2044 Outlet Structure (unit = feet)

\begin{tabular}{|l|l|}
\hline Property & Value \\
\hline Name & OrO2 \\
\hline Inlet Node & The_Vistas \\
\hline Outlet Node & 1179 ControlJunction \\
\hline Description & \\
\hline Tag & \\
\hline Type & SIDE \\
\hline Shape & CIRCULAR \\
\hline Height & 1 \\
\hline Width & 0 \\
\hline Inlet Offset & 0 \\
\hline Discharge Coeff. & 0.6 \\
\hline Flap Gate & NO \\
\hline Time to Open/Close & 0 \\
\hline
\end{tabular}

Figure A4. Detention Basin 0388 Outlet Structure (unit = feet) 


\begin{tabular}{|c|c|c|c|}
\hline Property & Value & Property & Value \\
\hline Name & Or03 & Name & Or16 \\
\hline Inlet Node & Silverleaf_2 & Inlet Node & Silverleaf_2 \\
\hline Outlet Node & 1360 & Outlet Node & 1360 \\
\hline Description & & Description & \\
\hline Tag & & Tag & \\
\hline Type & SIDE & Type & BOTTOM \\
\hline Shape & CIRCULAR & Shape & RECT_CLOSED \\
\hline Height & 1.6667 & Height & 1.5 \\
\hline Width & 0 & Width & 3 \\
\hline Inlet Offset & 0 & Inlet Offset & 5.729 \\
\hline Discharge Coeff. & 0.6 & Discharge Coeff. & 0.65 \\
\hline Flap Gate & NO & Flap Gate & NO \\
\hline Time to Open/Close & 0 & Time to Open/Close & 0 \\
\hline
\end{tabular}

Figure A5. Detention Basin 0274 Outlet Structures (unit = feet)

\begin{tabular}{|l|l|}
\hline Property & Value \\
\hline Name & Or06 \\
\hline Inlet Node & The_Chase \\
\hline Outlet Node & 1017 ControlJunction \\
\hline Description & \\
\hline Tag & \\
\hline Type & SIDE \\
\hline Shape & CIRCULAR \\
\hline Height & 1 \\
\hline Width & 0 \\
\hline Inlet Offset & 0 \\
\hline Discharge Coeff. & 0.6 \\
\hline Flap Gate & NO \\
\hline Time to Open/Close & 0 \\
\hline
\end{tabular}

Figure A6. Detention Basin 0262 Outlet Structure (unit = feet)

\begin{tabular}{|l|l|}
\hline Property & Value \\
\hline Name & Or01 \\
\hline Inlet Node & Vista_Pointe \\
\hline Outlet Node & 1303 ControlJunction \\
\hline Description & \\
\hline Tag & \\
\hline Type & SIDE \\
\hline Shape & CIRCULAR \\
\hline Height & 1.25 \\
\hline Width & 0 \\
\hline Inlet Offset & 0 \\
\hline Discharge Coeff. & 0.6 \\
\hline Flap Gate & NO \\
\hline Time to Open/Close & 0 \\
\hline
\end{tabular}

Figure A7. Detention Basin 0178 Outlet Structure (unit = feet) 


\section{Appendix B: SWMM Model Details}

- Calibration and Validation Summary of Events

- Calibration Events 1, 2, and 3

- Validation Events 1, 2, 3, 4, and 5

- SWMM Simulation Options and Map

- SWMM Subcatchment Parameters I

- SWMM Subcatchment Parameters II 
Table B1. Calibration and Validation Summary of Events

\begin{tabular}{|c|c|c|c|c|c|c|c|c|}
\hline & Storm & $\begin{array}{l}\text { Precip. } \\
\quad \text { (in) }\end{array}$ & $\begin{array}{c}\text { Storm } \\
\text { Duration } \\
\text { (hours) }\end{array}$ & $\begin{array}{l}\text { Peak } \\
\text { Flow } \\
\text { (CFS) } \\
\end{array}$ & $\begin{array}{c}\text { Volume } \\
\text { (ft3) }\end{array}$ & NSEC & $\begin{array}{l}\text { Error } \\
\text { Peak } \\
\text { Flow } \\
\end{array}$ & $\begin{array}{c}\text { Error } \\
\text { Volume }\end{array}$ \\
\hline \multirow{3}{*}{ } & $5 / 26 / 2009$ & 2.38 & 60 & 29.3 & 573,000 & 0.66 & $-17 \%$ & $24 \%$ \\
\hline & $1 / 17 / 2010$ & 0.7 & 8 & 11.8 & 137,000 & 0.91 & $-15 \%$ & $-14 \%$ \\
\hline & $3 / 13 / 2010$ & 1.08 & 17 & 20.3 & 222,000 & 0.76 & $41 \%$ & $16 \%$ \\
\hline \multirow{5}{*}{ } & $5 / 15 / 2009$ & 0.91 & 4 & 38.0 & 157,000 & 0.75 & 11.49 & 23.04 \\
\hline & $12 / 8 / 2009$ & 1.77 & 16 & 27.0 & 527,000 & 0.89 & -22.33 & -28.37 \\
\hline & $1 / 24 / 2010$ & 1.11 & 22 & 18.2 & 264,000 & 0.89 & 5.00 & -13.59 \\
\hline & $3 / 22 / 2010$ & 0.71 & 7 & 19.4 & 118,700 & 0.67 & 39.87 & 17.72 \\
\hline & $3 / 28 / 2010$ & 0.66 & 7 & 19.5 & 119,200 & 0.91 & 19.18 & 4.51 \\
\hline
\end{tabular}

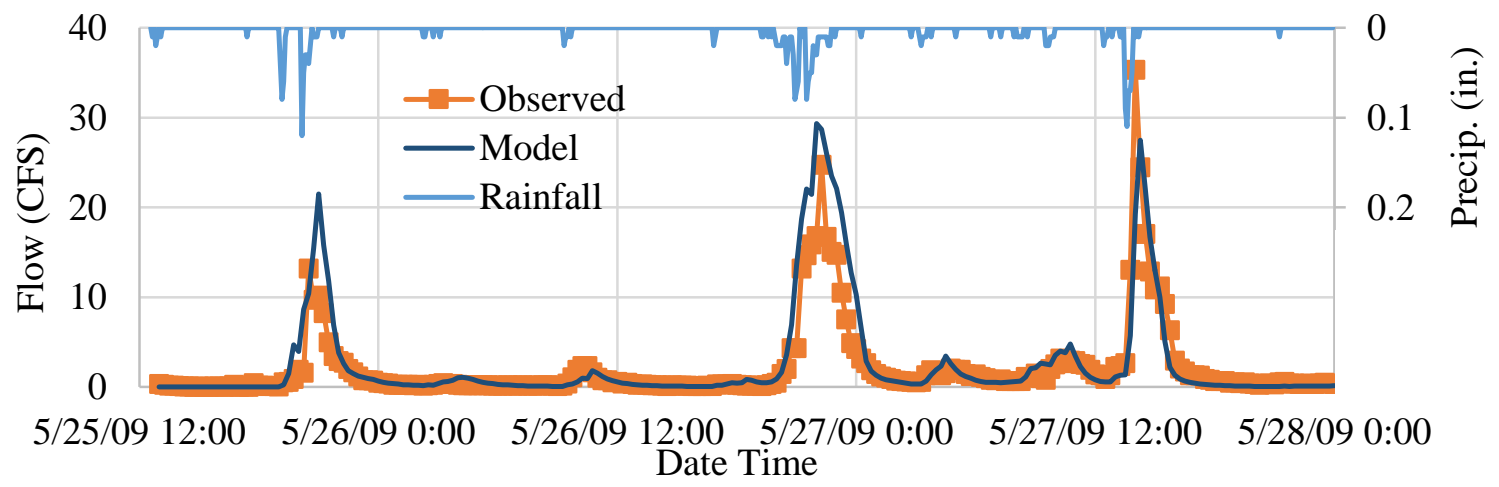

Figure B1. Calibration Event 1 - 5/26/2009

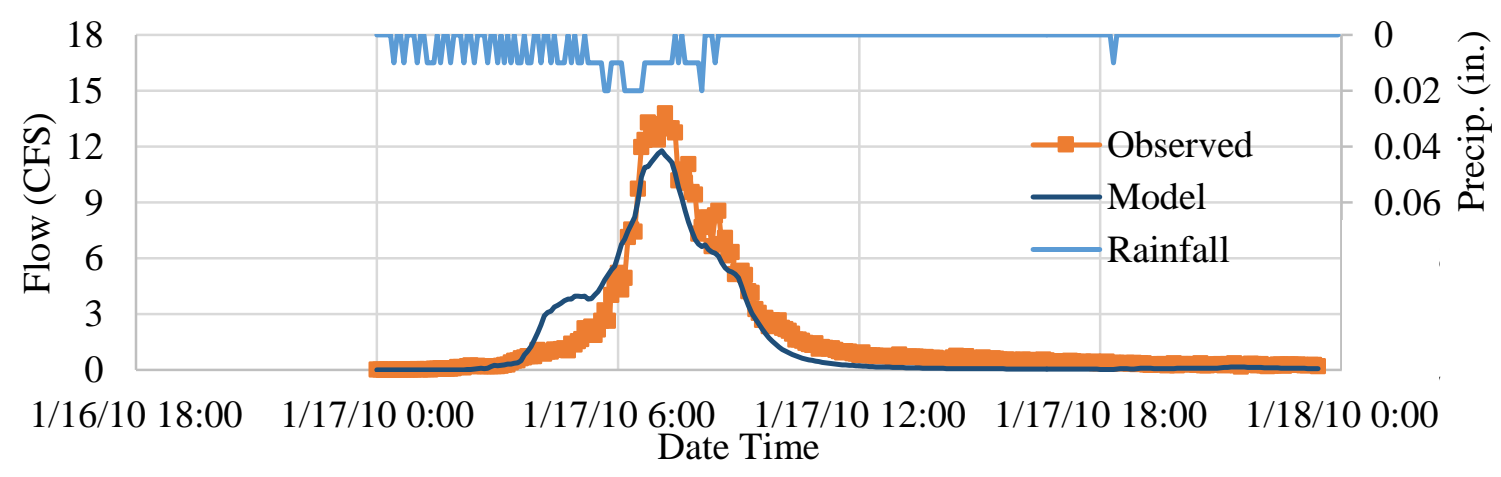

Figure B2. Calibration Event 2 - 1/17/2010 


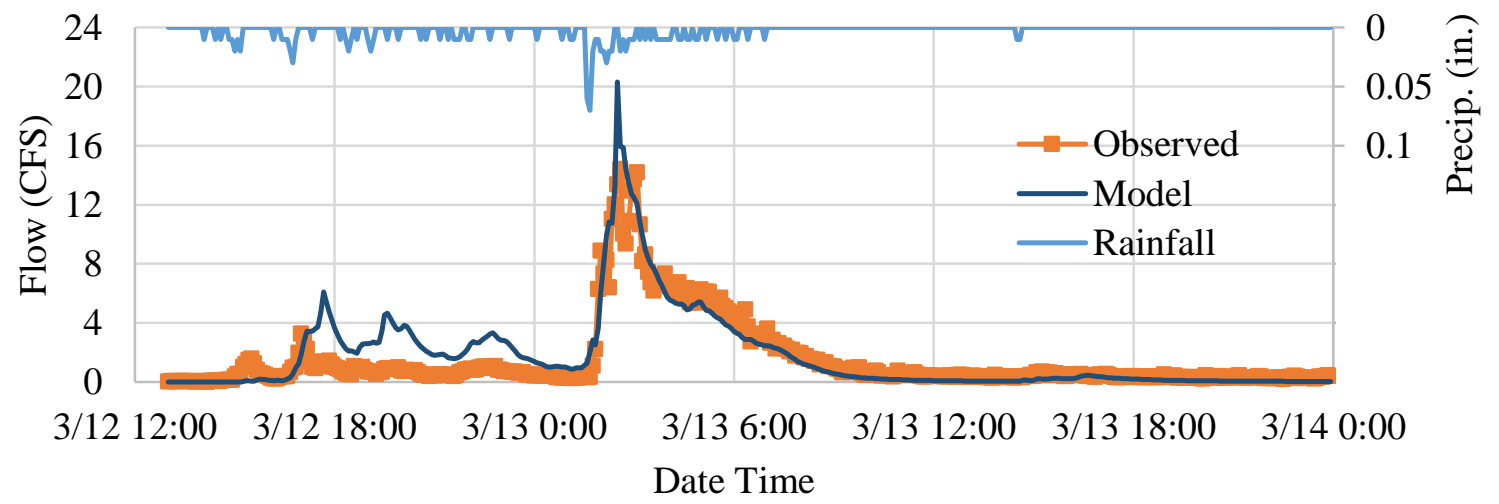

Figure B3. Calibration Event 3-3/13/2010

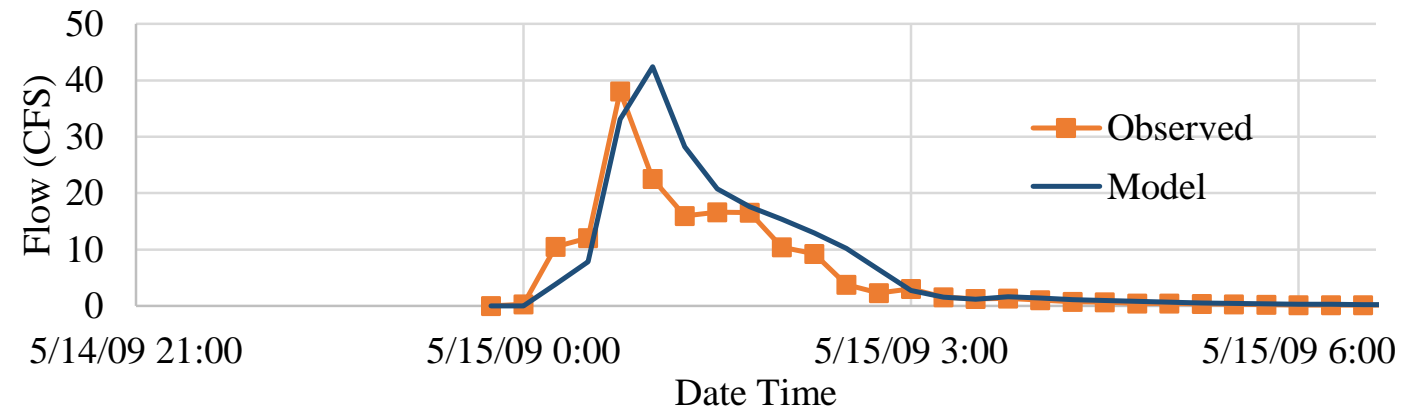

Figure B4. Validation Event 1 - 5/15/2009

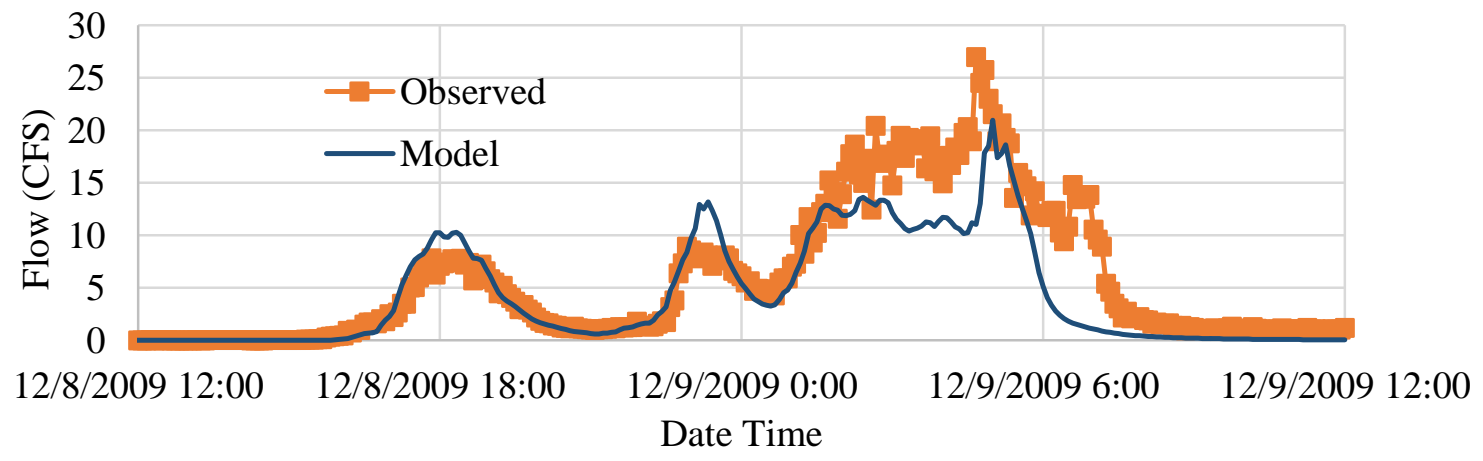

Figure B5. Validation Event 2 - 12/08/2009 


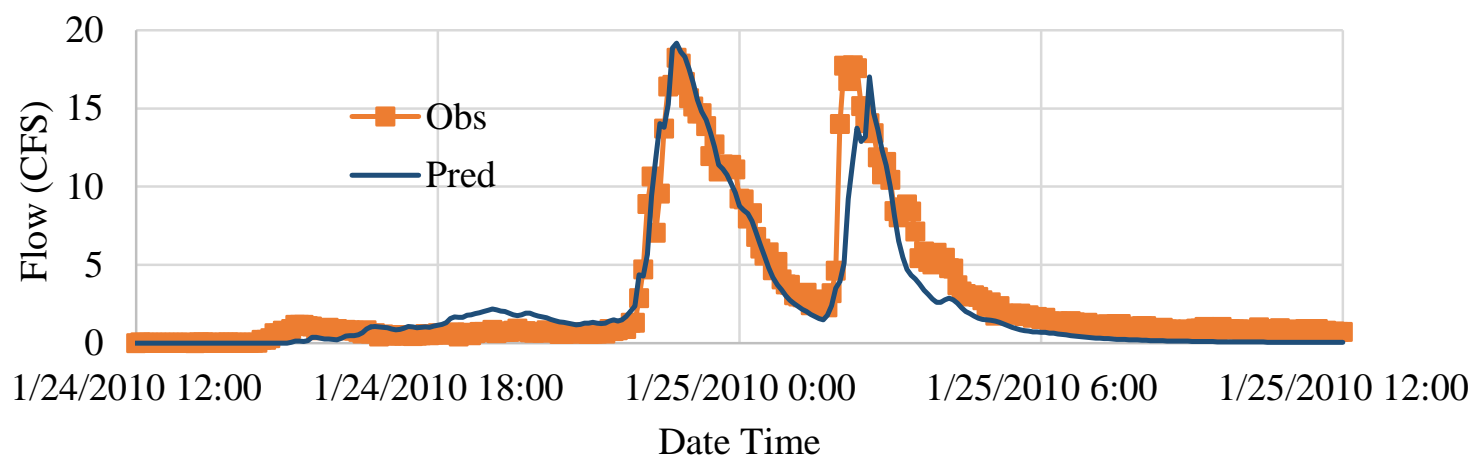

Figure B6. Validation Event 3 - 1/24/2010

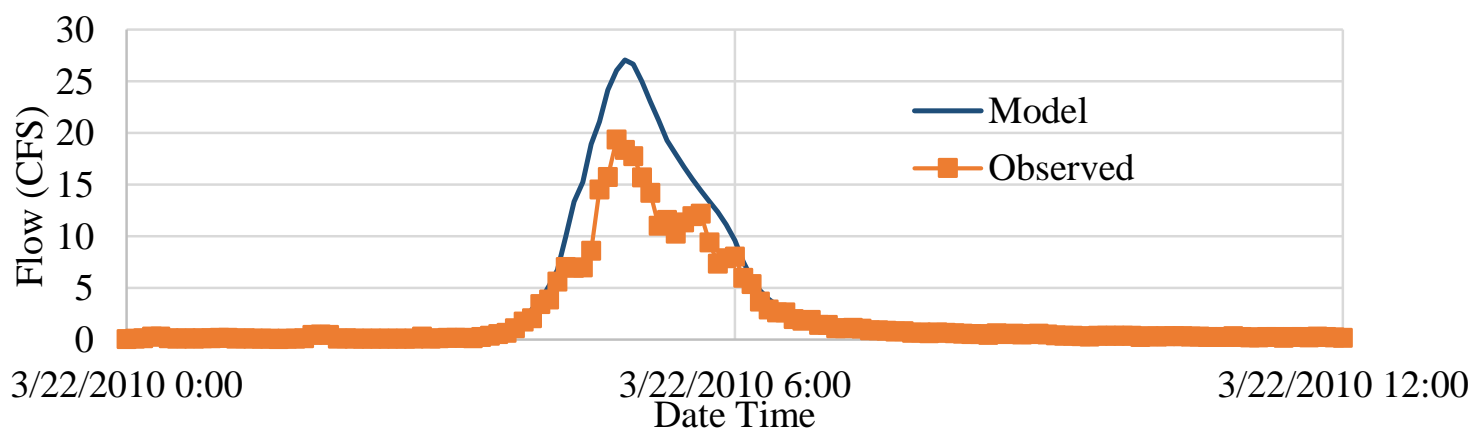

Figure B7. Validation Event 4-3/22/2010

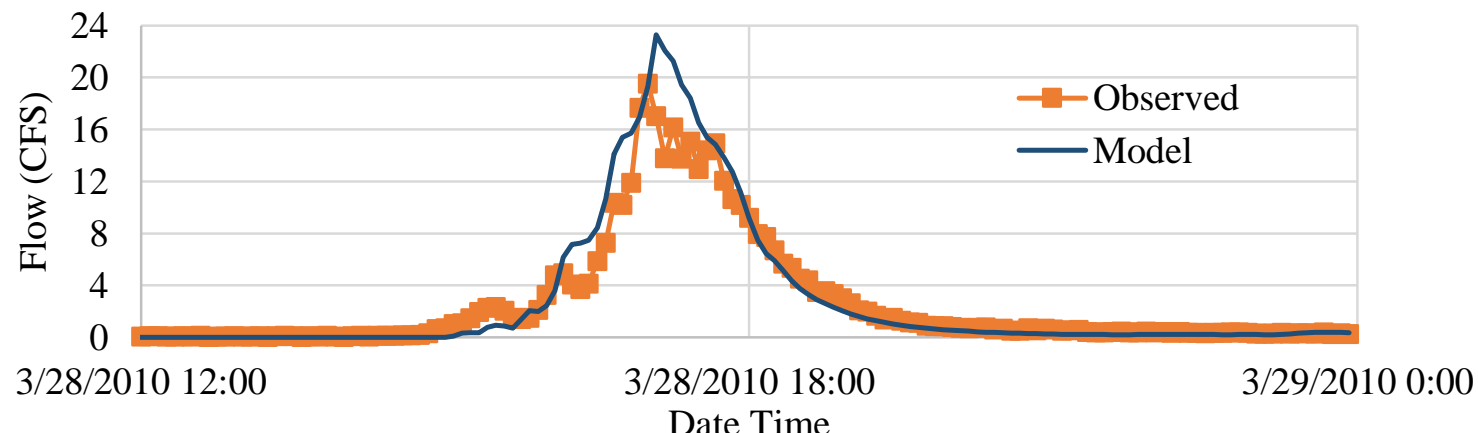

Figure B7. Validation Event 5-3/28/2010 


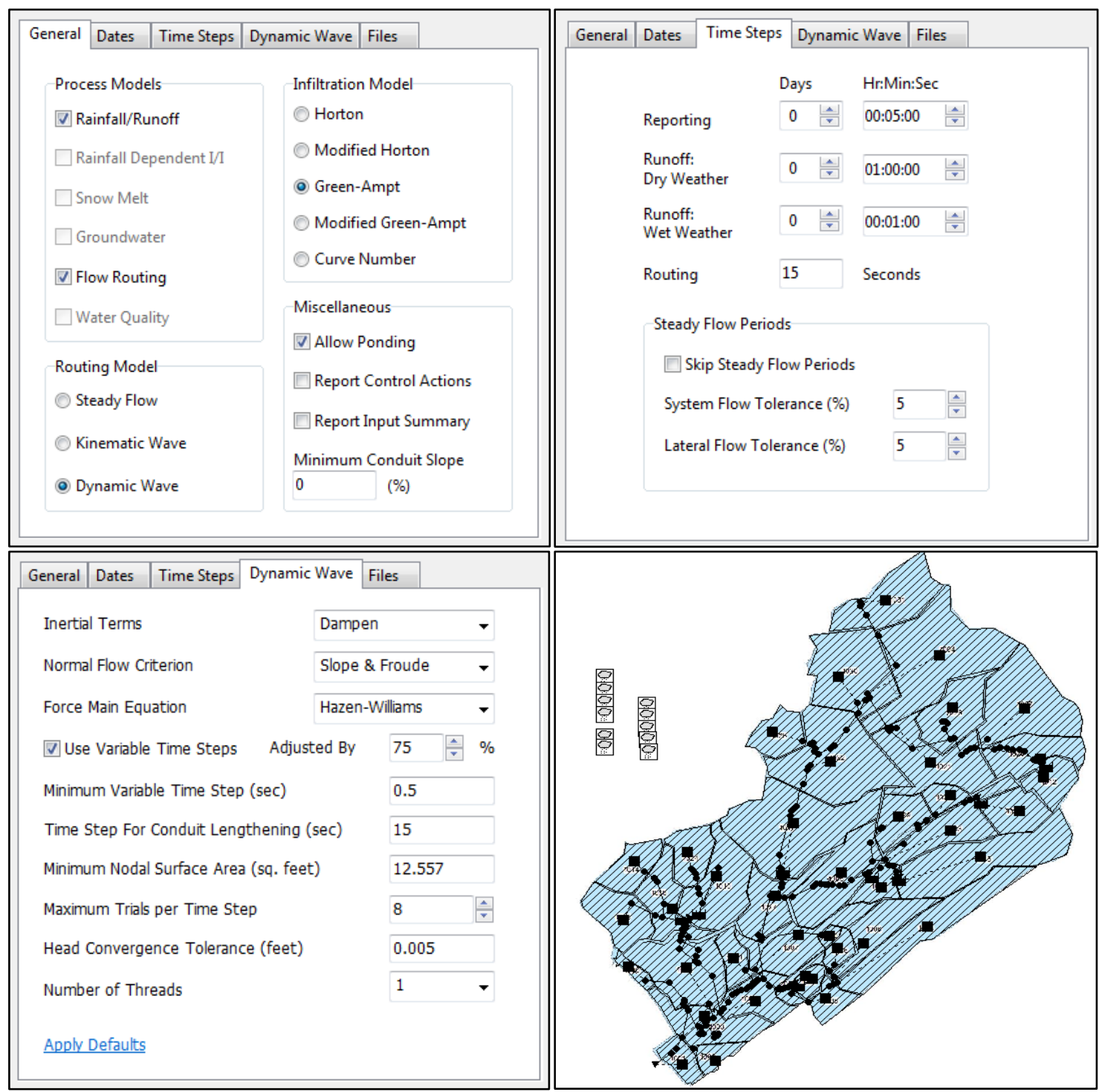

Figure B8. SWMM Simulation Options and Map 
Table B2. SWMM Subcatchment Parameters I

\begin{tabular}{|c|c|c|c|c|c|c|c|}
\hline Subcatch. & Area (ac) & \% Imperv & Width (ft) & \%Slope & Suction & Ksat & IMD \\
\hline SB1000 & 1.60 & 67.7 & 140 & 1.8 & 3.50 & 0.130 & 0.232 \\
\hline SB1001 & 3.74 & 81.5 & 352 & 2.2 & 3.50 & 0.130 & 0.232 \\
\hline SB1002 & 2.79 & 68.8 & 233 & 2.6 & 3.50 & 0.130 & 0.232 \\
\hline SB1003 & 10.25 & 63.5 & 398 & 3.0 & 3.50 & 0.130 & 0.232 \\
\hline SB1004 & 30.27 & 29.8 & 817 & 7.0 & 3.74 & 0.140 & 0.236 \\
\hline SB1005 & 15.27 & 36.0 & 402 & 4.5 & 3.50 & 0.130 & 0.232 \\
\hline SB1006 & 8.94 & 14.0 & 257 & 4.2 & 3.50 & 0.130 & 0.232 \\
\hline SB1007 & 11.31 & 34.4 & 315 & 4.2 & 3.50 & 0.130 & 0.232 \\
\hline SB1008 & 7.74 & 28.6 & 372 & 4.0 & 3.50 & 0.130 & 0.232 \\
\hline SB1009 & 4.20 & 36.5 & 244 & 4.9 & 3.50 & 0.130 & 0.232 \\
\hline SB1010 & 14.48 & 21.4 & 456 & 5.3 & 3.50 & 0.130 & 0.232 \\
\hline SB1011 & 27.43 & 16.9 & 601 & 5.7 & 3.50 & 0.130 & 0.232 \\
\hline SB1012 & 5.97 & 33.9 & 355 & 5.9 & 4.03 & 0.151 & 0.241 \\
\hline SB1013 & 7.56 & 39.2 & 314 & 6.5 & 3.50 & 0.130 & 0.232 \\
\hline SB1014 & 6.37 & 27.0 & 366 & 5.2 & 3.50 & 0.130 & 0.232 \\
\hline SB1015 & 21.53 & 15.4 & 539 & 6.2 & 3.50 & 0.130 & 0.232 \\
\hline SB1016 & 3.98 & 26.6 & 320 & 6.3 & 3.50 & 0.130 & 0.232 \\
\hline SB1017 & 9.13 & 25.3 & 379 & 5.6 & 3.50 & 0.130 & 0.232 \\
\hline SB1018 & 2.07 & 62.5 & 165 & 4.0 & 3.50 & 0.130 & 0.232 \\
\hline SB1019 & 15.94 & 41.5 & 519 & 4.1 & 3.50 & 0.130 & 0.232 \\
\hline SB1020 & 1.07 & 55.6 & 161 & 4.0 & 3.50 & 0.130 & 0.232 \\
\hline SB1021 & 16.47 & 20.8 & 445 & 4.9 & 4.42 & 0.167 & 0.247 \\
\hline SB1022 & 24.89 & 18.7 & 780 & 6.0 & 4.41 & 0.167 & 0.247 \\
\hline SB1023 & 8.78 & 33.9 & 382 & 3.6 & 3.50 & 0.130 & 0.232 \\
\hline SB1024 & 6.59 & 25.1 & 398 & 5.1 & 3.50 & 0.130 & 0.232 \\
\hline SB1025 & 6.05 & 18.8 & 447 & 5.1 & 3.50 & 0.130 & 0.232 \\
\hline SB1026 & 9.20 & 28.3 & 307 & 5.4 & 4.71 & 0.179 & 0.252 \\
\hline SB1027 & 19.38 & 20.7 & 567 & 5.3 & 4.07 & 0.153 & 0.241 \\
\hline SB1028 & 10.84 & 20.6 & 430 & 6.2 & 3.50 & 0.130 & 0.232 \\
\hline SB1029 & 6.21 & 10.0 & 323 & 5.7 & 3.50 & 0.130 & 0.232 \\
\hline SB1030 & 18.03 & 13.2 & 476 & 3.9 & 4.08 & 0.154 & 0.242 \\
\hline SB1031 & 13.35 & 16.7 & 448 & 6.0 & 3.93 & 0.147 & 0.239 \\
\hline SB1032 & 3.44 & 27.5 & 259 & 4.3 & 3.50 & 0.130 & 0.232 \\
\hline SB1033 & 11.43 & 21.3 & 259 & 6.0 & 3.50 & 0.130 & 0.232 \\
\hline SB1034 & 16.27 & 24.0 & 289 & 6.3 & 3.50 & 0.130 & 0.232 \\
\hline SB1035 & 3.87 & 36.8 & 226 & 4.2 & 3.50 & 0.130 & 0.232 \\
\hline SB1036 & 2.35 & 49.9 & 298 & 3.5 & 3.50 & 0.130 & 0.232 \\
\hline SB1037 & 2.41 & 10.8 & 167 & 5.7 & 3.50 & 0.130 & 0.232 \\
\hline SB1038 & 8.83 & 19.7 & 284 & 4.7 & 3.51 & 0.130 & 0.232 \\
\hline
\end{tabular}


Table B3. SWMM Subcatchment Parameters II

\begin{tabular}{|c|c|c|c|c|c|c|c|}
\hline Subcatch. & N-Imperv & $N$-Perv & S-Imperv (in) & S-Perv (in) & PctZero & RouteTo & \%Routed \\
\hline SB1000 & 0.012 & 0.295 & 0.08 & 0.240 & 0.25 & OUTLET & \\
\hline SB1001 & 0.012 & 0.093 & 0.08 & 0.128 & 0.25 & OUTLET & \\
\hline SB1002 & 0.012 & 0.157 & 0.08 & 0.183 & 0.25 & OUTLET & \\
\hline SB1003 & 0.012 & 0.329 & 0.08 & 0.263 & 0.25 & OUTLET & \\
\hline SB1004 & 0.012 & 0.403 & 0.08 & 0.270 & 0.25 & OUTLET & \\
\hline SB1005 & 0.012 & 0.262 & 0.08 & 0.229 & 0.25 & OUTLET & \\
\hline SB1006 & 0.012 & 0.287 & 0.08 & 0.243 & 0.25 & PERVIOUS & 80 \\
\hline SB1007 & 0.012 & 0.245 & 0.08 & 0.222 & 0.25 & OUTLET & \\
\hline SB1008 & 0.012 & 0.285 & 0.08 & 0.236 & 0.25 & OUTLET & \\
\hline SB1009 & 0.012 & 0.313 & 0.08 & 0.248 & 0.25 & OUTLET & \\
\hline SB1010 & 0.012 & 0.237 & 0.08 & 0.205 & 0.25 & PERVIOUS & 80 \\
\hline SB1011 & 0.012 & 0.361 & 0.08 & 0.259 & 0.25 & PERVIOUS & 80 \\
\hline SB1012 & 0.012 & 0.231 & 0.08 & 0.210 & 0.25 & OUTLET & \\
\hline SB1013 & 0.012 & 0.291 & 0.08 & 0.243 & 0.25 & OUTLET & \\
\hline SB1014 & 0.012 & 0.270 & 0.08 & 0.225 & 0.25 & OUTLET & \\
\hline SB1015 & 0.012 & 0.287 & 0.08 & 0.233 & 0.25 & PERVIOUS & 80 \\
\hline SB1016 & 0.012 & 0.350 & 0.08 & 0.261 & 0.25 & OUTLET & \\
\hline SB1017 & 0.012 & 0.209 & 0.08 & 0.201 & 0.25 & OUTLET & \\
\hline SB1018 & 0.012 & 0.279 & 0.08 & 0.228 & 0.25 & OUTLET & \\
\hline SB1019 & 0.012 & 0.326 & 0.08 & 0.250 & 0.25 & OUTLET & \\
\hline SB1020 & 0.012 & 0.301 & 0.08 & 0.230 & 0.25 & OUTLET & \\
\hline SB1021 & 0.012 & 0.320 & 0.08 & 0.246 & 0.25 & OUTLET & \\
\hline SB1022 & 0.012 & 0.340 & 0.08 & 0.255 & 0.25 & PERVIOUS & 80 \\
\hline SB1023 & 0.012 & 0.367 & 0.08 & 0.268 & 0.25 & OUTLET & \\
\hline SB1024 & 0.012 & 0.280 & 0.08 & 0.228 & 0.25 & PERVIOUS & 80 \\
\hline SB1025 & 0.012 & 0.250 & 0.08 & 0.225 & 0.25 & PERVIOUS & 80 \\
\hline SB1026 & 0.012 & 0.256 & 0.08 & 0.224 & 0.25 & OUTLET & \\
\hline SB1027 & 0.012 & 0.265 & 0.08 & 0.234 & 0.25 & PERVIOUS & 80 \\
\hline SB1028 & 0.012 & 0.317 & 0.08 & 0.251 & 0.25 & PERVIOUS & 80 \\
\hline SB1029 & 0.012 & 0.334 & 0.08 & 0.265 & 0.25 & PERVIOUS & 80 \\
\hline SB1030 & 0.012 & 0.161 & 0.08 & 0.183 & 0.25 & PERVIOUS & 80 \\
\hline SB1031 & 0.012 & 0.354 & 0.08 & 0.252 & 0.25 & OUTLET & \\
\hline SB1032 & 0.012 & 0.325 & 0.08 & 0.240 & 0.25 & OUTLET & \\
\hline SB1033 & 0.012 & 0.363 & 0.08 & 0.264 & 0.25 & OUTLET & \\
\hline SB1034 & 0.012 & 0.261 & 0.08 & 0.228 & 0.25 & OUTLET & \\
\hline SB1035 & 0.012 & 0.300 & 0.08 & 0.241 & 0.25 & OUTLET & \\
\hline SB1036 & 0.012 & 0.272 & 0.08 & 0.226 & 0.25 & OUTLET & \\
\hline SB1037 & 0.012 & 0.333 & 0.08 & 0.241 & 0.25 & PERVIOUS & 80 \\
\hline SB1038 & 0.012 & 0.356 & 0.08 & 0.255 & 0.25 & PERVIOUS & 80 \\
\hline
\end{tabular}




\section{Appendix C: PySWMM Sample Code}

- PySWMM Model Initialization

- PySWMM Script for Static Scenario

- PySWMM Script for RTC 1 applied to facility 4860

- PySWMM Script for RTC 2 applied to facility 4860 


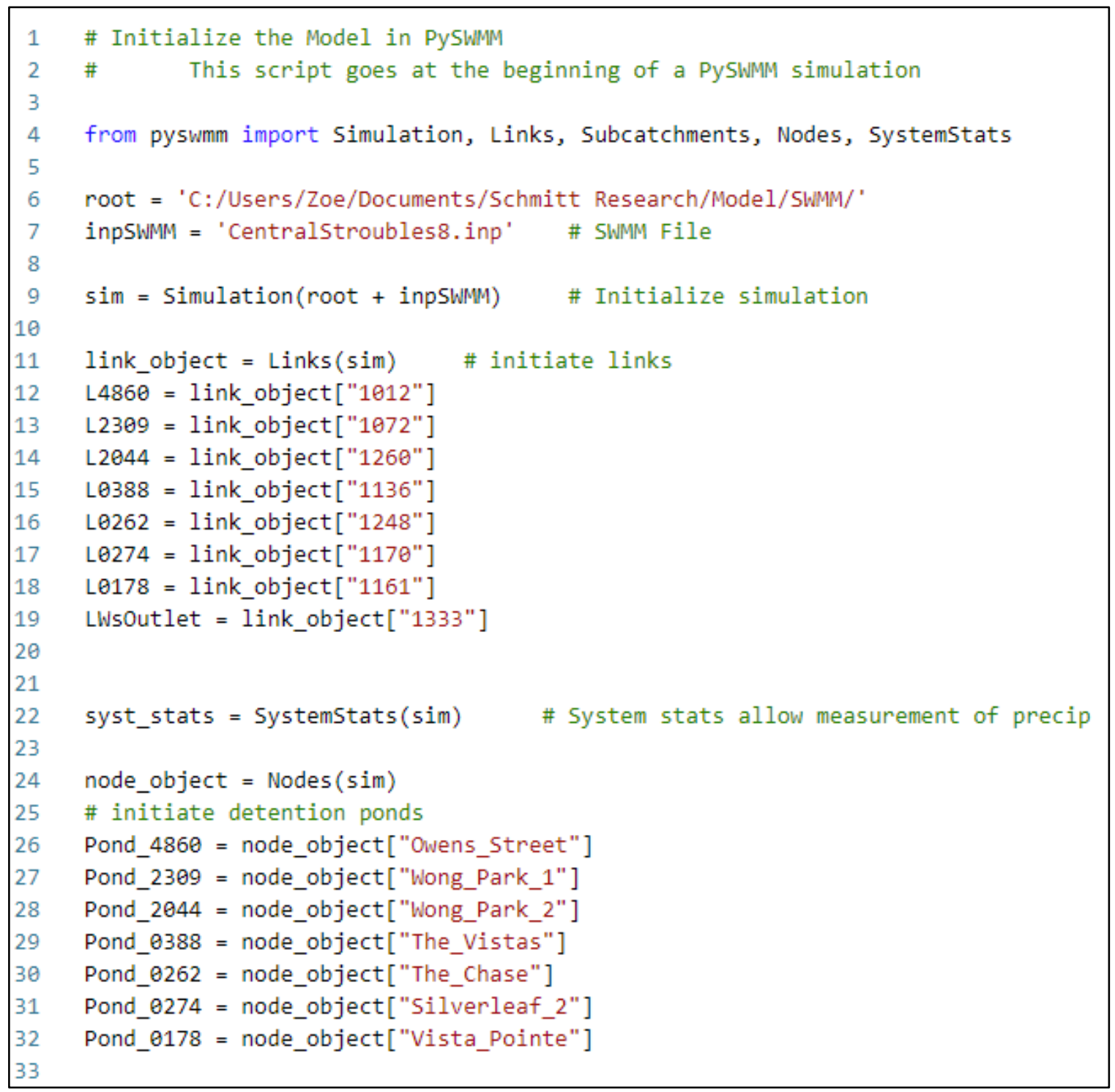

Figure C1. PySWMM Model Initialization 


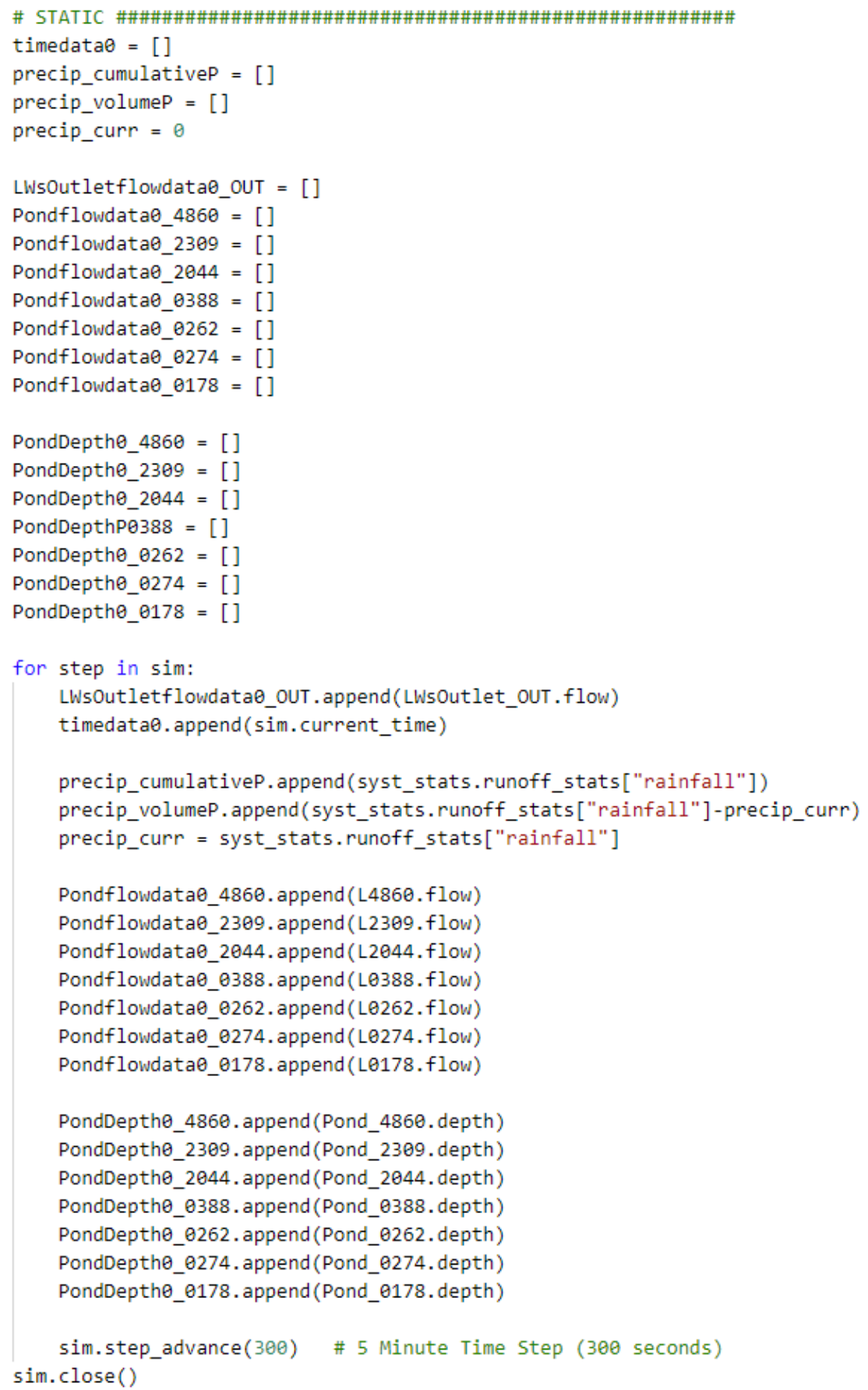

Figure C2. PySWMM Script for Static Scenario

- Static scenario has no controls applied - only observation of watershed conditions (precipitation, pond depth, flow data at facility and watershed outlets).

- Note: Predevelopment scenario has similar script, except the input SWMM file is that of the predevelopment watershed, and there is no pond depth information because there are no detention facilities. 


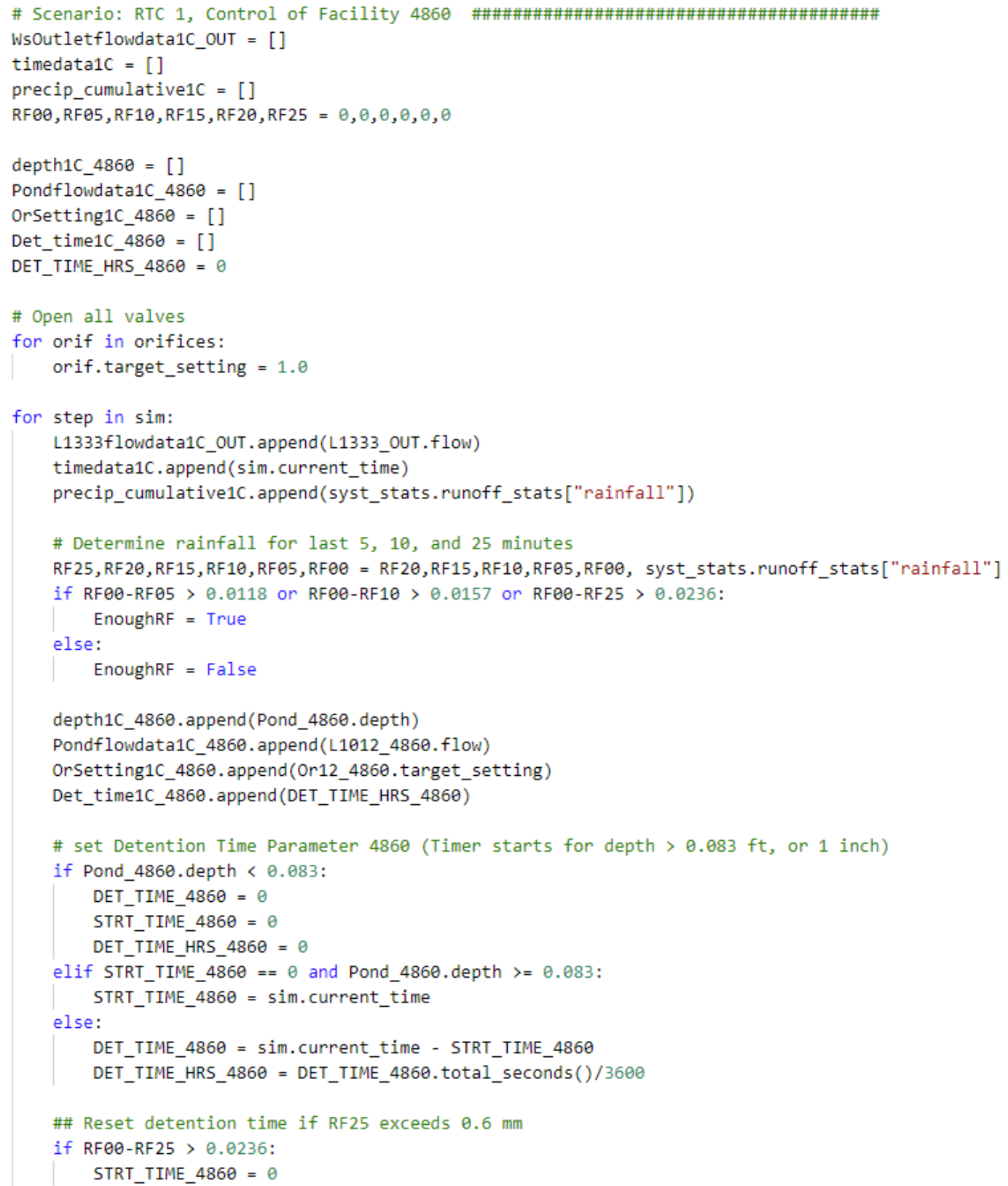

Figure C3. PySWMM Script for RTC 1 applied to facility 4860 - Part I 


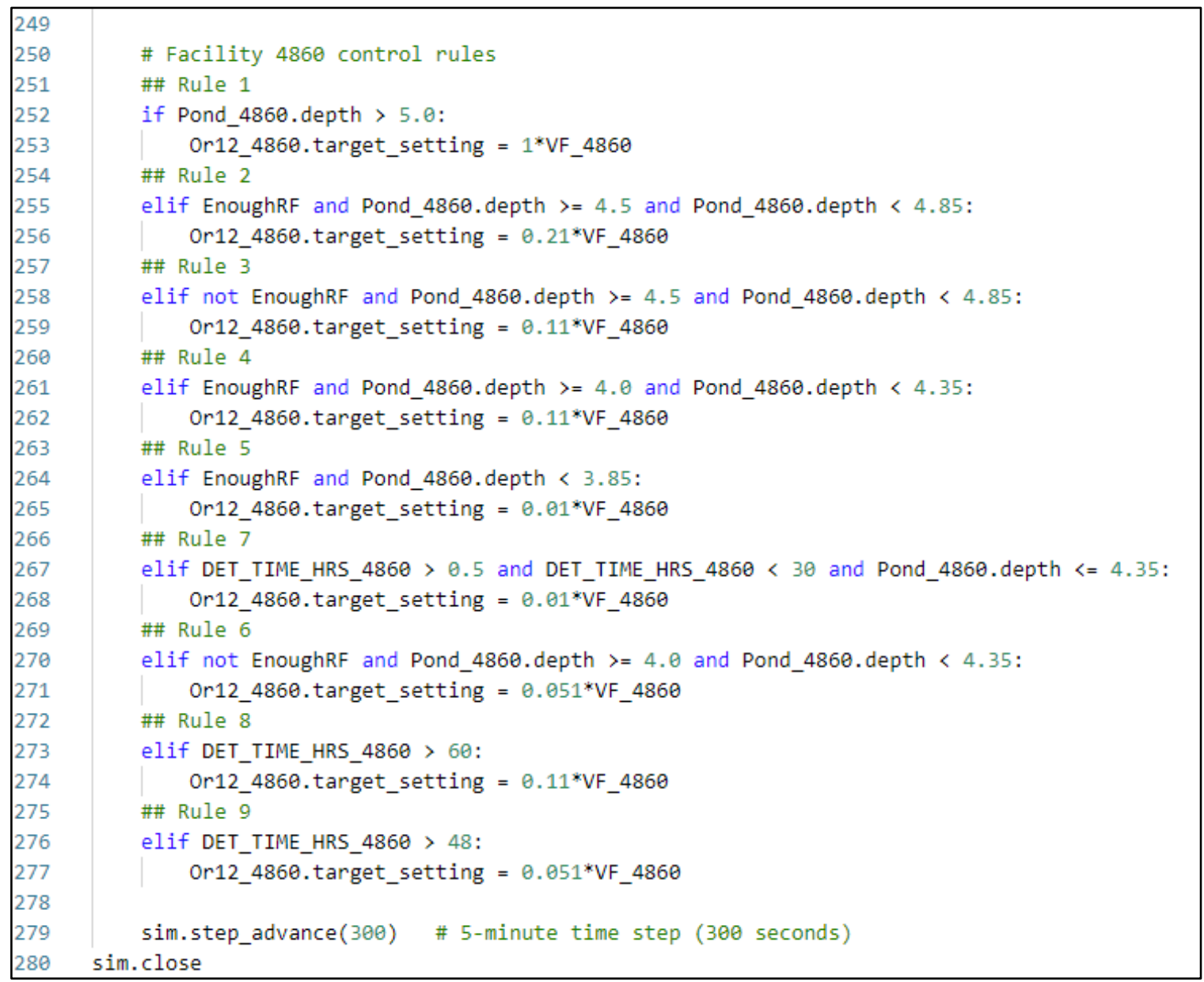

Figure C4. PySWMM Script for RTC 1 applied to facility 4860 - Part II 


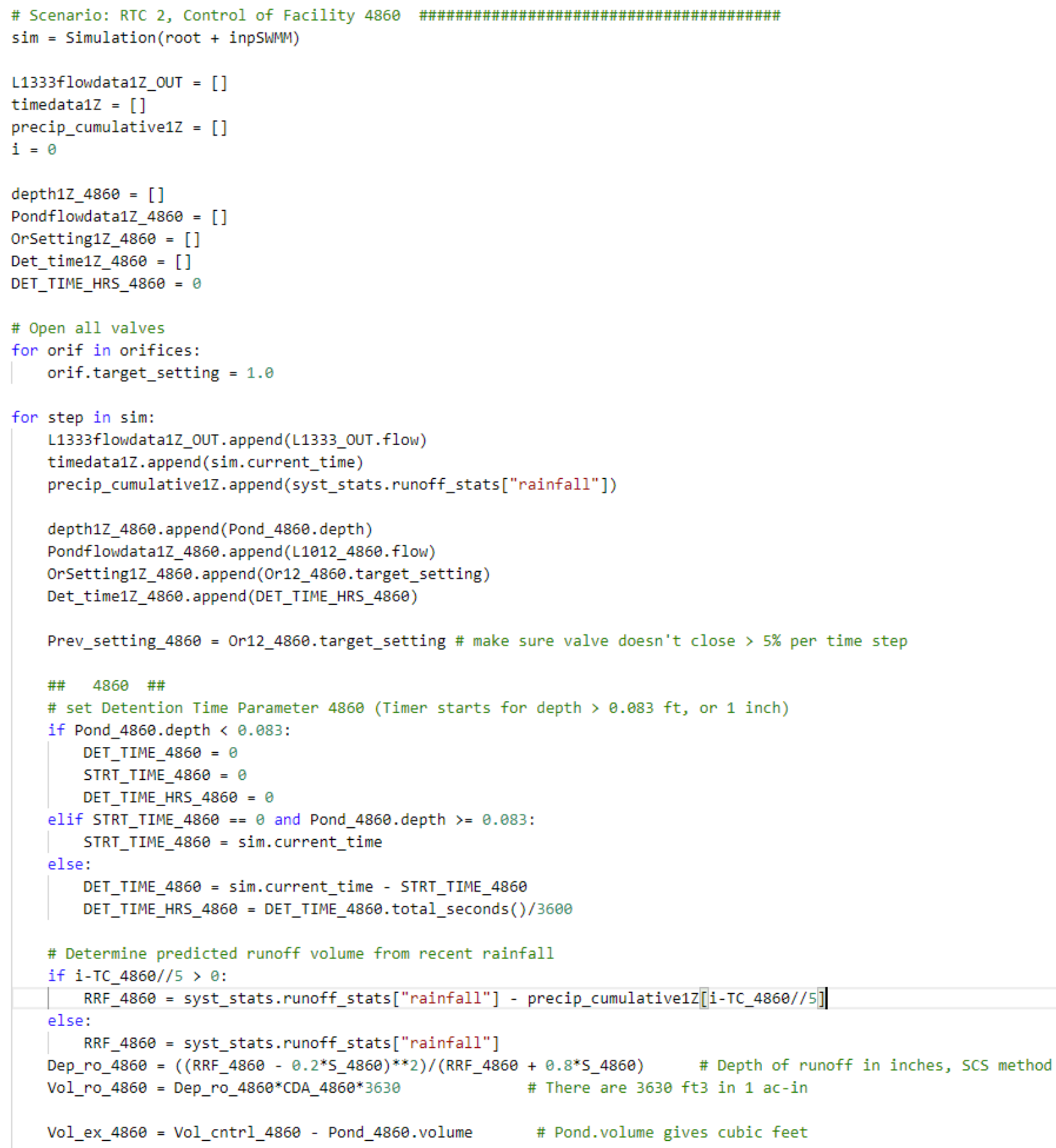

Figure C5. PySWMM Script for RTC 2 applied to facility 4860 - Part I 


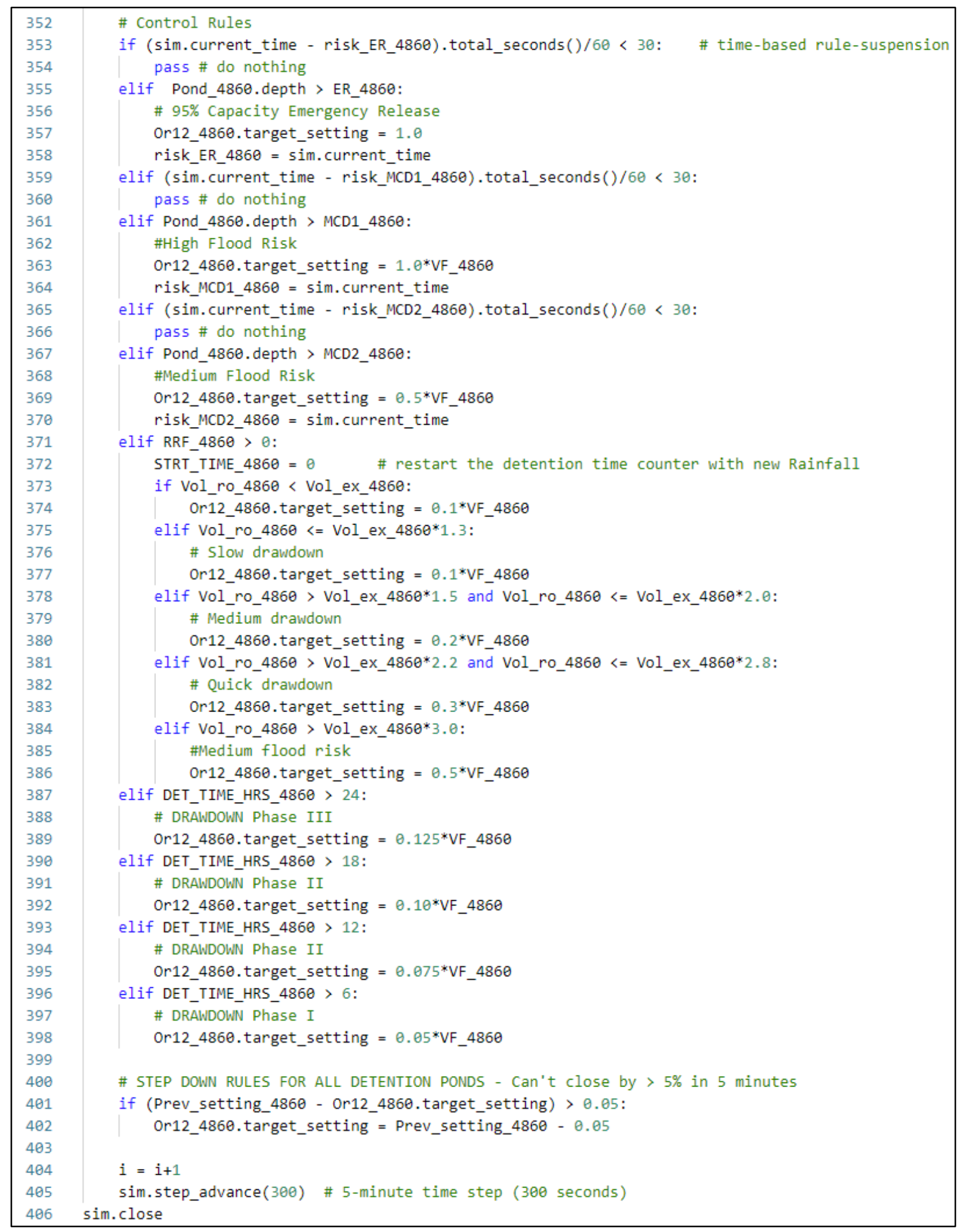

Figure C6. PySWMM Script for RTC 2 applied to facility 4860 - Part II 


\section{Appendix D: Simulation Results}

- Peak Flow Results

- Exceedance Time Values

- Flow Duration Curves 
Table D1. Change in Peak Flows at Detention Basin Outlets (RTC-1 and RTC-2 compared to Static) for NRCS 24-Hour Design Storms

\begin{tabular}{|c|c|c|c|c|c|c|c|c|c|c|c|c|c|c|c|}
\hline \multirow{3}{*}{\multicolumn{2}{|c|}{$\begin{array}{r}\text { Detention } \\
\text { Pond: } \\
\text { RTC } \\
\text { Method: }\end{array}$}} & \multicolumn{14}{|c|}{ Change in Peak Flow (\%) } \\
\hline & & \multicolumn{2}{|c|}{$\underline{4860}$} & \multicolumn{2}{|c|}{2309} & \multicolumn{2}{|c|}{2044} & \multicolumn{2}{|c|}{$\underline{0388}$} & \multicolumn{2}{|c|}{$\underline{0262}$} & \multicolumn{2}{|c|}{$\underline{0274}$} & \multicolumn{2}{|c|}{$\underline{0178}$} \\
\hline & & $\begin{array}{c}\text { RTC } \\
1\end{array}$ & $\begin{array}{c}\text { RTC } \\
2\end{array}$ & $\begin{array}{c}\mathrm{RTC} \\
1\end{array}$ & $\begin{array}{c}\text { RTC } \\
2\end{array}$ & RTC & $\begin{array}{c}\mathrm{RTC} \\
2\end{array}$ & & & & & $\mathrm{TC}$ & & $\begin{array}{c}\text { RTC } \\
1\end{array}$ & $\begin{array}{c}\text { RTC } \\
2\end{array}$ \\
\hline \multirow{9}{*}{ 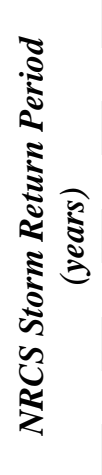 } & 0.25 & 15.2 & 13.6 & -72.5 & -72.7 & -89.4 & -87.2 & 62.7 & -75.7 & -82.1 & -85.1 & 26.3 & -54.7 & 99.7 & 89.0 \\
\hline & 0.5 & 69.9 & 55.5 & 14.7 & 8.2 & -89.6 & -90.1 & 43.9 & -26.7 & -85.7 & -87.4 & -25.0 & 24.9 & 51.8 & 51.3 \\
\hline & 1 & 18.2 & 13.4 & 40.4 & 29.2 & -76.6 & -91.3 & 33.2 & 24.6 & -68.3 & -70.4 & 154.8 & 142.6 & 34.6 & 39.3 \\
\hline & 2 & 15.7 & 14.9 & 1.7 & 1.1 & 34.2 & -31.7 & 21.4 & 18.1 & 71.7 & -13.4 & 91.5 & -0.6 & 9.4 & 16.3 \\
\hline & 5 & 0.0 & 0.0 & 0.0 & 0.0 & 13.2 & 12.2 & 7.8 & 7.8 & 56.3 & 43.7 & 34.5 & 32.2 & 8.2 & 6.2 \\
\hline & 10 & -0.2 & 0.3 & 0.0 & 0.0 & 8.4 & 6.4 & 0.0 & 0.0 & 41.8 & 32.7 & 6.9 & 17.3 & 0.0 & 0.0 \\
\hline & 25 & 0.5 & 0.0 & 0.0 & 13.8 & 0.0 & 0.1 & -0.2 & 0.1 & 27.3 & 28.1 & 0.0 & 0.0 & 0.1 & 0.0 \\
\hline & 50 & 1.4 & -1.8 & -0.9 & 7.8 & 1.0 & 1.2 & 0.0 & 0.0 & 20.4 & 18.9 & 0.0 & 0.0 & -0.1 & -0.1 \\
\hline & 100 & -2.0 & -2.0 & 0.0 & 0.0 & -0.4 & 2.6 & -0.6 & -0.6 & 11.1 & 11.2 & 0.0 & 0.0 & 0.0 & 0.0 \\
\hline
\end{tabular}

Table D2. Change in Peak Flows at Watershed Outlet (RTC 1 and 2 compared to Static) for NRCS 24-Hour Design Storms ( $T_{R}$ of 0.25- to 5-year)

\begin{tabular}{|c|c|c|c|c|c|c|c|c|c|c|c|}
\hline \multirow{4}{*}{\multicolumn{2}{|c|}{$\begin{array}{r}\text { Storm Return } \\
\text { Period: }\end{array}$}} & \multicolumn{10}{|c|}{ Change in Peak Flow (\%) } \\
\hline & & \multirow{2}{*}{\multicolumn{2}{|c|}{0.25}} & \multirow{2}{*}{\multicolumn{2}{|c|}{0.5}} & & & & & & \\
\hline & & & & & & \multicolumn{2}{|c|}{1} & \multicolumn{2}{|c|}{2} & \multicolumn{2}{|c|}{5} \\
\hline & & RTC & RTC & RTC & RTC & RTC & RTC & RTC & RTC & RTC & RTC \\
\hline & & 1 & 2 & 1 & 2 & 1 & 2 & 1 & 2 & 1 & 2 \\
\hline \multirow{7}{*}{ 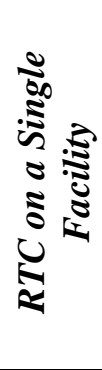 } & 4860 & -20.5 & -19.6 & 1.0 & 3.3 & 58.1 & 0.4 & -20.9 & -18.5 & 4.5 & 7.0 \\
\hline & 2309 & -7.2 & -6.3 & 1.4 & 2.2 & -2.0 & -1.7 & -0.7 & -4.5 & 0.1 & -0.5 \\
\hline & 3044 & -0.5 & -1.5 & 2.7 & -2.0 & -0.2 & -0.8 & 3.6 & 6.3 & -1.0 & -5.6 \\
\hline & 0388 & -4.8 & -3.1 & -5.3 & -4.7 & -3.5 & -2.9 & -0.7 & -1.8 & -0.2 & -0.6 \\
\hline & 0262 & -5.4 & -5.1 & -1.4 & -1.1 & -3.0 & -3.3 & 0.6 & -1.5 & -1.3 & -1.7 \\
\hline & 0274 & -1.1 & -0.2 & -2.7 & -1.0 & -1.1 & -0.2 & 6.9 & 7.0 & -0.3 & -0.5 \\
\hline & 0178 & -1.3 & -0.1 & -0.6 & -0.3 & -1.7 & -0.9 & 4.3 & 6.9 & -0.2 & -0.1 \\
\hline \multirow{7}{*}{ 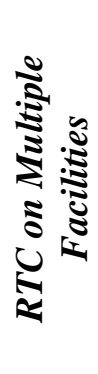 } & Combo \#8 & -30.5 & -28.4 & -20.7 & -16.9 & 16.2 & -4.5 & 6.0 & -27.6 & 7.1 & 0.1 \\
\hline & Combo \#9 & -30.8 & -28.4 & -20.7 & -17.4 & 30.5 & -5.2 & 13.2 & -28.3 & 1.0 & -1.3 \\
\hline & Combo \#10 & -29.5 & -27.6 & -17.1 & -13.4 & 39.5 & -2.2 & 14.4 & -28.4 & 2.0 & 0.4 \\
\hline & Combo \#11 & -26.2 & -25.1 & -10.9 & -7.3 & 38.6 & -0.5 & 13.6 & -27.8 & 4.3 & -3.4 \\
\hline & Combo \#12 & -9.7 & -7.4 & -6.9 & -6.5 & -6.6 & -6.1 & 6.0 & -0.9 & -2.3 & -3.0 \\
\hline & Combo \#13 & -16.5 & -13.6 & -6.7 & -5.5 & -7.0 & -6.7 & -8.1 & -8.9 & 5.7 & 4.1 \\
\hline & Combo \#14 & -6.0 & -6.6 & 1.4 & -3.5 & -3.3 & -4.1 & 3.2 & 5.0 & -2.6 & -5.0 \\
\hline
\end{tabular}


Table D3. Change in Peak Flows at Watershed Outlet (RTC 1 and 2 compared to Static) for NRCS 24-Hour Design Storms ( $T_{R}$ of 10- to 100-year)

\begin{tabular}{|c|c|c|c|c|c|c|c|c|c|}
\hline \multirow{5}{*}{ (1) } & \multirow{5}{*}{$\begin{array}{r}\text { Storm Return } \\
\text { Period: } \\
\text { RTC Method: }\end{array}$} & \multicolumn{8}{|c|}{ Change in Peak Flow (\%) } \\
\hline & & \multirow{2}{*}{\multicolumn{2}{|c|}{10}} & \multirow{2}{*}{\multicolumn{2}{|c|}{25}} & \multirow{2}{*}{\multicolumn{2}{|c|}{50}} & \multirow{2}{*}{\multicolumn{2}{|c|}{100}} \\
\hline & & & & & & & & & \\
\hline & & RTC & RTC & RTC & RTC & RTC & RTC & RTC & RTC \\
\hline & & 1 & 2 & 1 & 2 & 1 & 2 & 1 & 2 \\
\hline \multirow{7}{*}{ 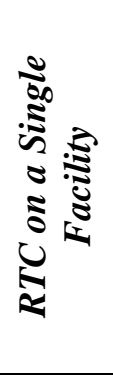 } & 4860 & -2.9 & -0.7 & 9.5 & 1.3 & $\mathbf{1 7 . 3}$ & 7.5 & -0.8 & -0.8 \\
\hline & 2309 & 0.0 & 0.6 & 3.2 & 3.2 & 1.2 & 1.9 & -3.7 & -3.9 \\
\hline & 3044 & 0.3 & -0.1 & -0.9 & -1.8 & 2.5 & 0.5 & -1.0 & -0.9 \\
\hline & 0388 & -1.0 & -1.6 & -1.8 & -3.4 & 0.1 & 0.8 & 0.3 & -0.1 \\
\hline & 0262 & -0.4 & -2.2 & -2.1 & -3.7 & -0.9 & 0.5 & 0.2 & -0.2 \\
\hline & 0274 & -1.3 & -0.4 & -3.1 & -2.4 & 0.1 & 0.8 & 0.3 & -0.3 \\
\hline & 0178 & -0.5 & -0.5 & 0.2 & -1.1 & 0.3 & 2.1 & 0.1 & 0.2 \\
\hline \multirow{7}{*}{ 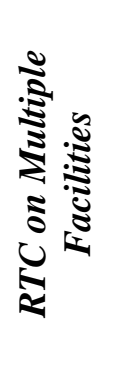 } & Combo \#8 & 0.5 & 2.1 & 8.4 & 2.4 & 6.7 & 2.5 & -0.3 & -0.1 \\
\hline & Combo \#9 & -0.5 & 3.1 & 3.6 & 1.1 & 1.9 & 2.9 & -1.5 & -1.4 \\
\hline & Combo \#10 & -0.6 & 3.1 & 2.0 & 0.2 & 1.0 & 2.4 & 0.5 & -1.0 \\
\hline & Combo \#11 & 2.9 & 3.6 & 4.2 & 2.3 & 1.4 & 2.3 & -2.1 & -1.6 \\
\hline & Combo \#12 & -1.2 & -2.4 & -3.1 & -4.7 & -0.6 & 0.8 & 0.3 & -0.1 \\
\hline & Combo \#13 & 0.3 & -2.1 & 1.7 & 3.4 & -3.4 & -1.4 & -2.0 & -2.0 \\
\hline & Combo \#14 & -0.2 & -2.3 & -2.0 & -3.8 & 1.8 & 2.5 & -1.2 & 0.0 \\
\hline
\end{tabular}


Table D4. Change in Exceedance Time of Erosive Flows at Detention Basin Outlets

\begin{tabular}{|c|c|c|c|c|c|c|c|}
\hline \multirow{3}{*}{ Facility } & \multirow{3}{*}{$\begin{array}{c}\text { RTC } \\
\text { Method }\end{array}$} & \multicolumn{6}{|c|}{ Impact of RTC at Detention Pond Outlet } \\
\hline & & \multicolumn{2}{|c|}{$\begin{array}{c}\text { Change* in Exceed. } \\
\text { Time of Q-crit }\end{array}$} & \multicolumn{2}{|c|}{$\begin{array}{l}\text { Change in Exceed. } \\
\text { Time of Q-2yr }\end{array}$} & \multicolumn{2}{|c|}{$\begin{array}{c}\text { Change in Exceed. } \\
\text { Time of Q-10yr }\end{array}$} \\
\hline & & (hours) & $(\%)$ & (hours) & $(\%)$ & (hours) & $(\%)$ \\
\hline \multirow{2}{*}{4860} & RTC 1 & 28 & 27 & 9 & 16 & 6 & 16 \\
\hline & RTC 2 & 17 & 16 & 5 & 9 & 4 & 9 \\
\hline \multirow{2}{*}{2309} & RTC 1 & 59 & 54 & 24 & 32 & 0 & NA \\
\hline & RTC 2 & 35 & 32 & 13 & 17 & 0 & NA \\
\hline \multirow{2}{*}{2044} & RTC 1 & -194 & -83 & -60 & -60 & 0 & NA \\
\hline & RTC 2 & -150 & -64 & -65 & -65 & 0 & NA \\
\hline \multirow{2}{*}{0388} & RTC 1 & -186 & -74 & -53 & -45 & 18 & 202 \\
\hline & RTC 2 & -112 & -44 & -8 & -7 & 10 & 112 \\
\hline \multirow{2}{*}{0262} & RTC 1 & -183 & -72 & -26 & -27 & -17 & -72 \\
\hline & RTC 2 & -223 & -87 & -71 & -75 & -10 & -43 \\
\hline \multirow{2}{*}{0274} & RTC 1 & -33 & -19 & -25 & -38 & 27 & 276 \\
\hline & RTC 2 & -32 & -19 & 4 & 6 & 1 & 11 \\
\hline \multirow{2}{*}{0178} & RTC 1 & -122 & -70 & -17 & -26 & 30 & 251 \\
\hline & RTC 2 & -70 & -40 & 8 & 13 & 10 & 82 \\
\hline
\end{tabular}


Table D5. Change in Exceedance Time of Erosive Flows at Watershed Outlet

\begin{tabular}{|c|c|c|c|c|c|c|c|c|}
\hline \multirow{3}{*}{\multicolumn{2}{|c|}{ RTC Location }} & \multirow{5}{*}{$\begin{array}{c}\begin{array}{c}\text { RTC } \\
\text { Method }\end{array} \\
\text { RTC 1 } \\
\text { RTC 2 }\end{array}$} & \multicolumn{6}{|c|}{ Impact of RTC at Watershed Outlet } \\
\hline & & & \multicolumn{2}{|c|}{$\begin{array}{c}\text { Change in Exceed. } \\
\text { Time of Q-crit }\end{array}$} & \multicolumn{2}{|c|}{$\begin{array}{c}\text { Change in Exceed. } \\
\text { Time of Q-2yr }\end{array}$} & \multicolumn{2}{|c|}{$\begin{array}{c}\text { Change in Exceed. } \\
\text { Time of Q-10yr }\end{array}$} \\
\hline & & & (hours) & $(\%)$ & (hours) & $(\%)$ & (hours) & $(\%)$ \\
\hline \multirow{14}{*}{ 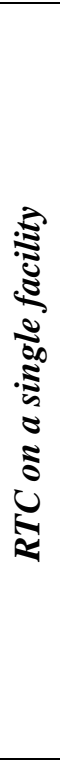 } & \multirow{2}{*}{4860} & & 0.9 & 0.5 & 3.9 & 5.4 & 3.2 & 11.7 \\
\hline & & & -5.6 & -2.9 & 2.0 & 2.7 & 1.6 & 5.7 \\
\hline & \multirow{2}{*}{2309} & RTC 1 & -2.5 & -1.3 & 0.5 & 0.7 & -0.7 & -2.5 \\
\hline & & RTC 2 & -4.6 & -2.4 & 0.6 & 0.9 & -0.2 & -0.7 \\
\hline & \multirow{2}{*}{2044} & RTC 1 & -6.3 & -3.2 & -2.4 & -3.3 & -0.9 & -3.4 \\
\hline & & RTC 2 & -4.0 & -2.0 & -2.4 & -3.3 & -1.9 & -7.0 \\
\hline & \multirow{2}{*}{0388} & RTC 1 & -2.7 & -1.4 & -0.6 & -0.9 & -0.1 & -0.4 \\
\hline & & RTC 2 & -3.1 & -1.6 & -0.3 & -0.4 & -0.4 & -1.6 \\
\hline & \multirow{2}{*}{0262} & RTC 1 & -1.9 & -1.0 & -0.4 & -0.5 & -0.5 & -1.9 \\
\hline & & RTC 2 & -1.1 & -0.5 & -0.2 & -0.3 & -0.2 & -0.7 \\
\hline & \multirow{2}{*}{0274} & RTC 1 & -2.3 & -1.2 & -0.6 & -0.9 & -0.7 & -2.5 \\
\hline & & RTC 2 & -2.5 & -1.3 & -0.9 & -1.2 & -0.1 & -0.4 \\
\hline & \multirow{2}{*}{0178} & RTC 1 & -0.1 & -0.1 & -0.4 & -0.5 & -1.0 & -3.7 \\
\hline & & RTC 2 & 0.4 & 0.2 & -0.5 & -0.7 & -0.4 & -1.6 \\
\hline \multirow{14}{*}{ 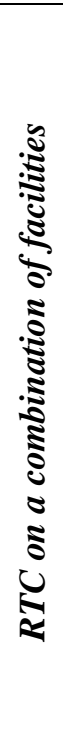 } & \multirow{2}{*}{ Combo \#1 } & RTC 1 & -18.7 & -9.6 & 0.9 & 1.2 & 1.8 & 6.6 \\
\hline & & RTC 2 & -22 & -11 & -2.3 & -3.2 & 1.1 & 3.9 \\
\hline & \multirow{2}{*}{ Combo \#2 } & RTC 1 & -17.6 & -9.0 & 1.8 & 2.5 & 2.2 & 8.1 \\
\hline & & RTC 2 & -22 & -11 & -1.3 & -1.8 & 0.1 & 0.5 \\
\hline & \multirow{2}{*}{ Combo \#3 } & RTC 1 & -14.7 & -7.6 & 2.2 & 3.1 & 2.3 & 8.4 \\
\hline & & RTC 2 & -21 & -11 & -1.6 & -2.2 & -0.3 & -1.0 \\
\hline & \multirow{2}{*}{ Combo \#4 } & RTC 1 & -13.6 & -7.0 & 2.8 & 3.9 & 2.3 & 8.4 \\
\hline & & RTC 2 & -18 & -9 & -0.6 & -0.9 & -0.1 & -0.4 \\
\hline & \multirow{2}{*}{ Combo \#5 } & RTC 1 & -5.1 & -2.6 & -0.5 & -0.8 & -0.9 & -3.4 \\
\hline & & RTC 2 & -4 & -2 & -0.7 & -1.0 & -0.6 & -2.2 \\
\hline & \multirow{2}{*}{ Combo \#6 } & RTC 1 & -19.2 & -9.9 & -3.1 & -4.4 & -1.4 & -4.9 \\
\hline & & RTC 2 & -20 & -10 & -2.6 & -3.7 & -0.9 & -3.1 \\
\hline & \multirow{2}{*}{ Combo \#7 } & RTC 1 & -7.3 & -3.8 & -2.5 & -3.5 & -2.1 & -7.6 \\
\hline & & RTC 2 & -6 & -3 & -2.5 & -3.5 & -2.2 & -7.9 \\
\hline
\end{tabular}




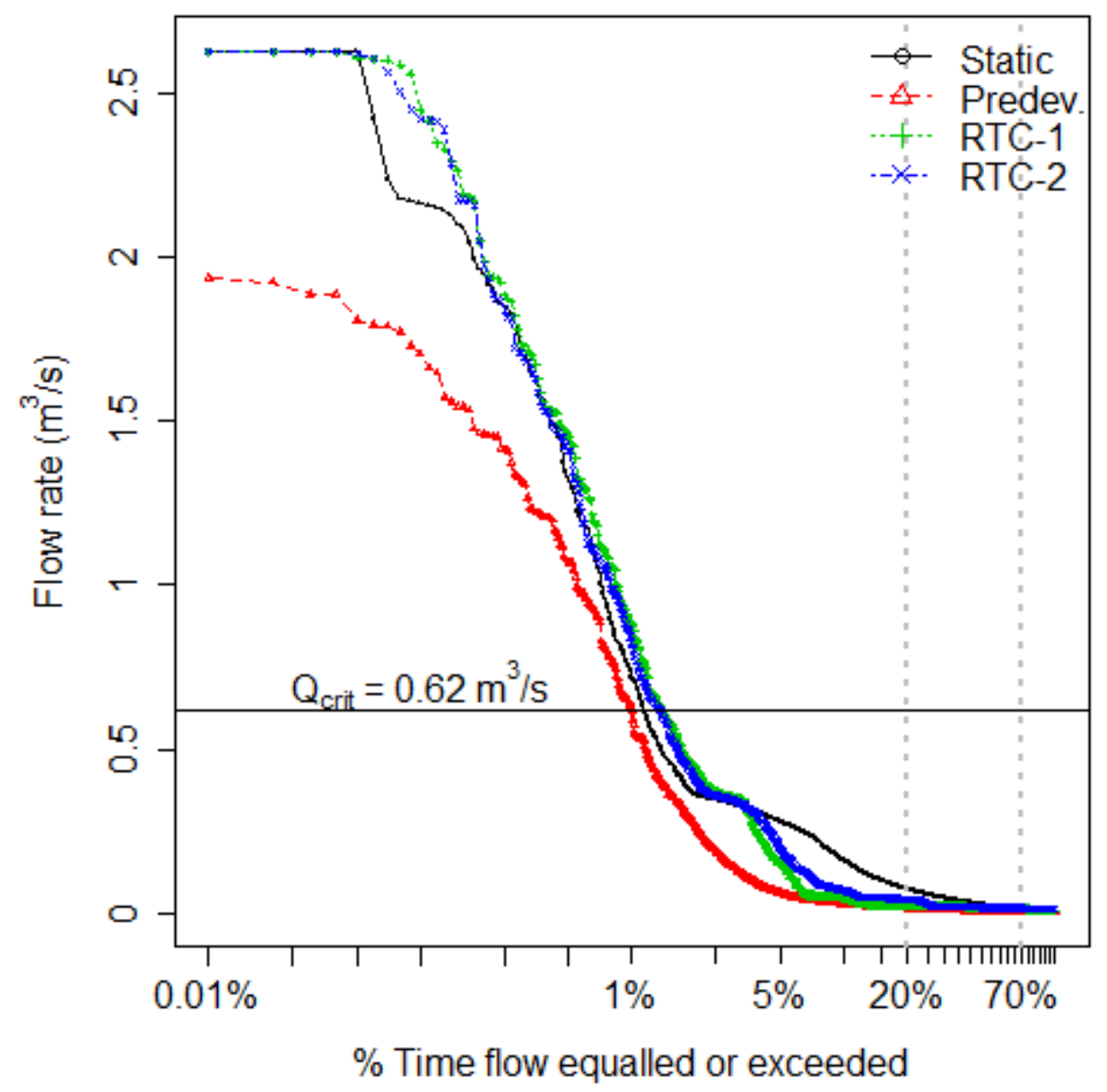

Figure D1. Flow Duration Curve at Facility 4860 Outlet 


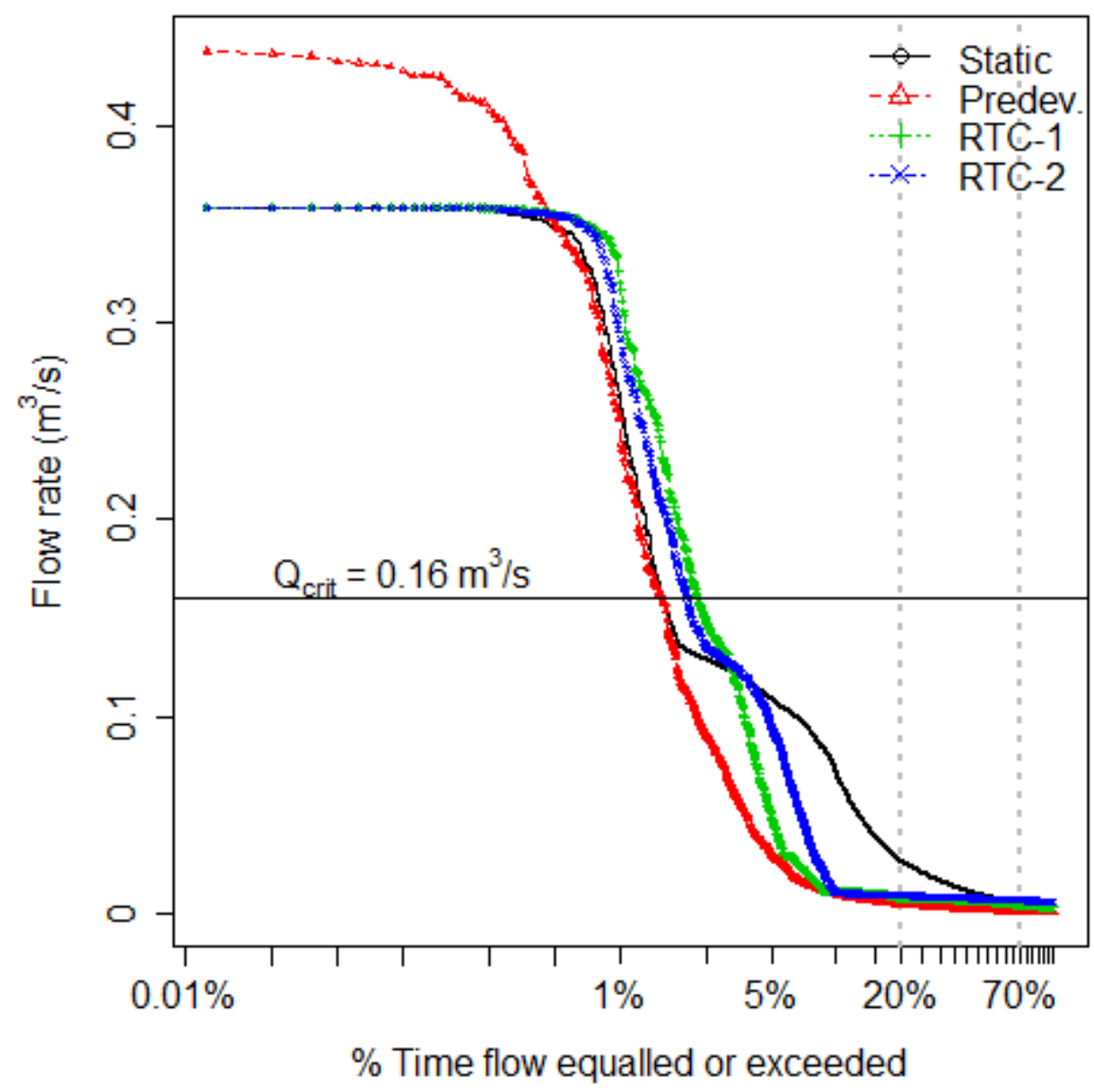

Figure D2. Flow Duration Curve at Facility 2309 Outlet 


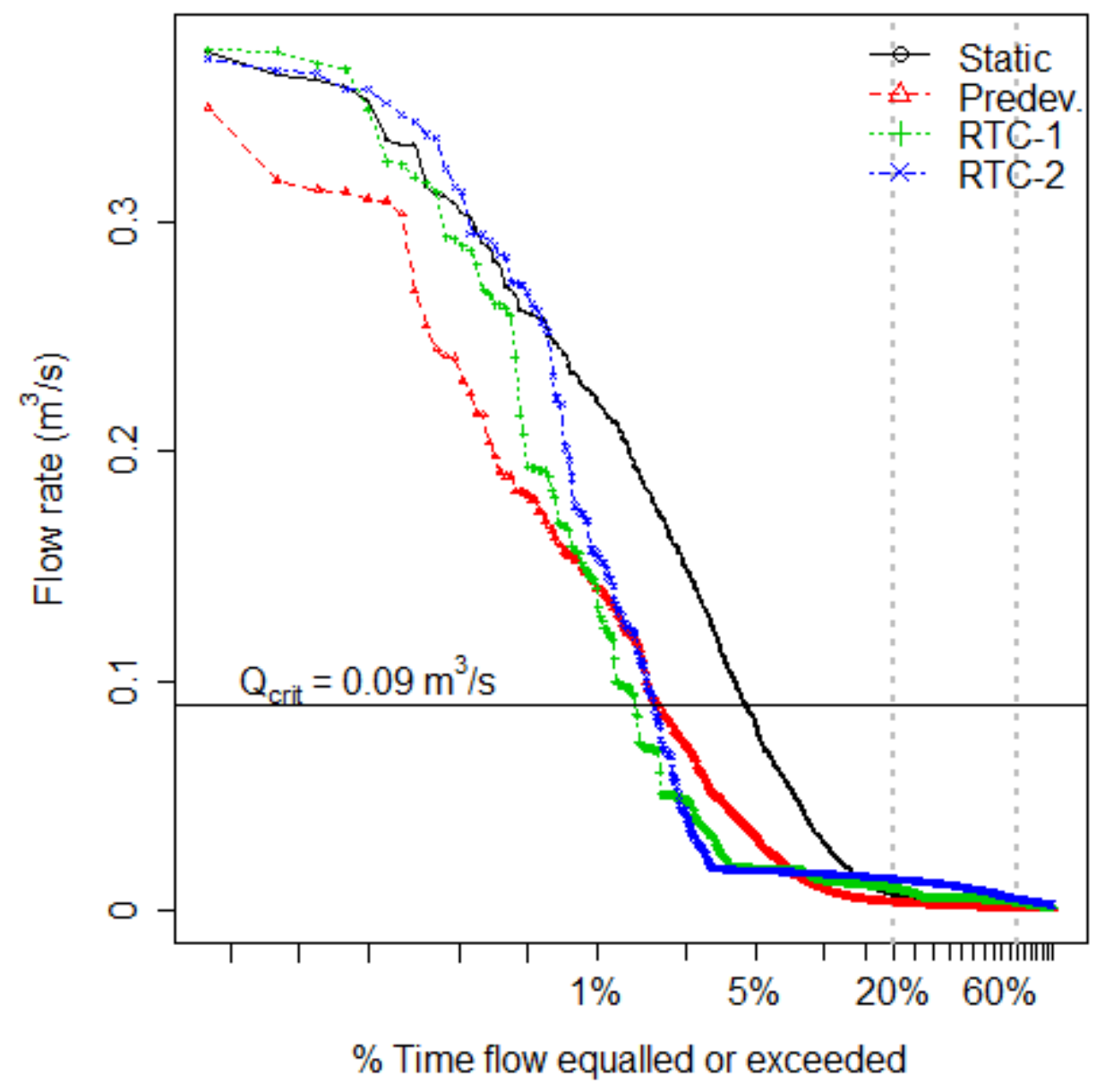

Figure D3. Flow Duration Curve at Facility 2044 Outlet 


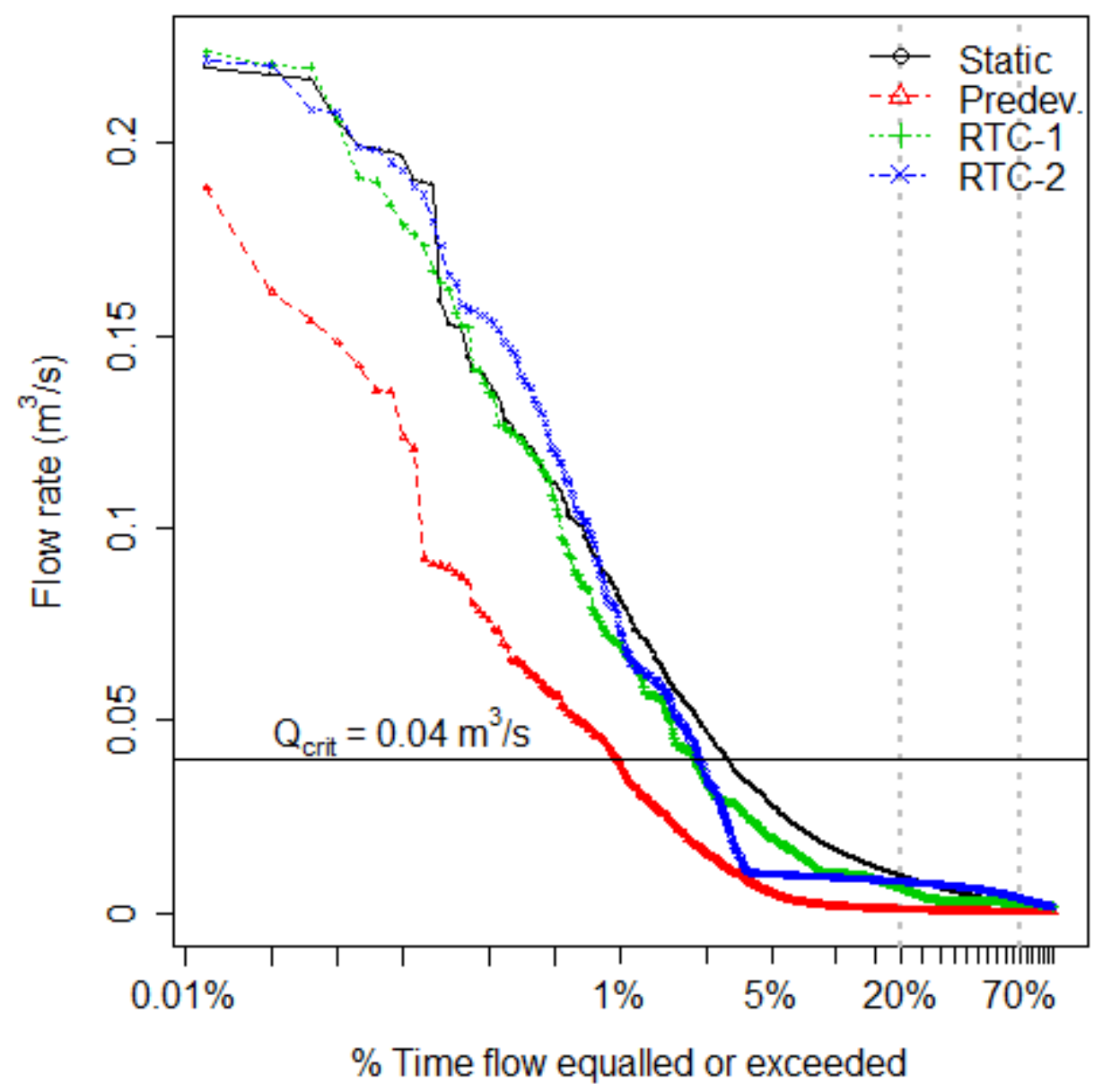

Figure D4. Flow Duration Curve at Facility 0388 Outlet 


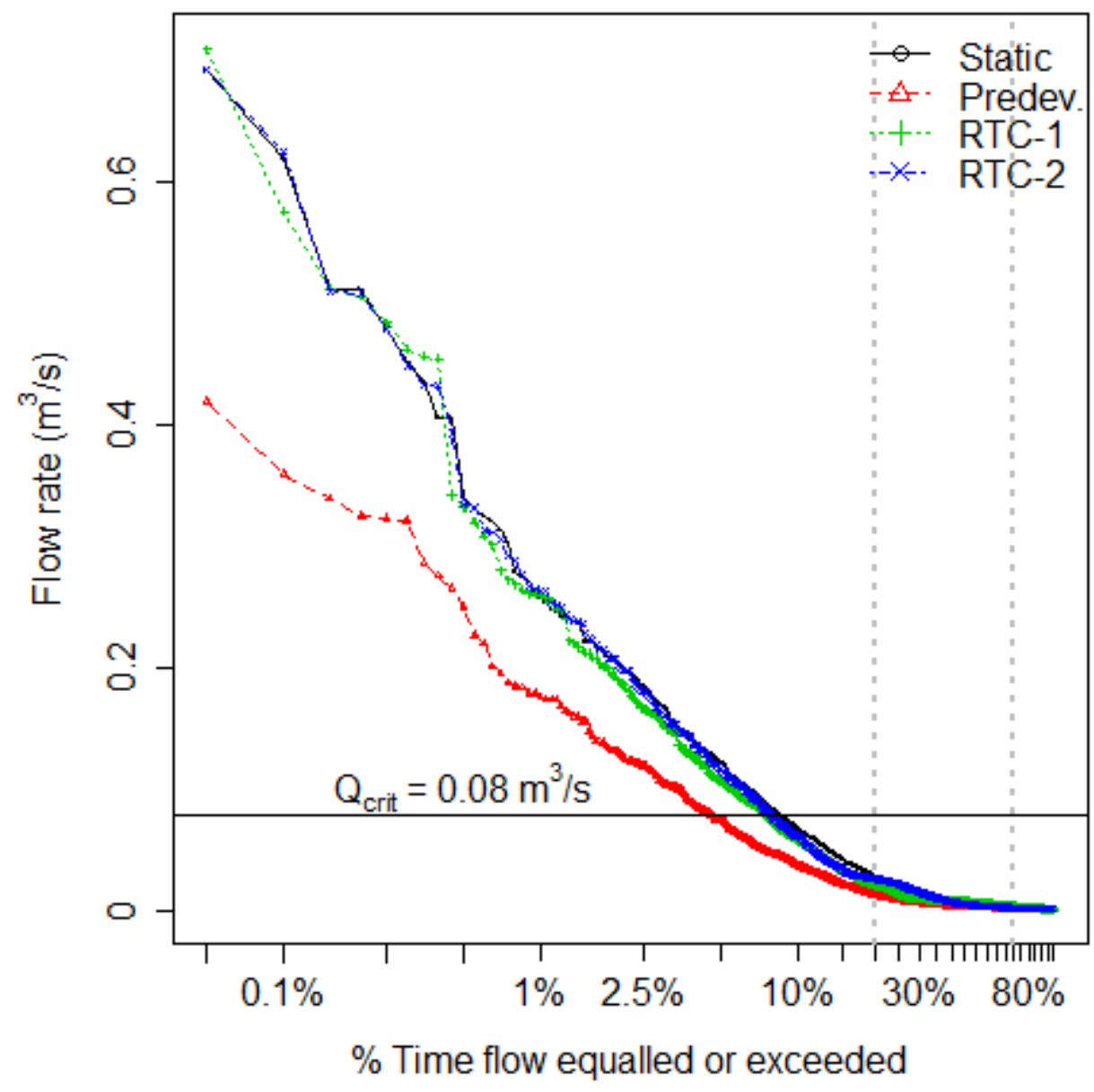

Figure D5. Flow Duration Curve at Facility 0274 Outlet 


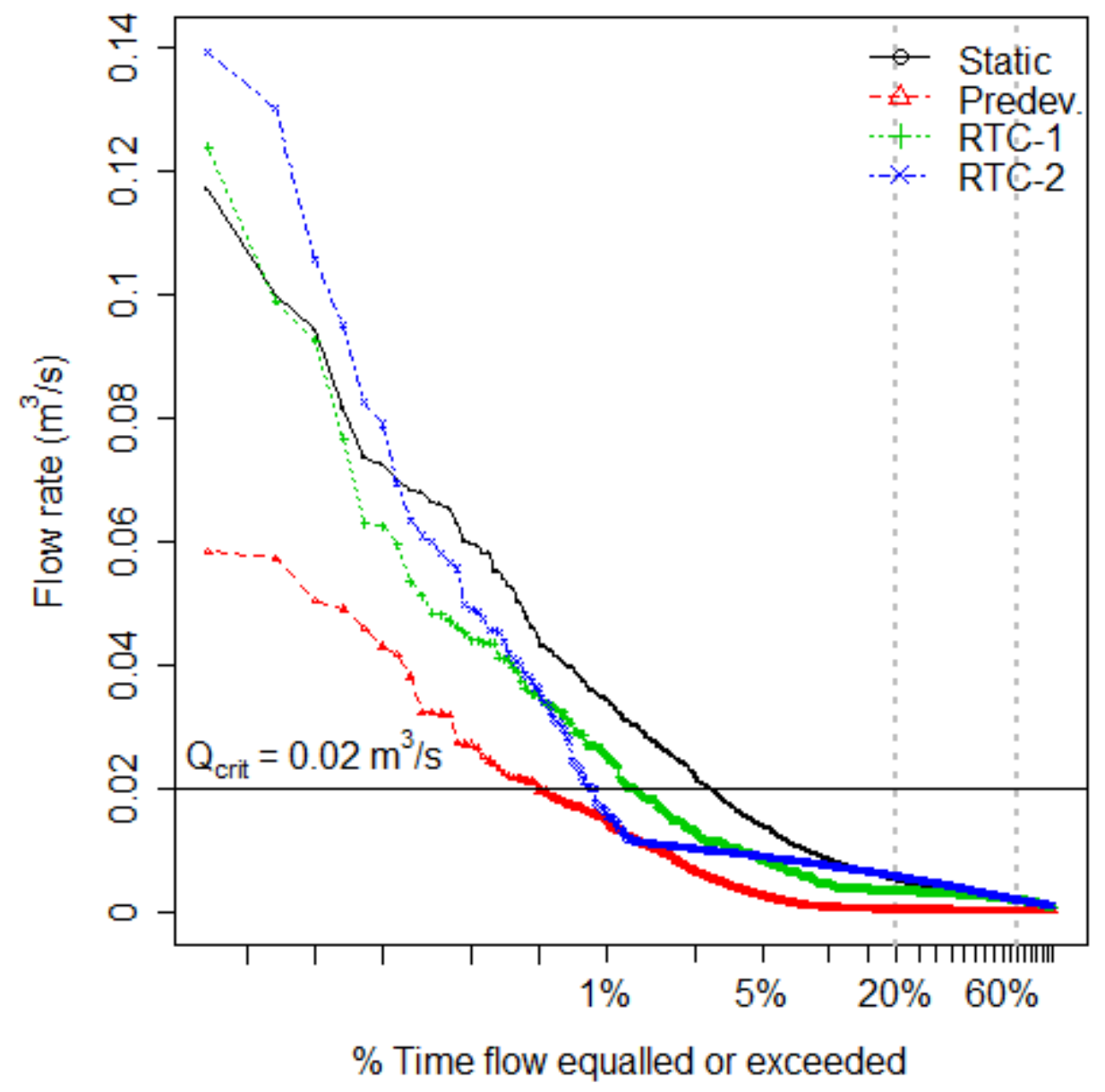

Figure D6. Flow Duration Curve at Facility 0262 Outlet 


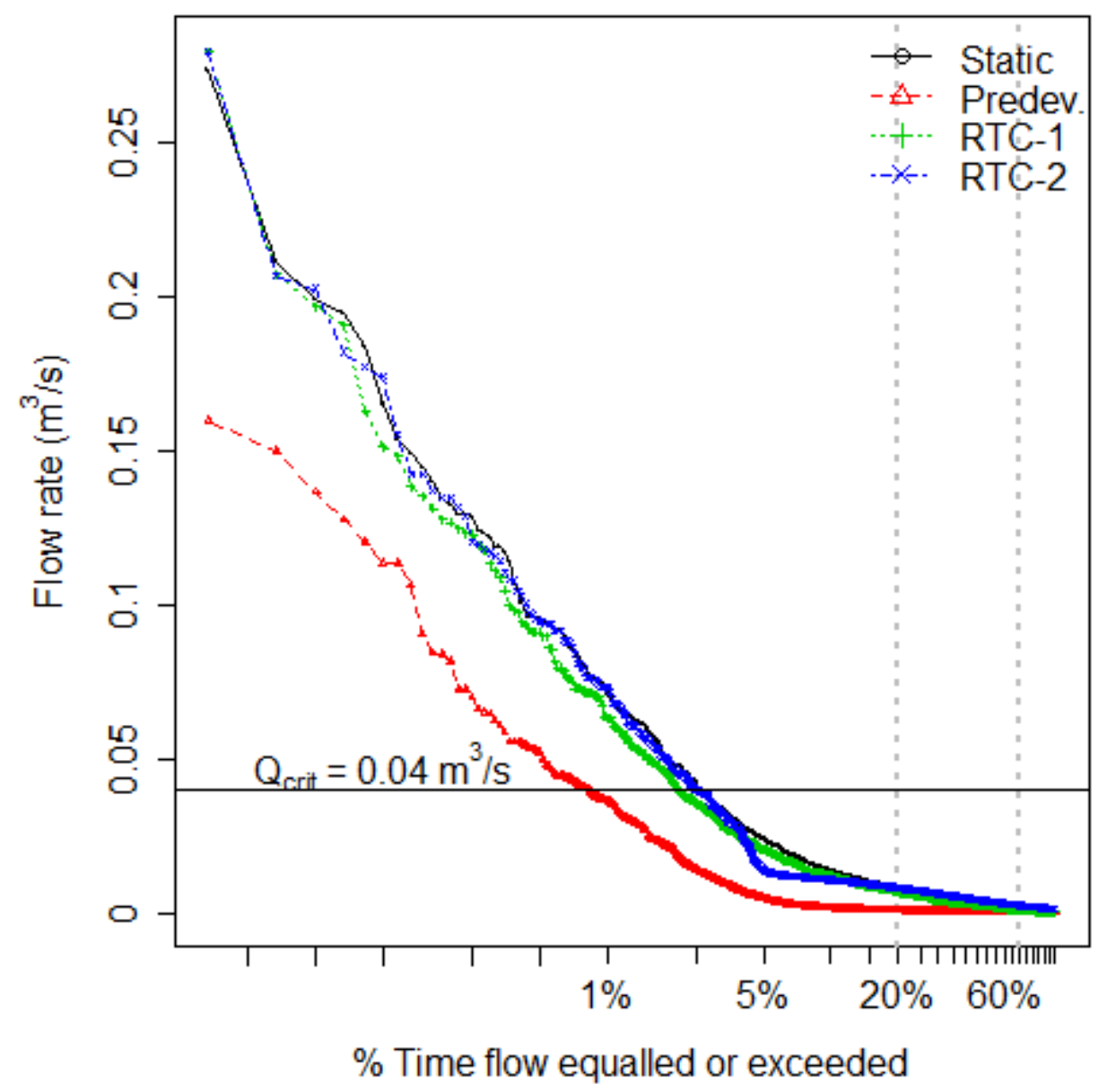

Figure D7. Flow Duration Curve at Facility 0178 Outlet 


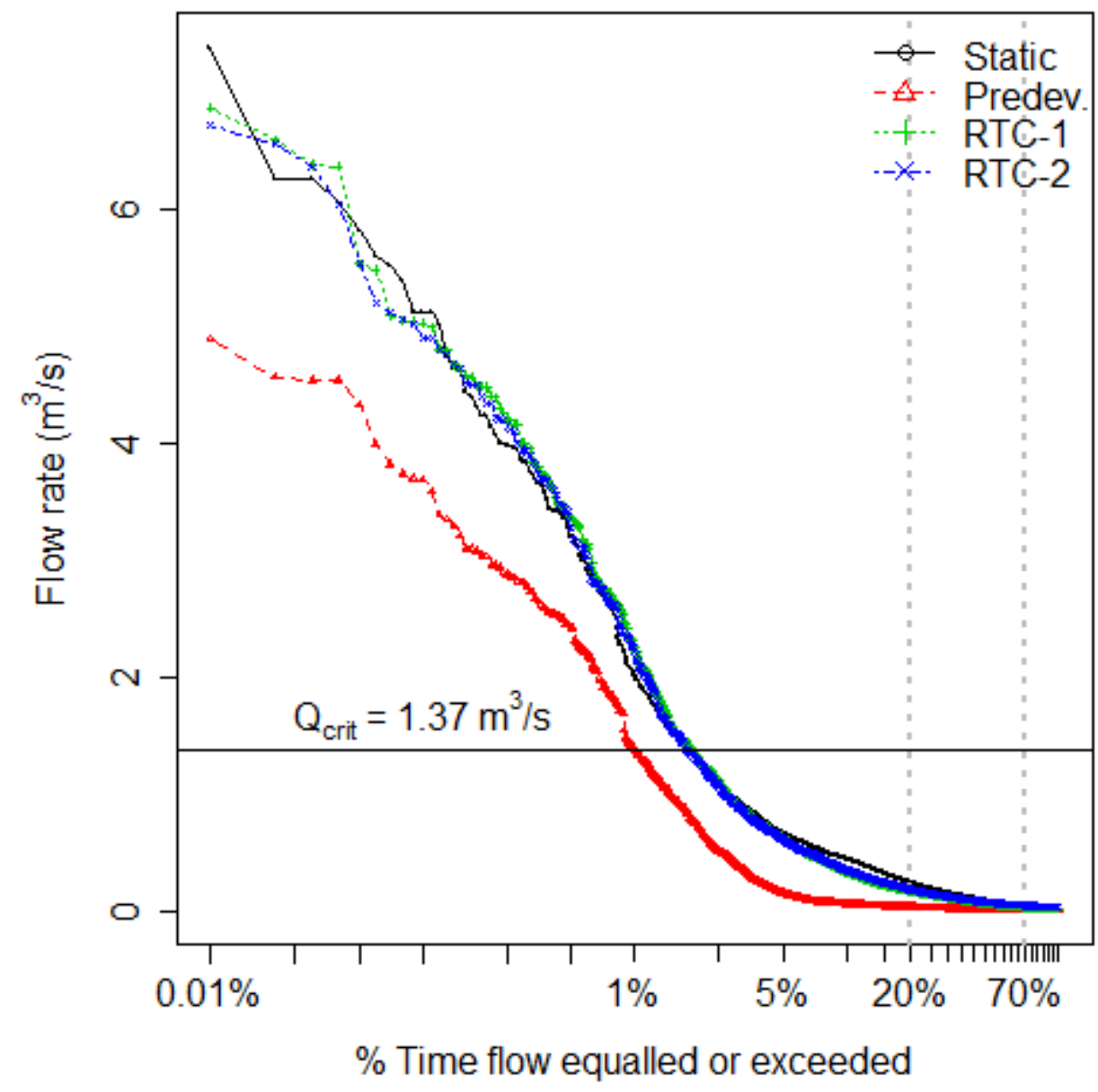

Figure D8. Flow Duration Curve at Watershed Outlet with RTC on Facility 4860 


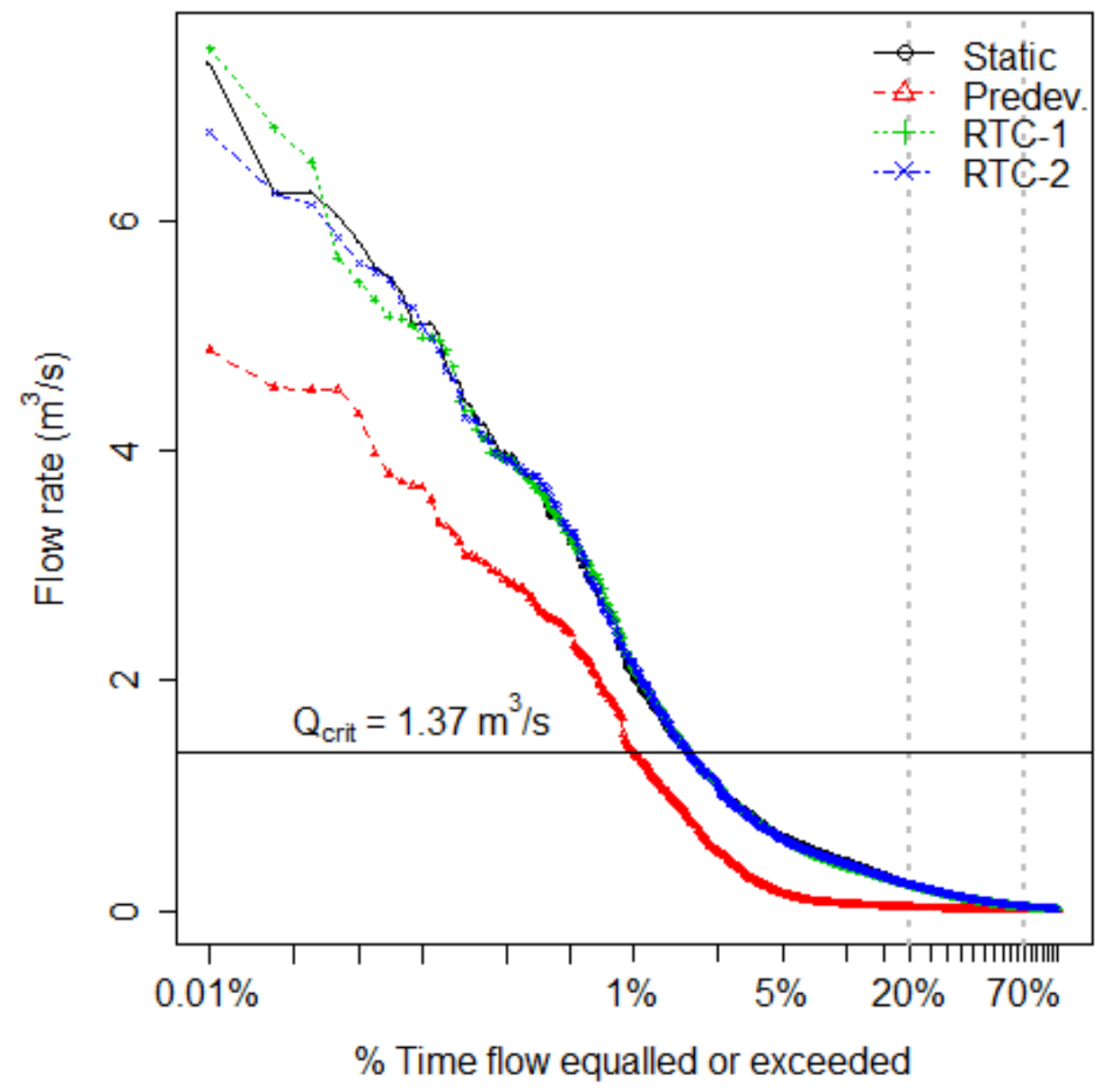

Figure D9. Flow Duration Curve at Watershed Outlet with RTC on Facility 2309 


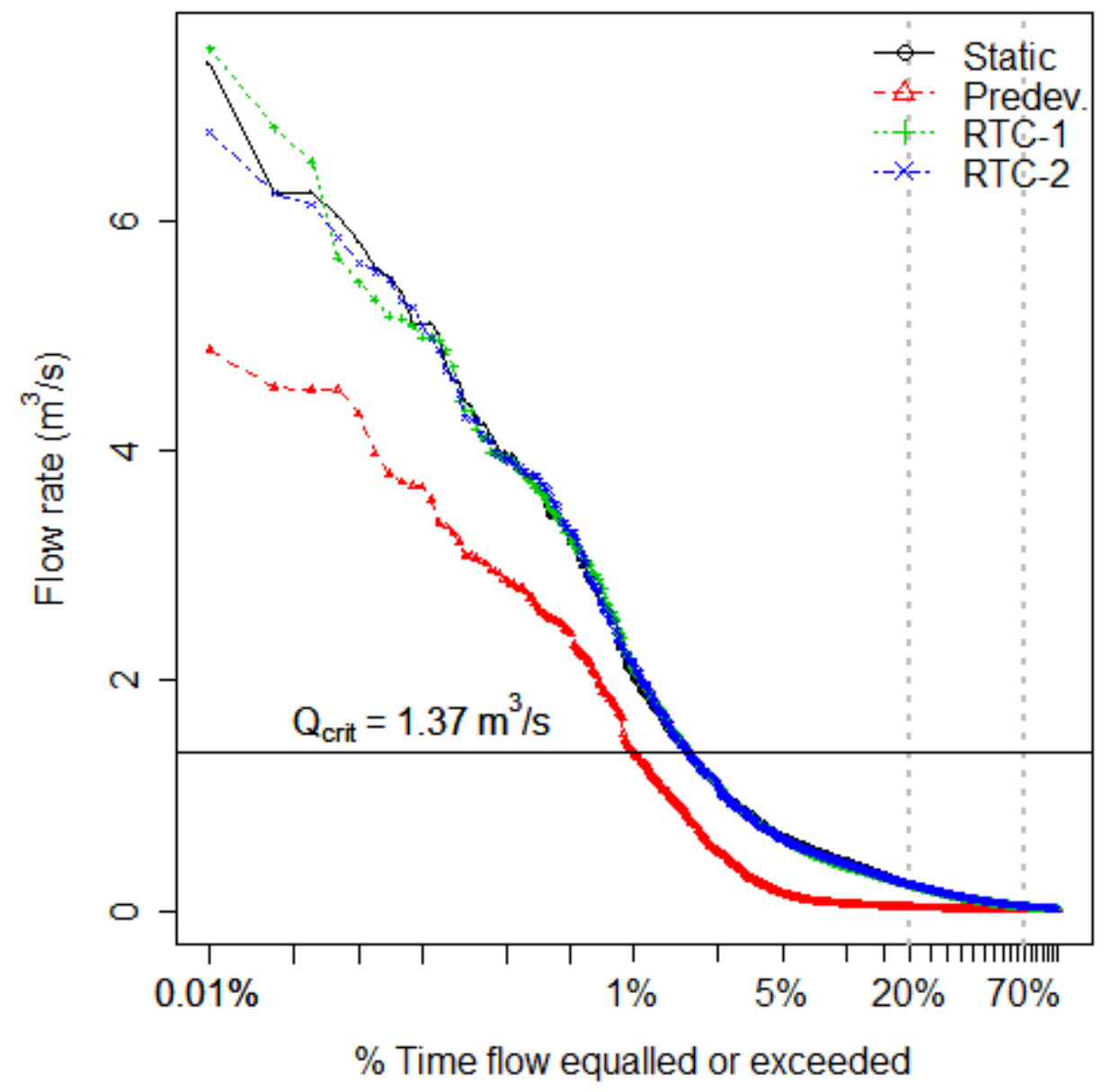

Figure D10. Flow Duration Curve at Watershed Outlet with RTC on Facility 2044 


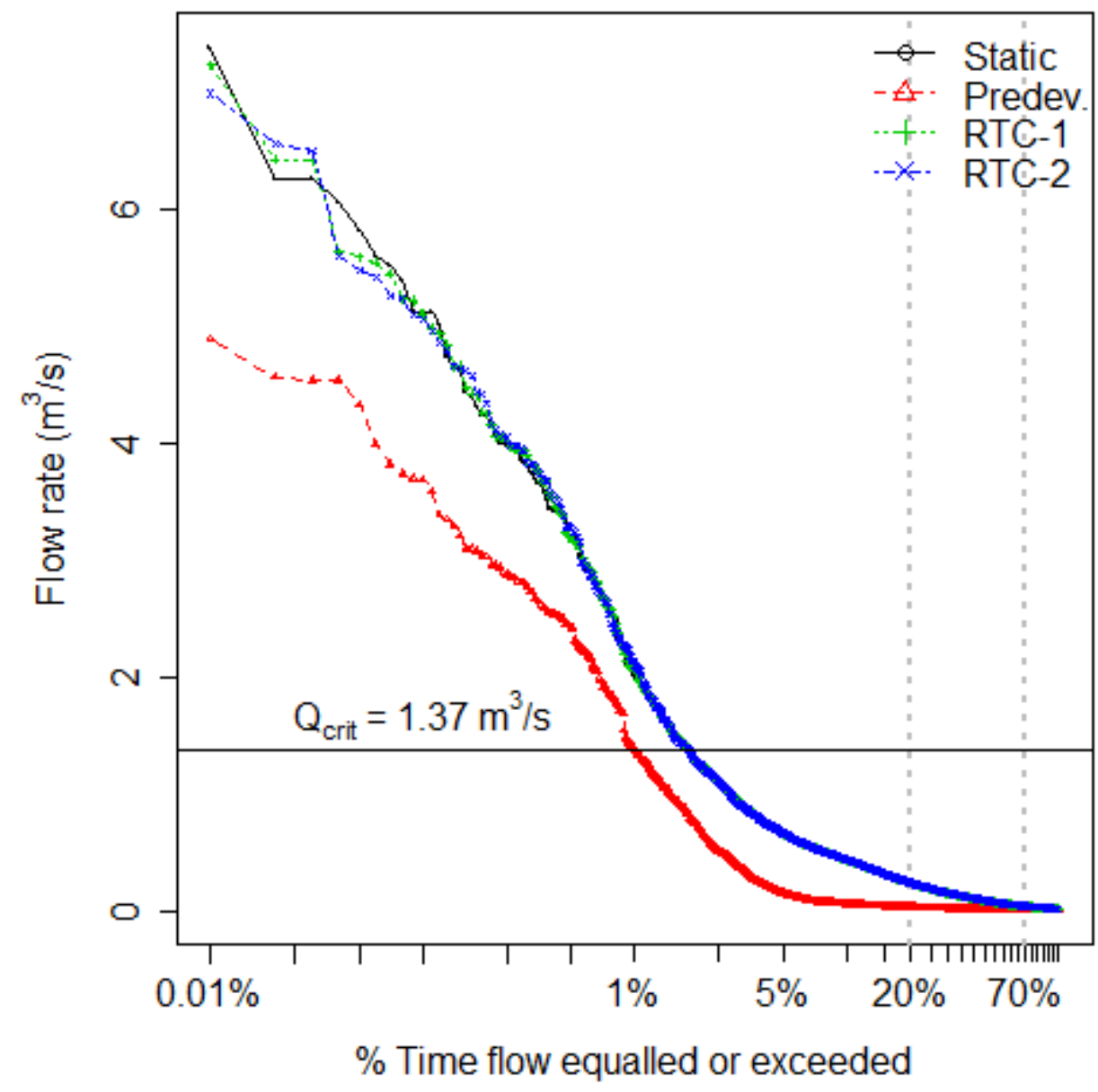

Figure D11. Flow Duration Curve at Watershed Outlet with RTC on Facility 0388 


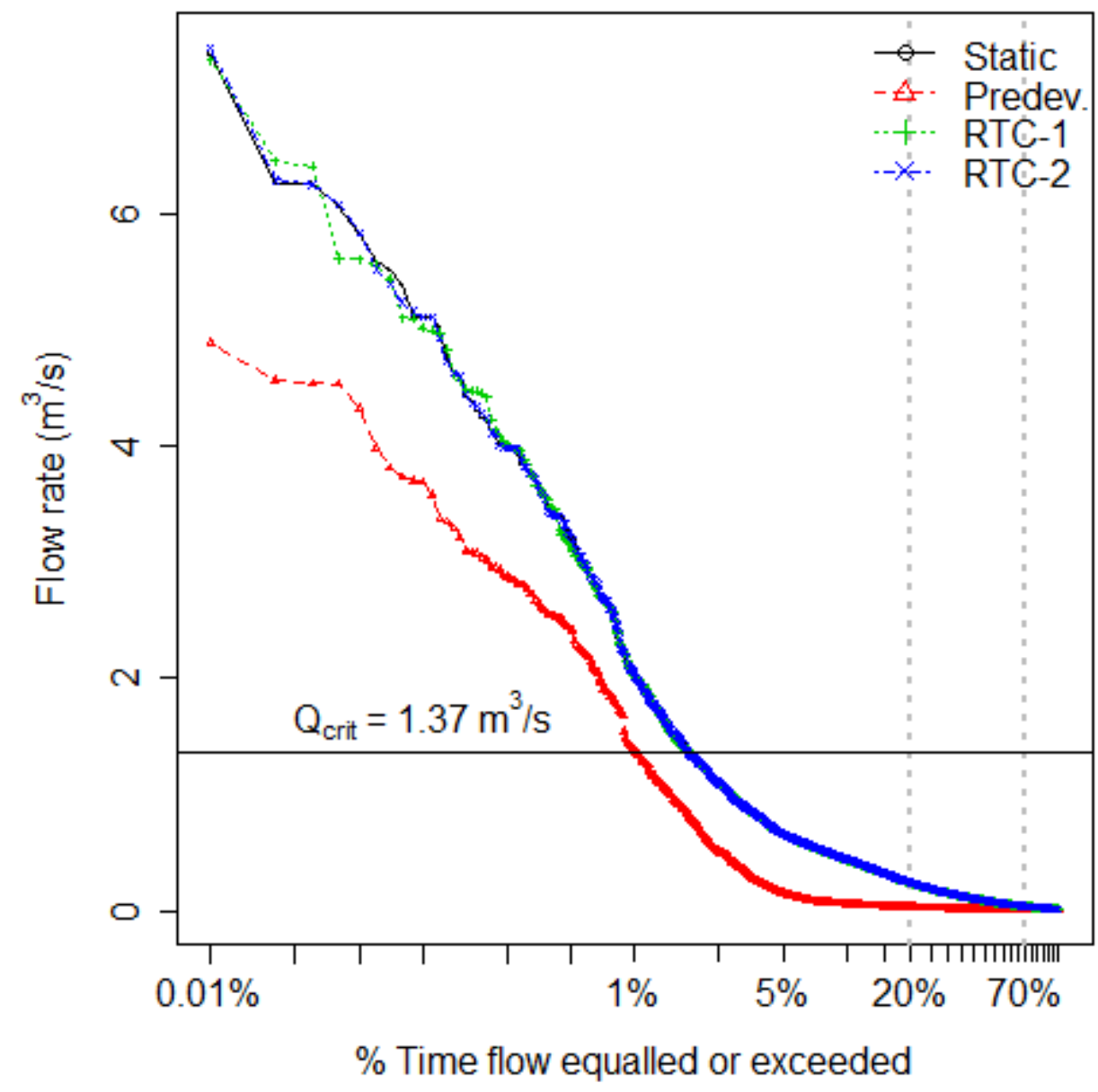

Figure D12. Flow Duration Curve at Watershed Outlet with RTC on Facility 0274 


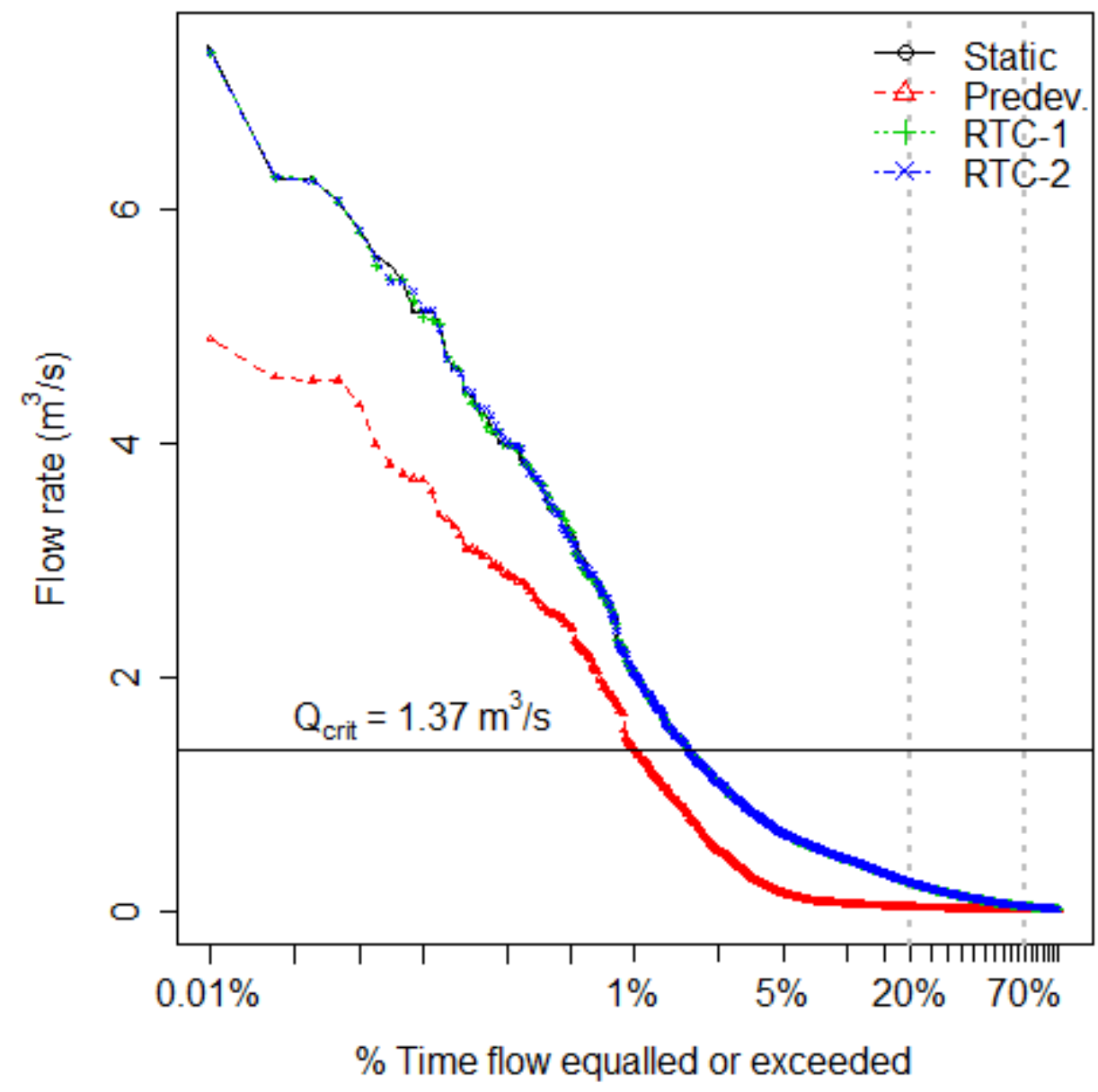

Figure D13. Flow Duration Curve at Watershed Outlet with RTC on Facility 0262 


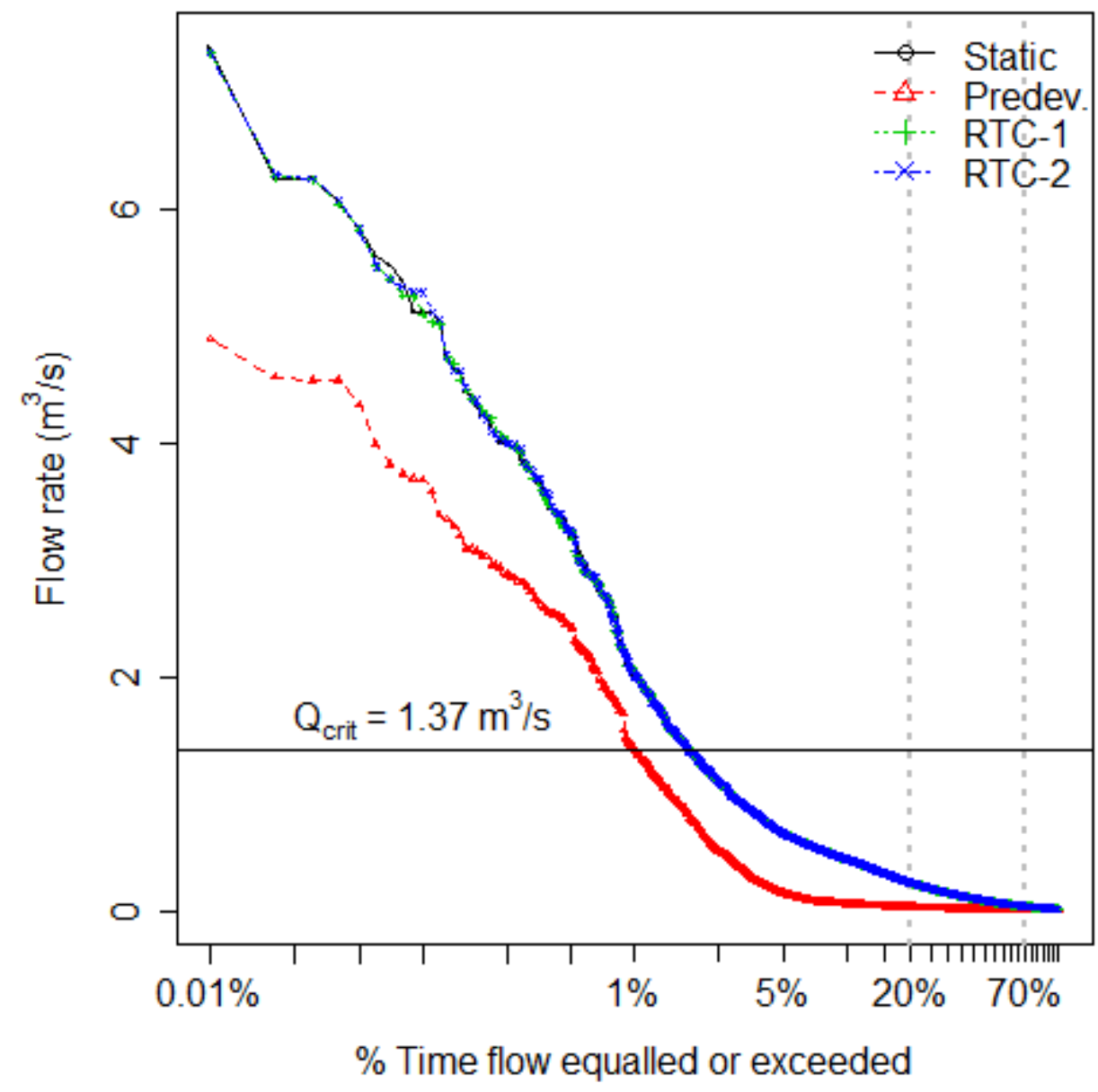

Figure D14. Flow Duration Curve at Watershed Outlet with RTC on Facility 0178 


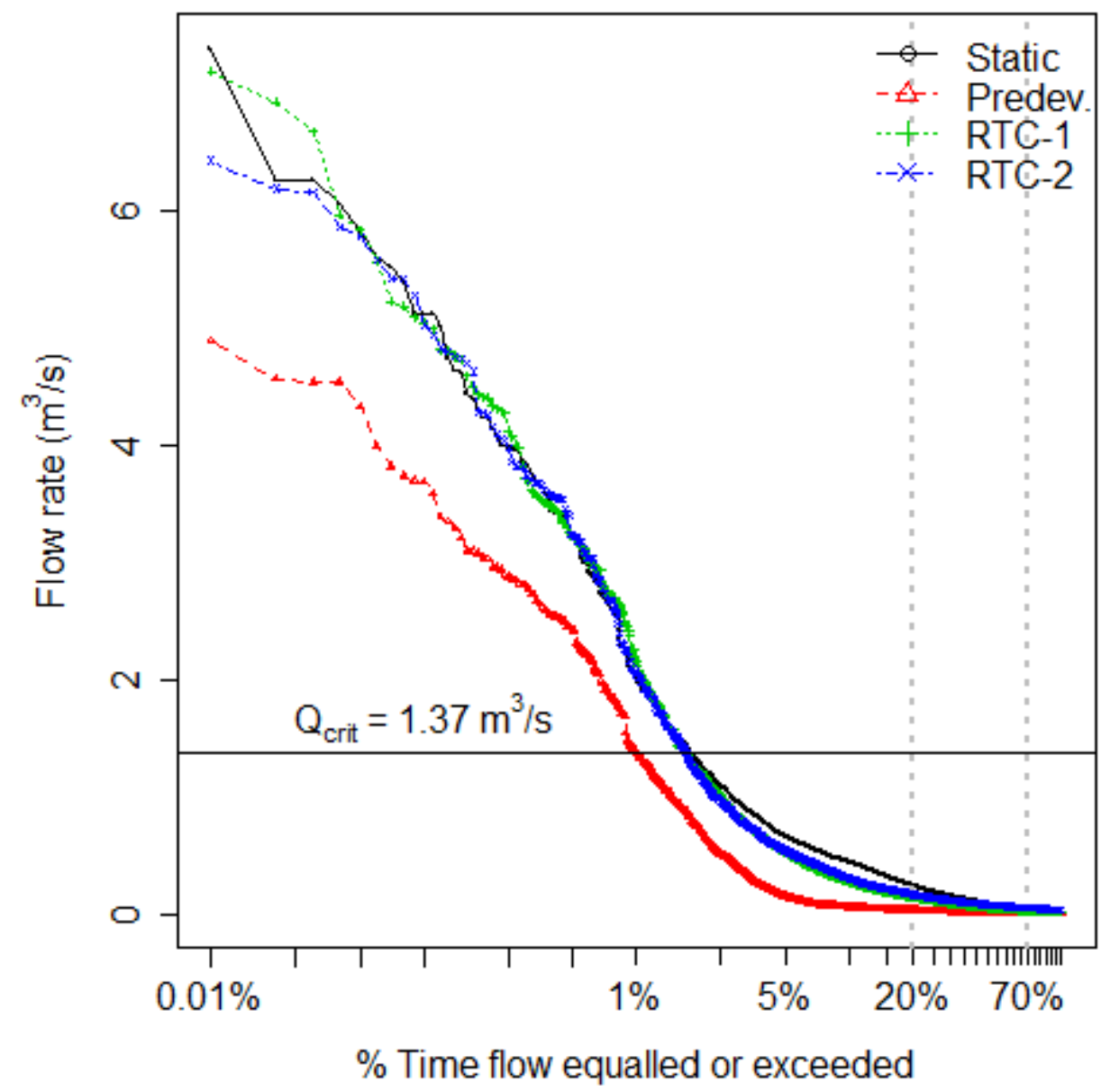

Figure D15. Flow Duration Curve at Watershed Outlet with RTC Combo \#1 


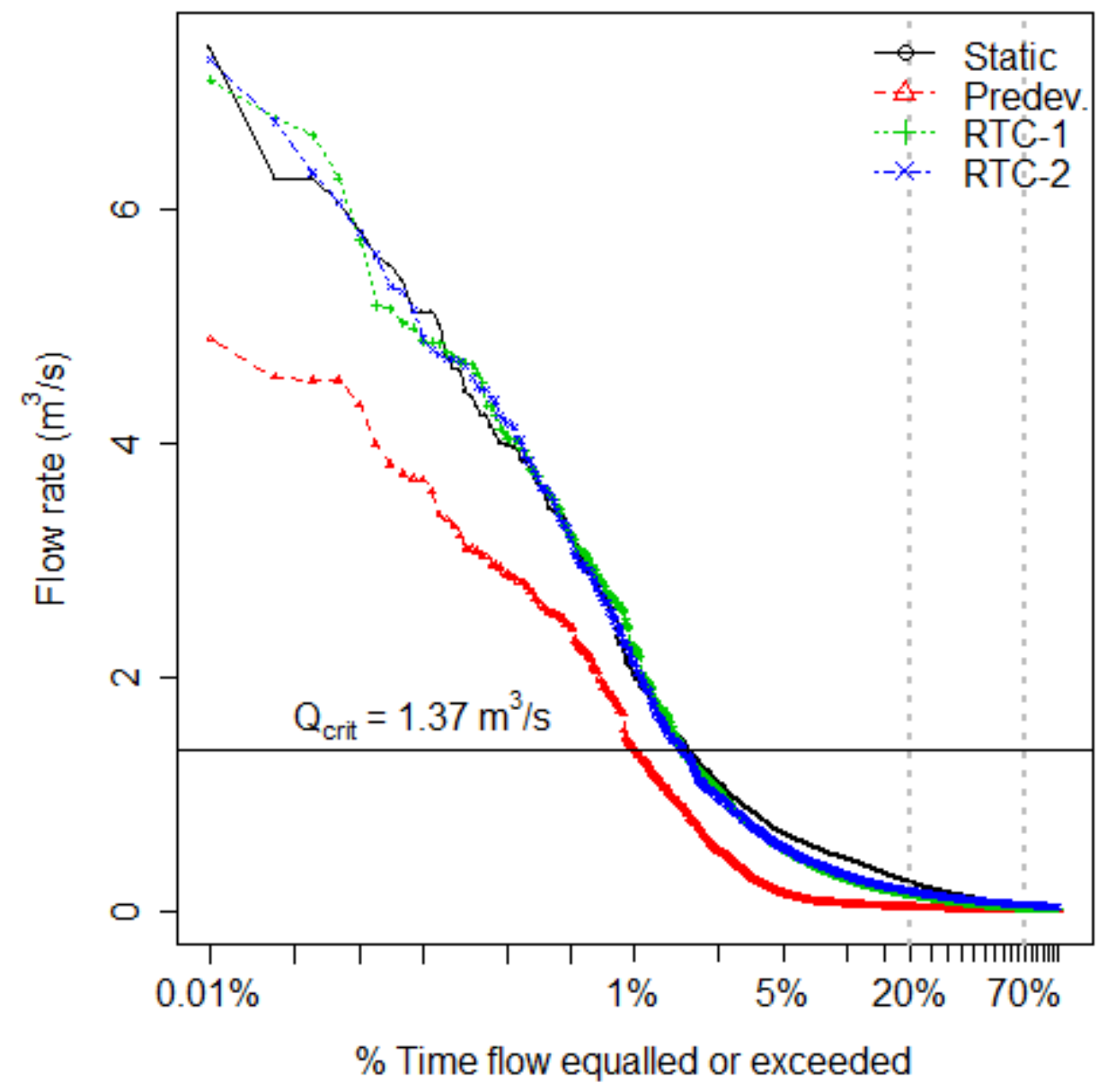

Figure D16. Flow Duration Curve at Watershed Outlet with RTC Combo \#2 


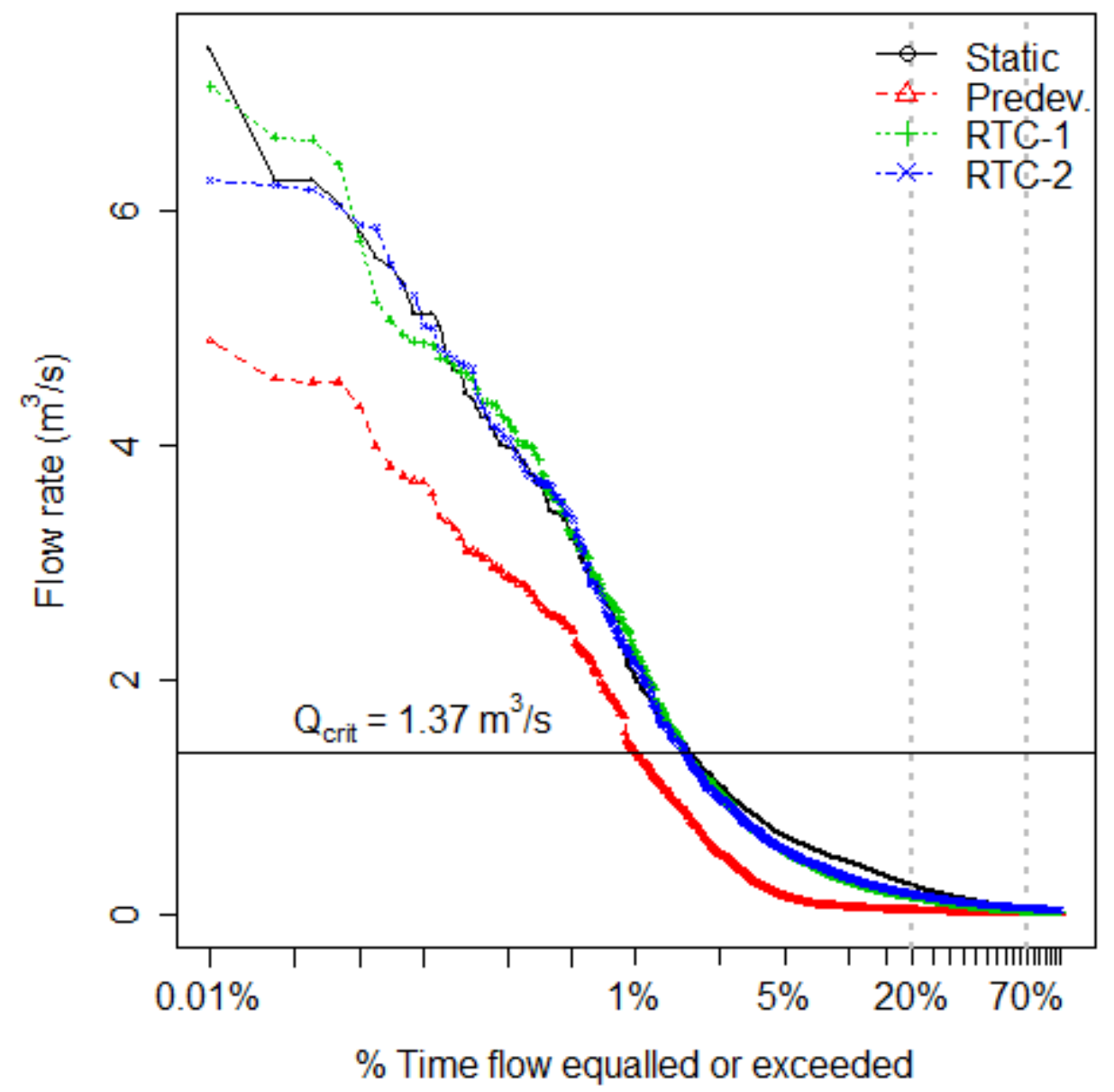

Figure D17. Flow Duration Curve at Watershed Outlet with RTC Combo \#3 


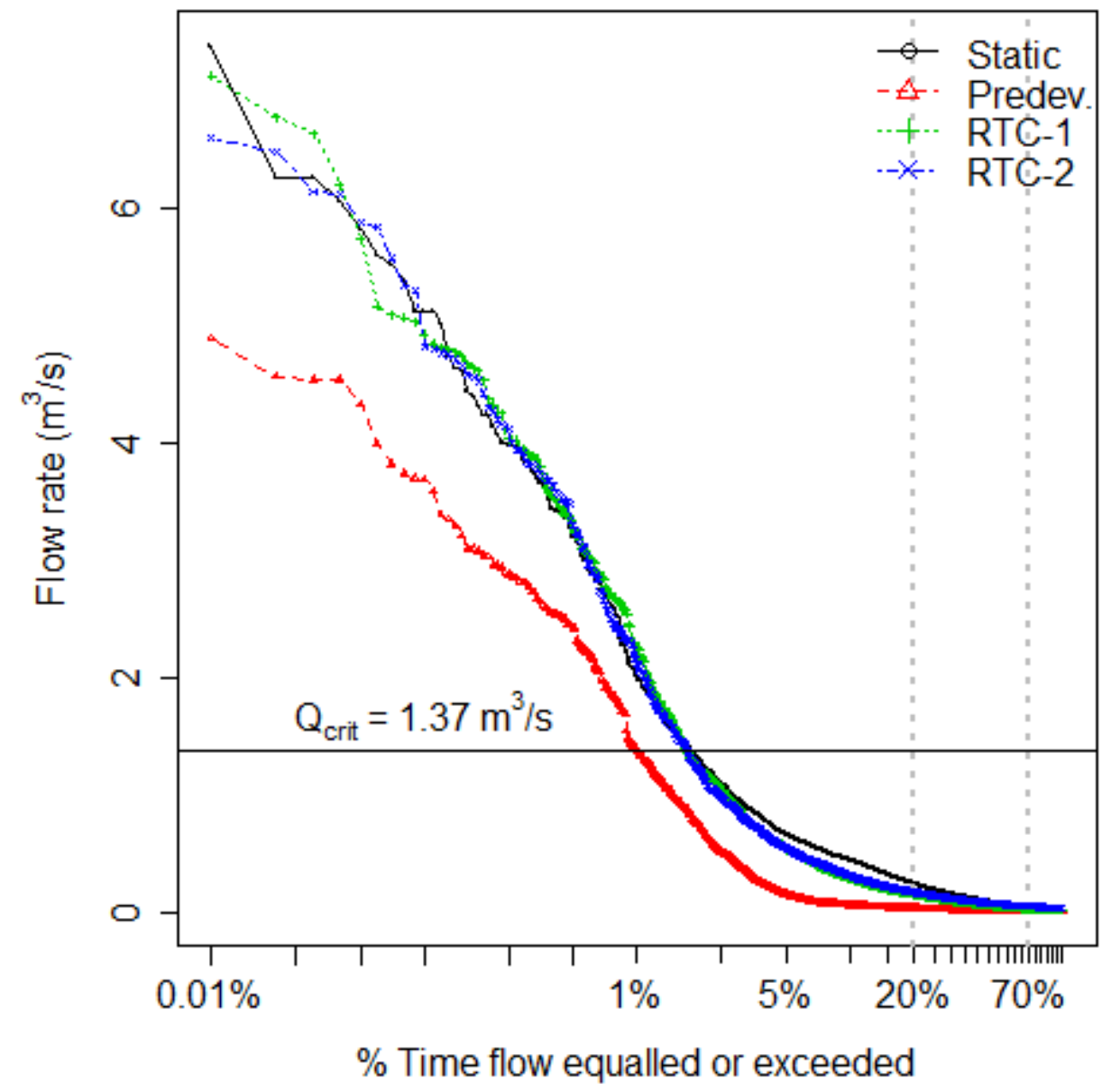

Figure D18. Flow Duration Curve at Watershed Outlet with RTC Combo \#4 


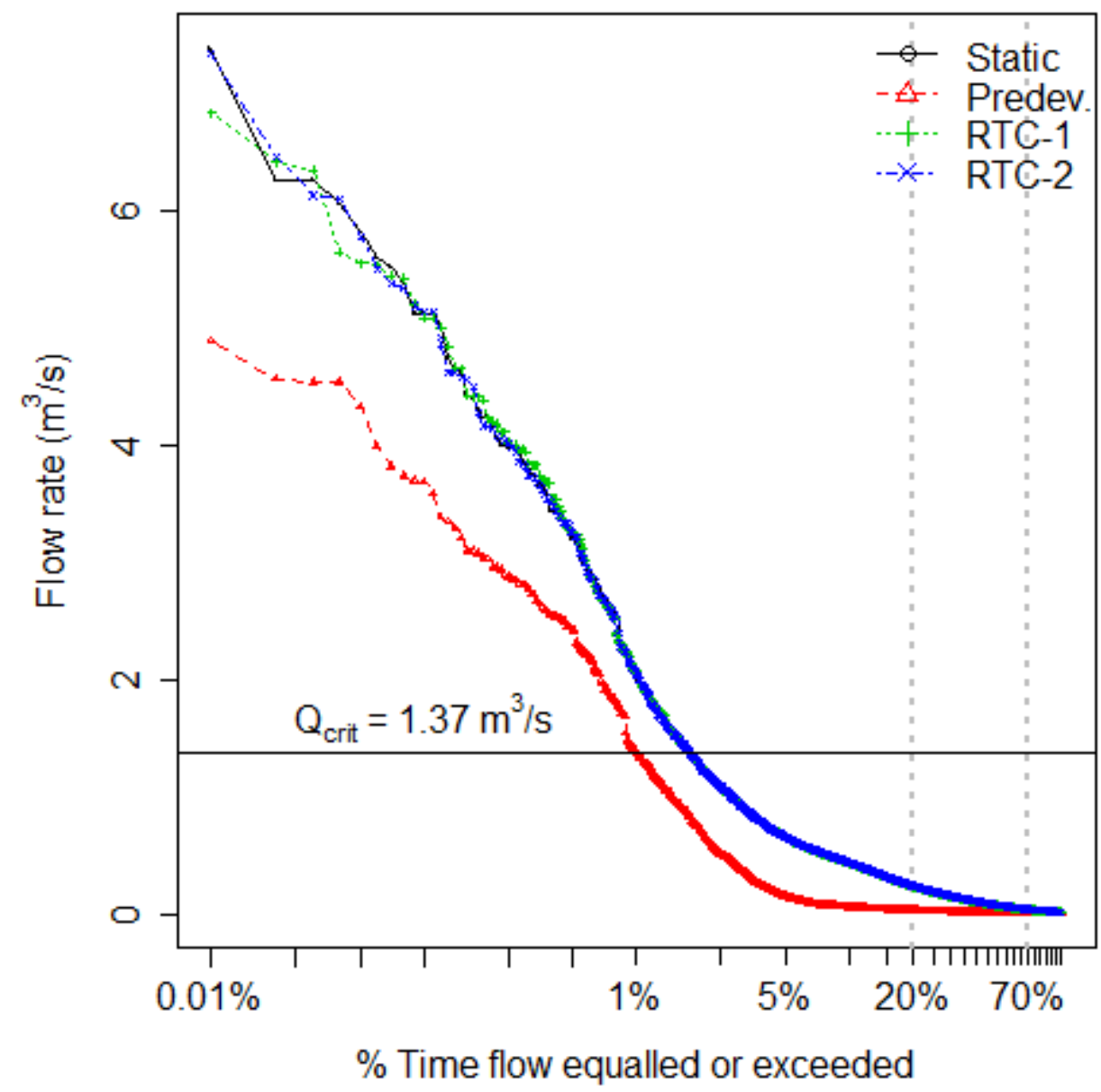

Figure D19. Flow Duration Curve at Watershed Outlet with RTC Combo \#5 


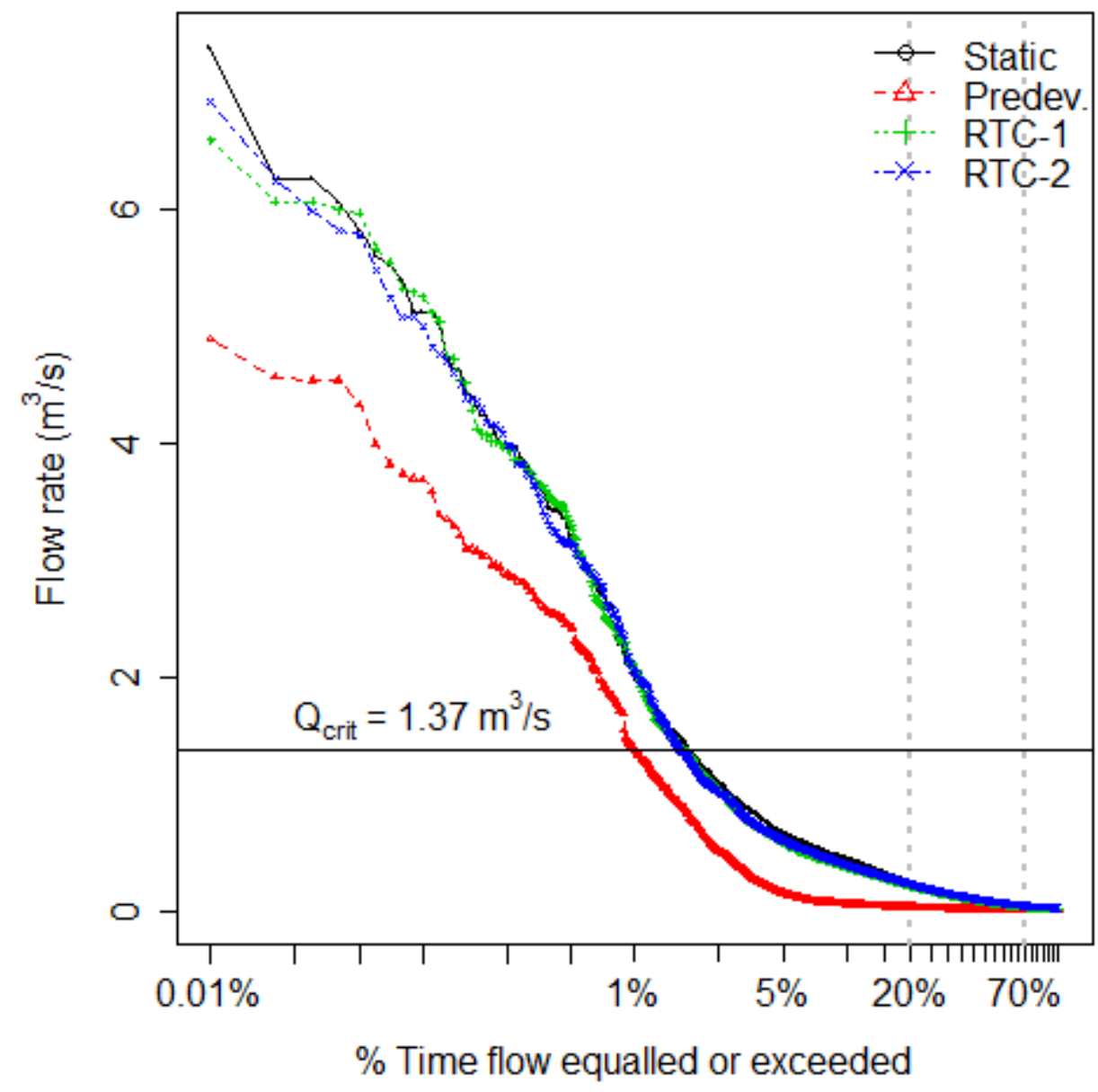

Figure D20. Flow Duration Curve at Watershed Outlet with RTC Combo \#6 


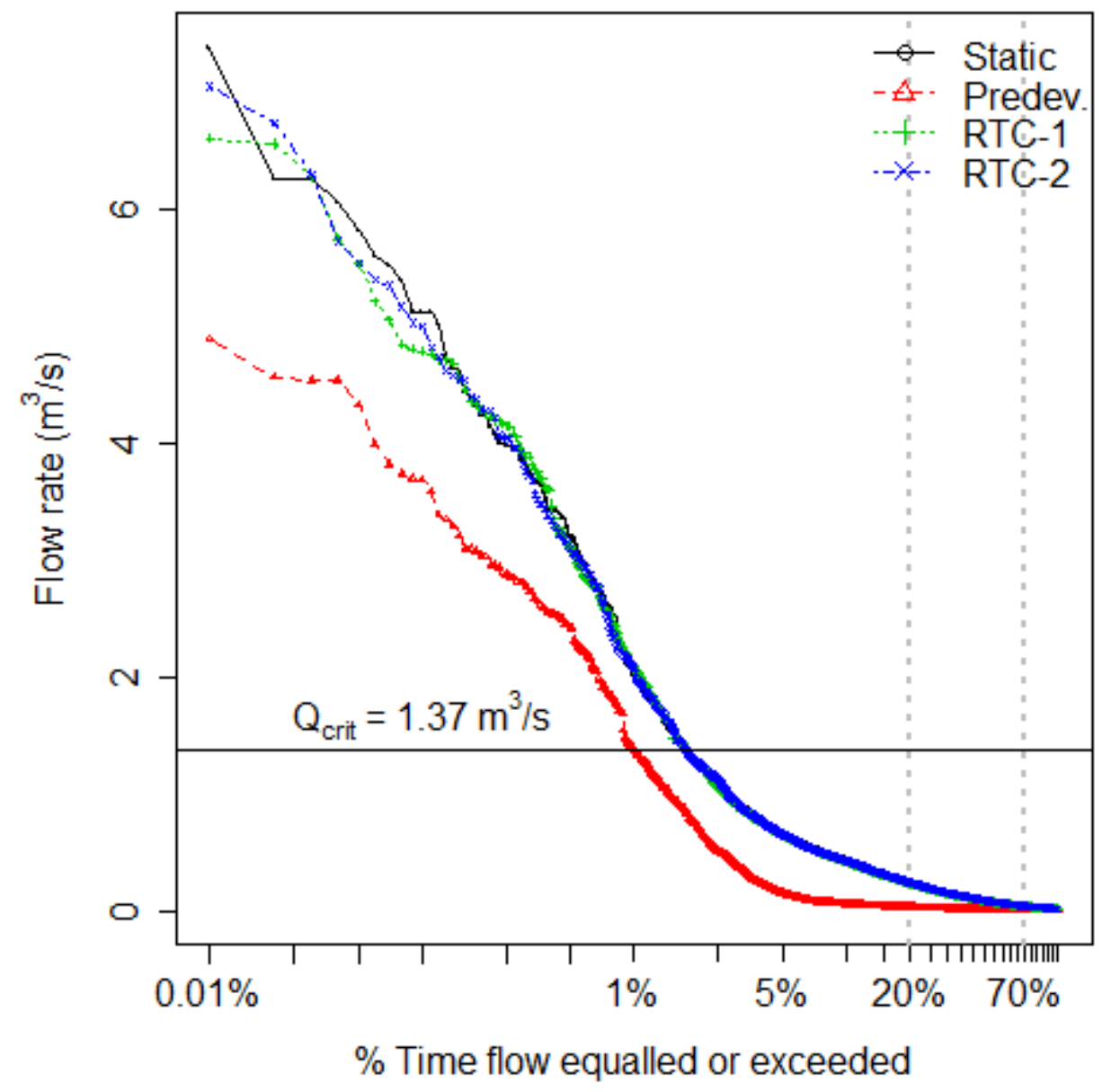

Figure D21. Flow Duration Curve at Watershed Outlet with RTC Combo \#7 


\section{Appendix E: Temporal Aliasing Investigation}

- Impact of PySWMM Time Step on Peak Flow Measurements

- Impact of PySWMM Time Step on RTC Change in Peak Flow

- Impact of PySWMM Time Step on Volume Measurements 


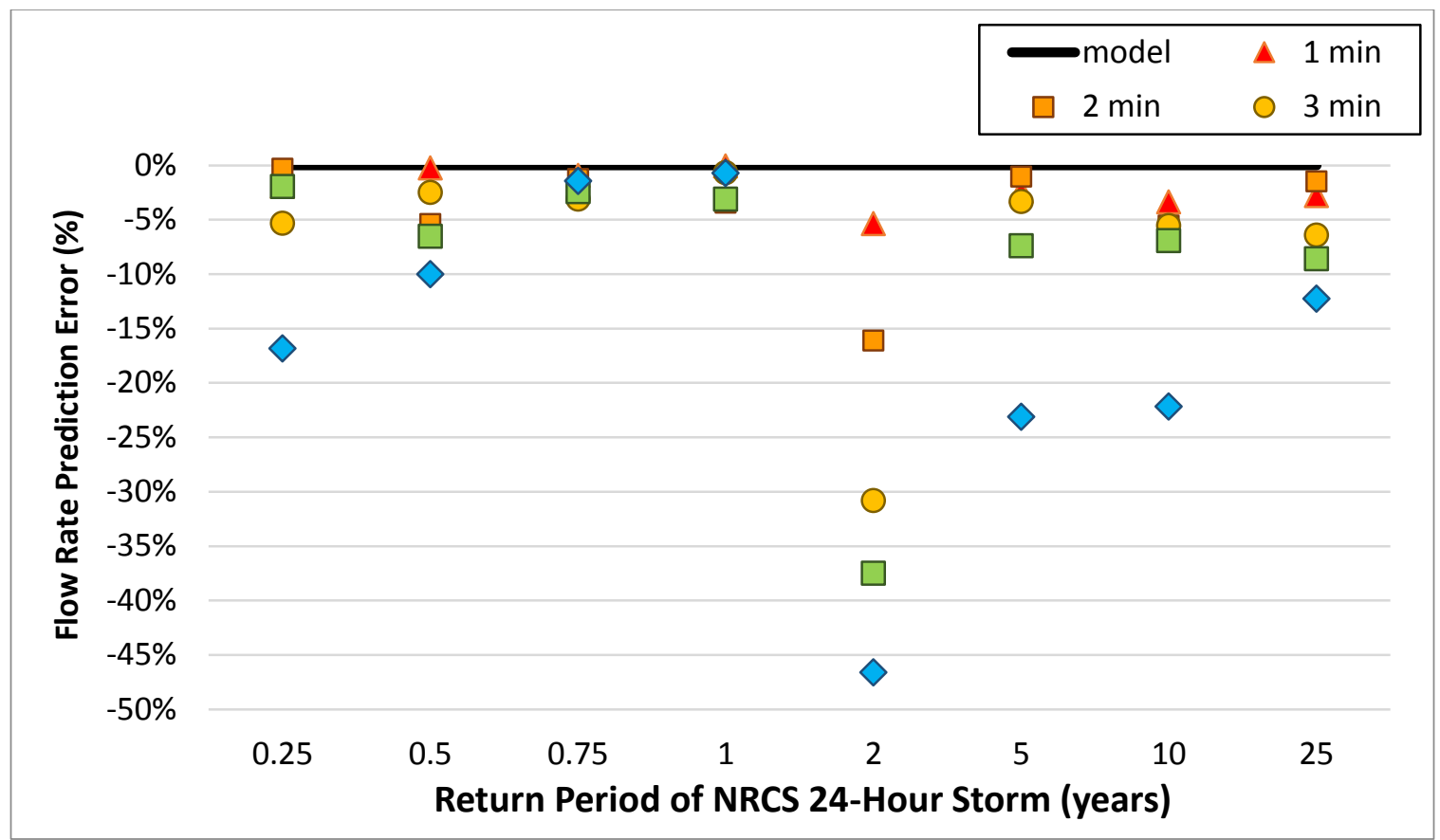

Figure E1. Impact of PySWMM Time Step on Peak Flow - Relative Error

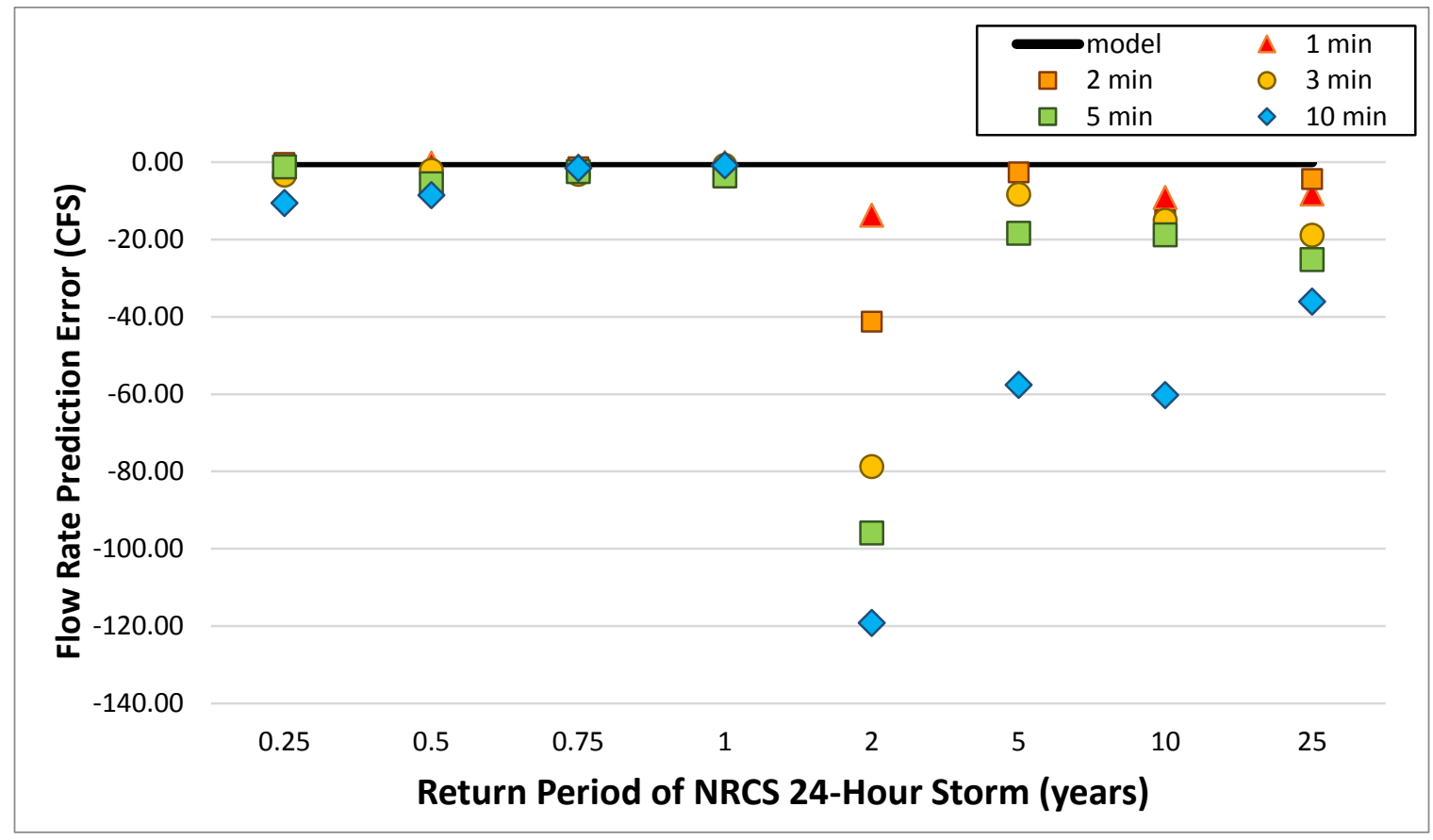

Figure E2. Impact of PySWMM Time Step on Peak Flow - Absolute Error 


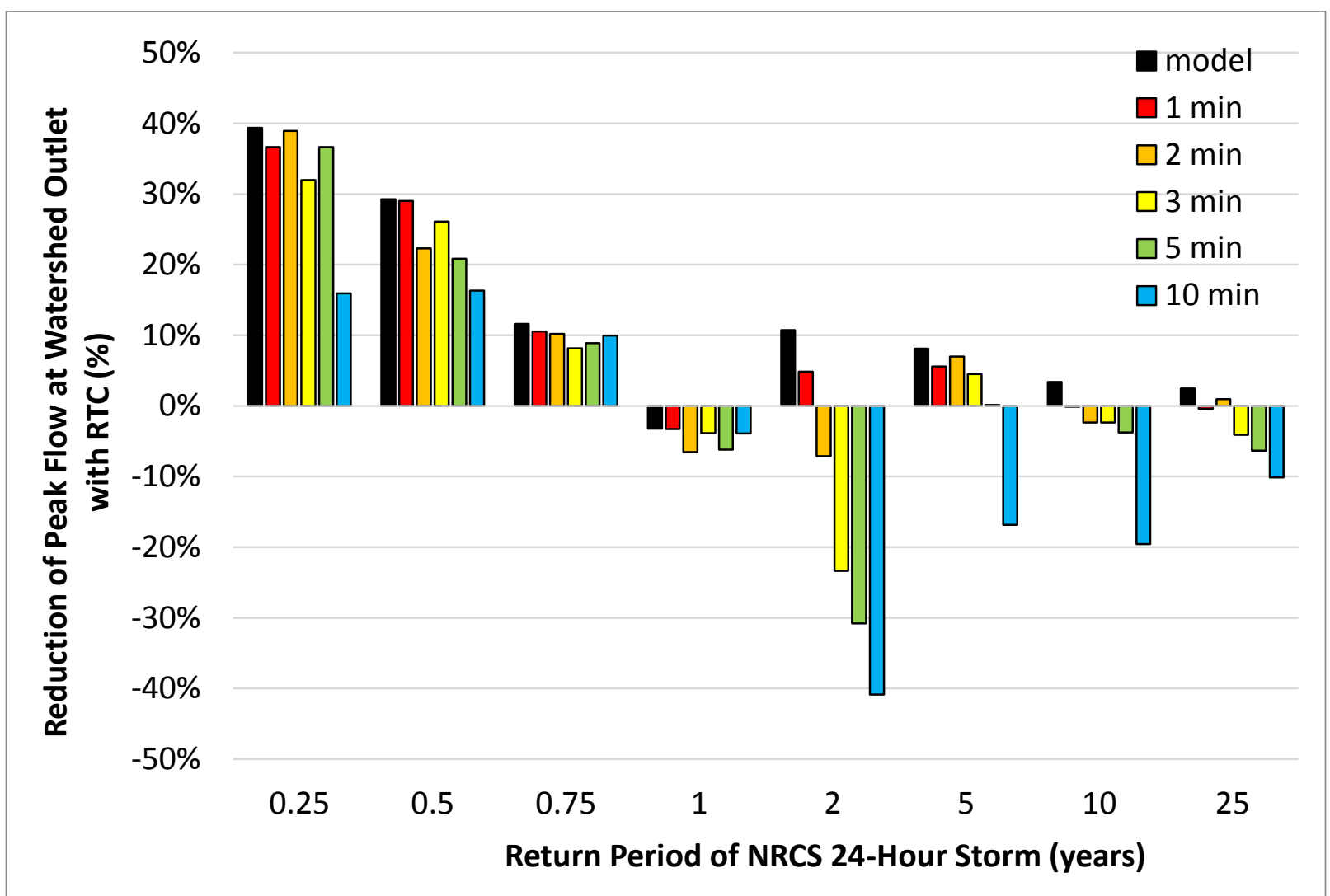

Figure E3. Impact of PySWMM Time Step on resulting RTC Change in Peak Flow 


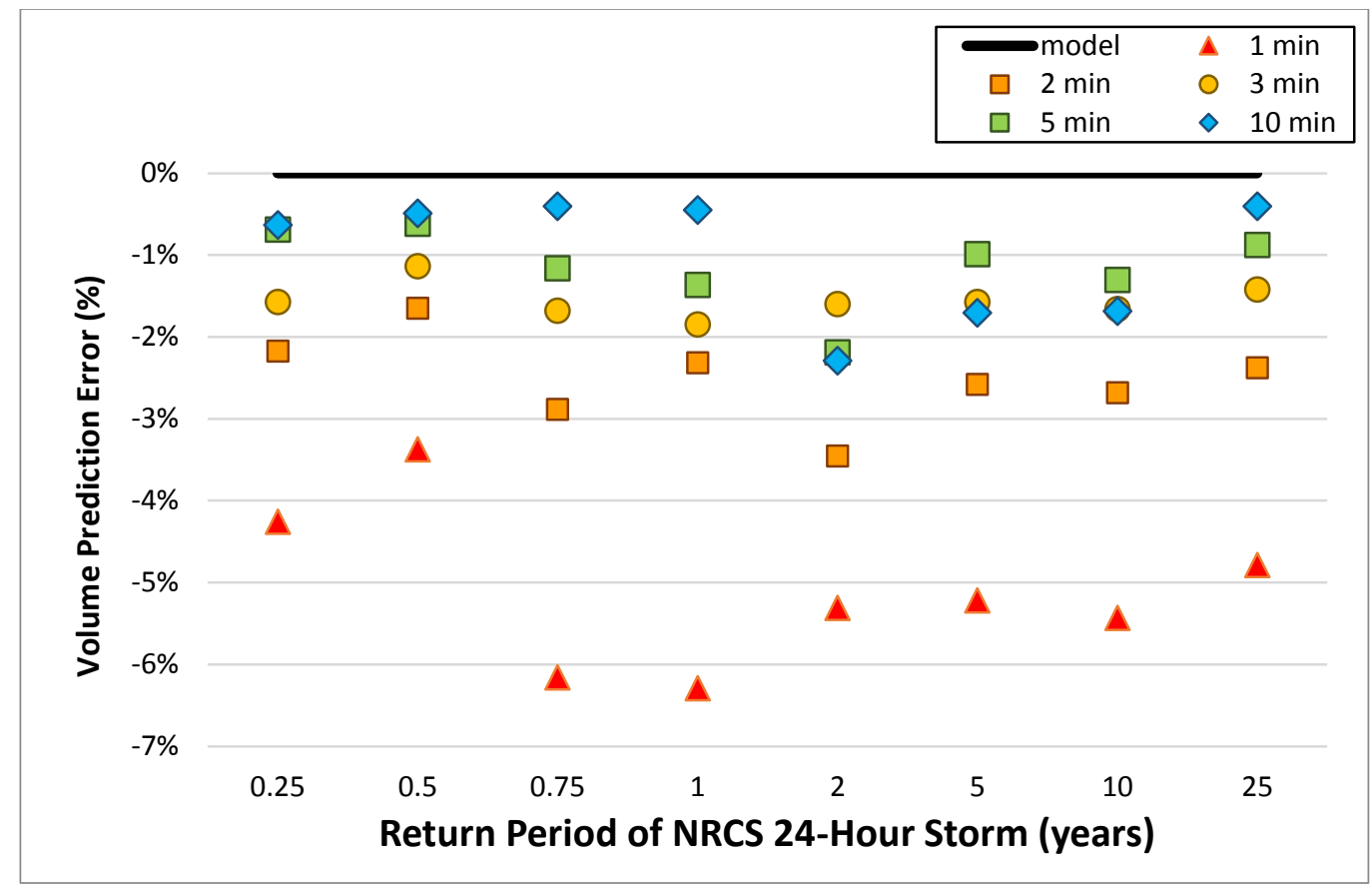

Figure E5. Impact of PySWMM Time Step on Volume - Relative Error

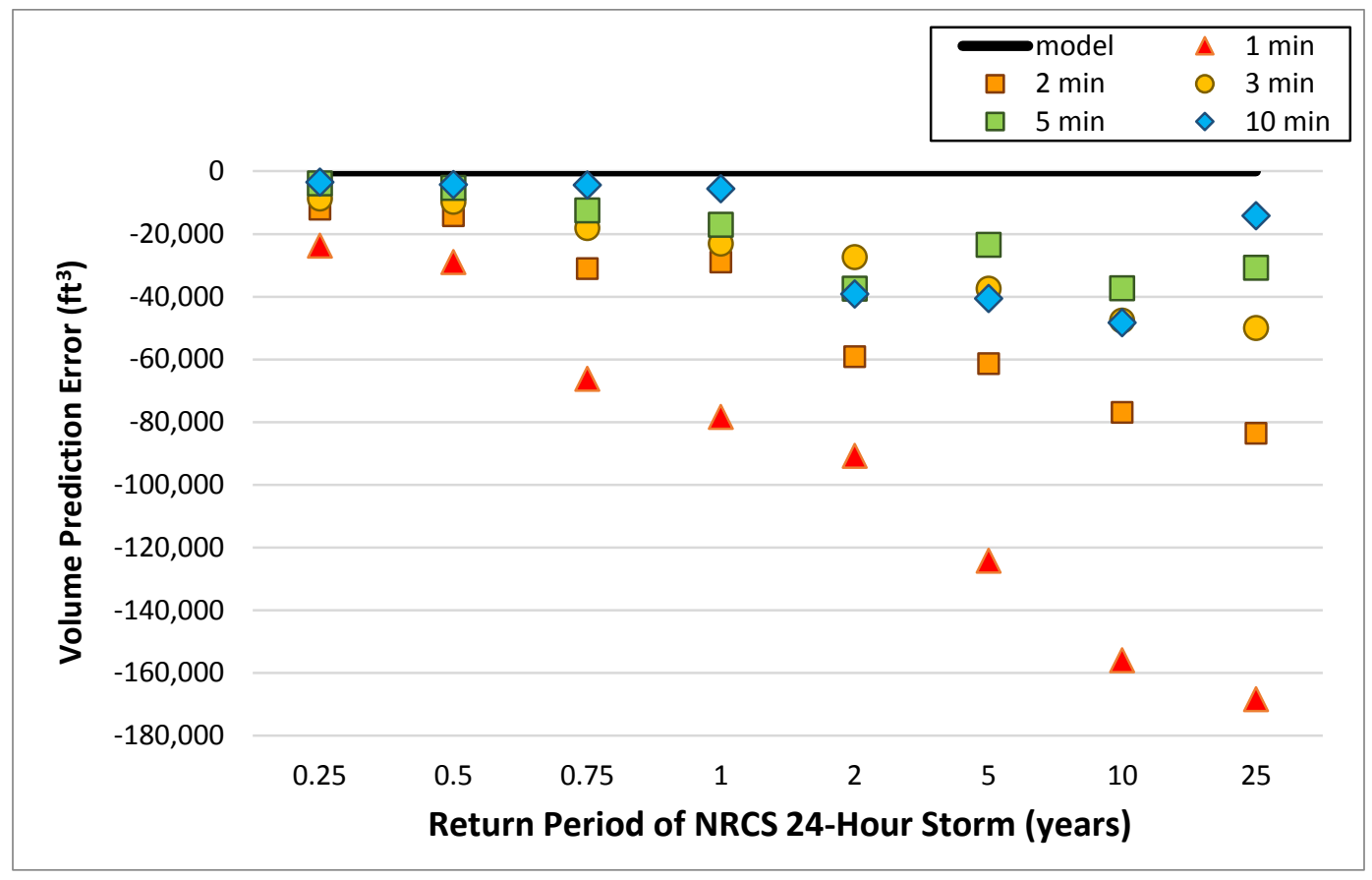

Figure E6. Impact of PySWMM Time Step on Volume - Absolute Error 